\title{
Non-innocent radical ion intermediates in photoredox catalysis: parallel reduction modes enable coupling of diverse aryl chlorides
}

Alyah F. Chmiel, ${ }^{1}$ Oliver P. Williams, ${ }^{1}$ Colleen P. Chernowsky, ${ }^{1}$ Charles S. Yeung, ${ }^{*}, 2$ Zachary K. Wickens ${ }^{*}, 1$

${ }^{1}$ Department of Chemistry, University of Wisconsin-Madison; Madison, Wisconsin, 53706, United States.

${ }^{2}$ Discovery Chemistry, Merck \& Co., Inc., 33 Avenue Louis Pasteur, Boston, MA, 02115, United States.

\section{SUPPORTING INFORMATION}

\section{TABLE OF CONTENTS}

1. General Methods and Materials

2. Experimental Setup

3. Preparation of Catalysts and Starting Materials

4. General Experimental Procedures for Photoredox Reductions

5. Reaction Optimization

6. Photocatalyst and Reductant Evaluation

7. Evaluation of Leaving Groups not Susceptible to XAT

8. Reductants Evaluated with 4-DPAIPN

9. Control Experiments

10. Radical Clock Experiment

11. High-Throughput Experimentation with Aryl Halide Informer Plate at Merck

12. Cyclic Voltammetry

13. Calibration Curves

14. Stern Volmer and UV/Vis Data

15. NMR Experiment for 4-DPAIPN•- Generation

16. Plausible Mechanism for $\mathrm{CO} 2 \bullet-$ Generation from Thiyl Radical

17. Probing Substrate Reduction by $\mathrm{CO} 2 \bullet-$

18. Product Characterization 


\section{General Methods and Materials}

Unless otherwise noted, reactions were performed under an inert N2 atmosphere in anhydrous DMSO thoroughly degassed by freeze-pump-thaw. Anhydrous DMSO was purchased from DriSolv. Crude mixtures were evaluated by thin-layer chromatography using EMD/Merck silica gel 60 F254 pre-coated plates $(0.25 \mathrm{~mm})$ and were visualized by UV, CAM, p- anisaldehyde, or $\mathrm{KMnO} 4$ staining. Flash chromatography was performed with a Biotage Isolera One automated chromatography system with re-packed silica columns (technical grade silica, pore size $60 \AA$, 230-400 mesh particle size, 40-63 particle size). Purified materials were dried in vacuo (0.050 Torr) to remove trace solvent. $1 \mathrm{H}, 13 \mathrm{C}, 31 \mathrm{P}$ Spectra were taken using a Bruker Avance-400 with a BBFO Probe or a Bruker Avance-500 with a DCH Cryoprobe. NMR data are reported relative to residual $\mathrm{CHCl} 3$ ( $1 \mathrm{H}, \delta=7.26 \mathrm{ppm}$ ), $\mathrm{CDCl} 3(13 \mathrm{C}, \delta=77.16 \mathrm{ppm}$ ). Data for $1 \mathrm{H}$ NMR spectra are reported as follows: chemical shift $(\delta \mathrm{ppm})$ (multiplicity, coupling constant $(\mathrm{Hz})$, integration). Multiplicity and qualifier abbreviations are as follows: $\mathrm{s}=$ singlet, $\mathrm{d}=$ doublet, $\mathrm{t}=$ triplet, $\mathrm{q}=$ quartet, $\mathrm{m}=$ multiplet, $\mathrm{br}=$ broad. $\mathrm{GC}$ traces were taken on an Agilent $7890 \mathrm{~A}$ GC with dual DB-5 columns $(20 \mathrm{~m} \times 180 \mu \mu \mathrm{m} \times 0.18 \mu \mathrm{m})$, dual FID detectors, and hydrogen as the carrier gas.

\section{Experimental Setup}

LEDs used in this study were purchased from HepatoChem (PAR20- 18W LG $405 \mathrm{~nm}$ ) and Kessil (KSPR160L-390, KSPR160L-440, KSPR160L-370).

\section{Standard Reaction Set-Up}

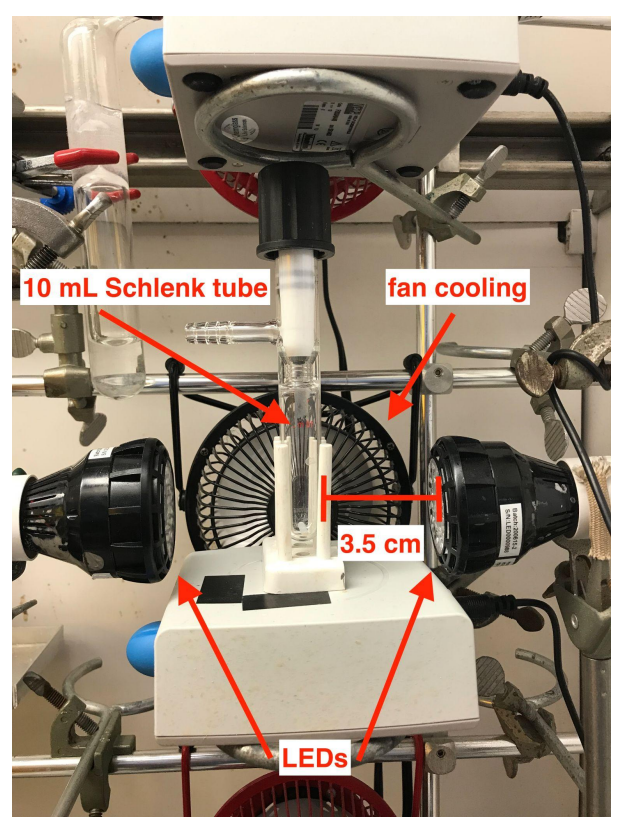

Figure S1. Standard setup for photoredox reactions with either 1 or 2 LEDs depending on the transformation. See General Experimental Procedures for Photoredox Reductions for details. 


\section{Preparation of Catalysts and Starting Materials}

\section{2,4,5,6-tetra(9H-carbazol-9-yl)isophthalonitrile (4-CzIPN)}<smiles>N#Cc1c(F)c(F)c(F)c(C#N)c1F</smiles>
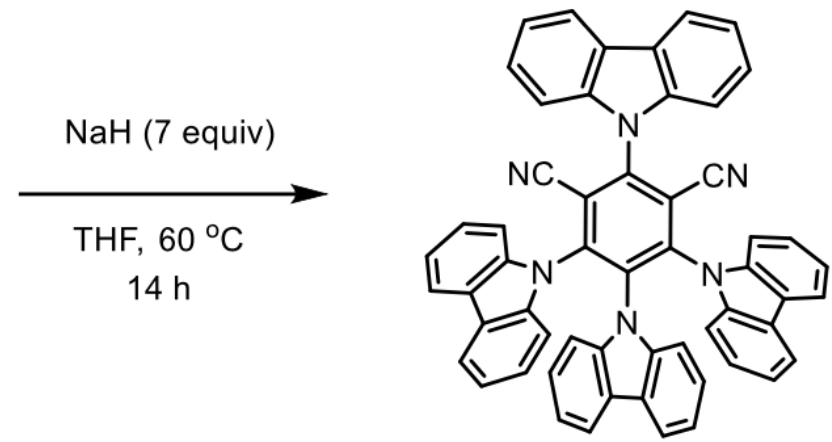

To a flame-dried flask under $\mathrm{N} 2$, $\mathrm{NaH}$ (60\% dispersion, $3.0 \mathrm{~g}, 75 \mathrm{mmol}, 7$ equiv) was added and evacuated then backfilled with $\mathrm{N} 2$ three times. THF $(100 \mathrm{~mL})$ was added to the flask followed by 1 -H-carbazole ( $8.4 \mathrm{~g}, 50 \mathrm{mmol}, 5$ equiv) in THF $(25 \mathrm{~mL})$. The carbazole solution was slowly added to the flask then heated to $60{ }^{\circ} \mathrm{C}$ and stirred for 1 hour. 2,4,5,6-tetrafluoroisophthalonitrile $(2.0 \mathrm{~g}, 10 \mathrm{mmol}, 1$ equiv) in THF $(25 \mathrm{~mL})$ was slowly added to the reaction mixture. The solution was then cooled and stirred at $40{ }^{\circ} \mathrm{C}$ overnight. After cooling the reaction to room temperature, excess $\mathrm{NaH}$ was quenched with isopropanol. Water $(200 \mathrm{~mL})$ was then added to precipitate the crude product. The precipitate was filtered then washed with excess water and dried in vacuo. The crude product dissolved in DCM then filtered through a silica plug and recrystallized from DCM hexanes to provide pure product as a yellow solid ( $6.2 \mathrm{~g}, 8.2 \mathrm{mmol}, 82$ \%). ${ }^{1} \mathbf{H}$ NMR (500 MHz, CDCl3) $\delta 8.24(\mathrm{~d}, \mathrm{~J}=7.8 \mathrm{~Hz}, 2 \mathrm{H}), 7.73(\mathrm{~m}, 8 \mathrm{H}), 7.51$ (ddd, J = 8.0, $6.7,1.5 \mathrm{~Hz}, 2 \mathrm{H}) 7.35(\mathrm{~m}, 2 \mathrm{H}), 7.25(\mathrm{dd}, \mathrm{J}=7.8,1.4 \mathrm{~Hz}, 4 \mathrm{H}), 7.11(\mathrm{tt}, \mathrm{J}=7.4,5.8 \mathrm{~Hz}, 8 \mathrm{H}), 6.85$ $(\mathrm{m}, 4 \mathrm{H}), 6.65(\mathrm{td}, \mathrm{J}=7.7,1.2 \mathrm{~Hz}, 2 \mathrm{H})$, consistent with reported spectrum (Chem. Eur. J. 2016, 22, 4889-4898).

\section{2,4,5,6-tetrakis(diphenylamino)isophthalonitrile (4-DPAIPN)}<smiles>N#Cc1c(F)c(F)c(F)c(C#N)c1F</smiles>
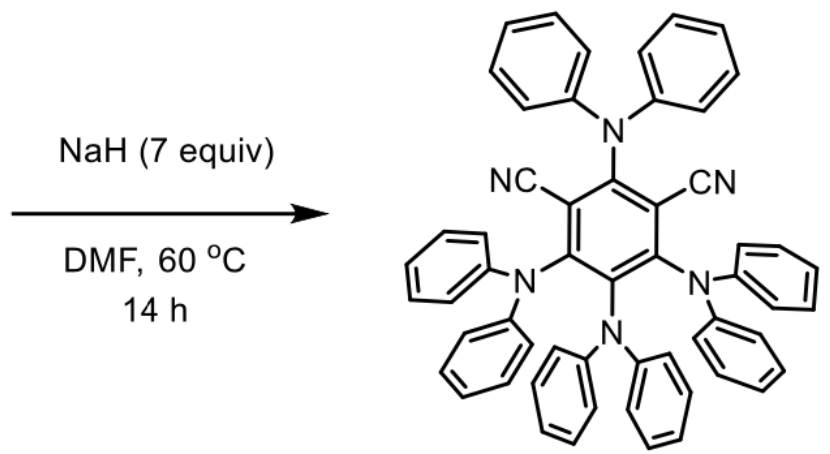
To a flame-dried flask under $\mathrm{N} 2$, $\mathrm{NaH}$ ( $60 \%$ dispersion, $3.0 \mathrm{~g}$, $75 \mathrm{mmol}, 7$ equiv) was added and evacuated then backfilled with $\mathrm{N} 2$ three times. THF $(100 \mathrm{~mL})$ was added to the flask followed by diphenylamine ( $8.5 \mathrm{~g}, 50 \mathrm{mmol}, 5$ equiv) in THF $(25 \mathrm{~mL})$. The diphenylamine solution was slowly added to the flask then heated to $60{ }^{\circ} \mathrm{C}$ and stirred for 1 hour. 2,4,5,6-tetrafluoroisophthalonitrile ( $2.0 \mathrm{~g}, 10 \mathrm{mmol}, 1$ equiv) in THF $(25 \mathrm{~mL})$ was slowly added to the reaction mixture. The solution was then cooled and stirred at $40{ }^{\circ} \mathrm{C}$ overnight. After cooling the reaction to room temperature, excess $\mathrm{NaH}$ was quenched with isopropanol. Water $(200 \mathrm{~mL})$ was then added to precipitate the crude product. The precipitate was filtered then washed with excess water and dried in vacuo. The crude product dissolved in DCM then filtered through a silica plug and recrystallized from DCM hexanes to provide pure product as a yellow solid (5.0 g, $6.2 \mathrm{mmol}, 62 \%) .{ }^{1} \mathbf{H}$ NMR (400 MHz, CDCl3) $\delta 7.31-7.23(\mathrm{~m}, 4 \mathrm{H}), 7.14-6.97$ $(\mathrm{m}, 14 \mathrm{H}), 6.95-6.83(\mathrm{~m}, 8 \mathrm{H}), 6.73-6.65(\mathrm{~m}, 10 \mathrm{H}), 6.59-6.51(\mathrm{~m}, 4 \mathrm{H})$, consistent with reported spectrum (Angew. Chem. Int. Ed. 2019, 131, 8266-8270).

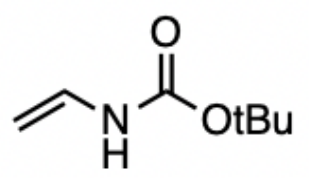

tert-butyl vinyl carbamate: Compound was synthesized according to a previous report ( $\mathrm{J}$. Am. Chem. Soc. 2019, 141, 9, 4147-4153) and 70\% yield was obtained as a white crystalline solid. ${ }^{1} \mathrm{H}$ NMR $(400 \mathrm{MHz}, \mathrm{CDCl} 3) \delta 6.66(\mathrm{~s}, 1 \mathrm{H}), 6.28(\mathrm{~s}, 1 \mathrm{H}), 4.40(\mathrm{~d}, \mathrm{~J}=15.7 \mathrm{~Hz}, 1 \mathrm{H}), 4.21(\mathrm{~d}, \mathrm{~J}=$ $8.8 \mathrm{~Hz}, 1 \mathrm{H}), 1.47(\mathrm{~s}, 9 \mathrm{H})$.

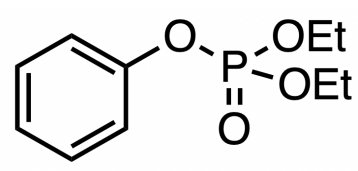

diethyl phenyl phosphate: Compound was synthesized according to a previous report (Chernowsky, Colleen; Chmiel, Alyah; Wickens, Zachary (2021): Photocatalytic Activity of Diverse Organic Radical Anions: Catalyst Discovery Enables Cleavage of Strong C(sp2)-N and C(sp2)-O Bonds. ChemRxiv. Preprint. https://doi.org/10.26434/chemrxiv.14710398.v1) and 68\% yield was obtained as a colorless oil. ${ }^{1} \mathbf{H}$ NMR $(400 \mathrm{MHz}, \mathrm{CDCl} 3) \delta 7.33(\mathrm{dd}, \mathrm{J}=8.6,7.2 \mathrm{~Hz}$, 2H), $7.24-7.19$ (m, 2H), 7.16 (t, J = 7.2 Hz, 1H), $4.29-4.14$ (m, 4H), 1.34 (td, J = 7.1, 1.1 Hz, $6 \mathrm{H})$. 


\section{General Experimental Procedures for Photoredox Reductions}

\section{General Procedure A - Dehalogenation}

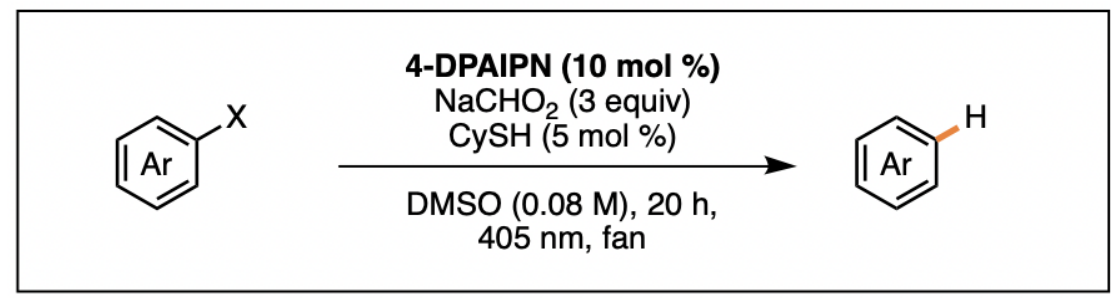

To an oven-dried $10 \mathrm{~mL}$ schlenk tube equipped with a stir bar, 4-DPAIPN (0.01 mmol, $10 \mathrm{~mol}$ $\%)$ and sodium formate ( $0.3 \mathrm{mmol}, 3$ equiv) were added. The tube was evacuated and backfilled with $\mathrm{N} 2$ three times. While under active N2, cyclohexylthiol $(0.005 \mathrm{mmol}, 5 \mathrm{~mol} \%)$ and chlorobenzene $(0.1 \mathrm{mmol}, 1$ equiv) were added to the schlenk tube followed by DMSO (1.25 $\mathrm{mL}, 0.08 \mathrm{M})$. The schlenk tube was sealed under N2 then stirred and irradiated with a $405 \mathrm{~nm}$ LED (3.5 cm from glass surface with fan cooling for 20 hours.

For GC analyses: After reaction completion, mesitylene (14 uL, $0.1 \mathrm{mmol}, 1$ equiv) was added as the internal standard to the crude mixture. $0.1 \mathrm{~mL}$ aliquot was removed from the crude and quenched with $1 \mathrm{~mL}$ water then extracted with $1 \mathrm{~mL}$ diethyl ether. Diethyl ether layer was filtered through a silica pipette plug then ran on the GC.

For NMR analyses: Added $\mathrm{CH} 2 \mathrm{Br} 2$ as the internal standard ( $7 \mathrm{uL}, 0.1 \mathrm{mmol}, 1$ equiv) to crude reaction mixture. Took $0.1 \mathrm{~mL}$ aliquot and quenched with $1 \mathrm{~mL}$ water then extracted with $1 \mathrm{~mL}$ $\mathrm{CDCl} 3$. Reactions were analyzed via ${ }^{1} \mathrm{H} \mathrm{NMR}$ of the $\mathrm{CDCl} 3$ layer.

\section{General Procedure B - Phosphonylation}

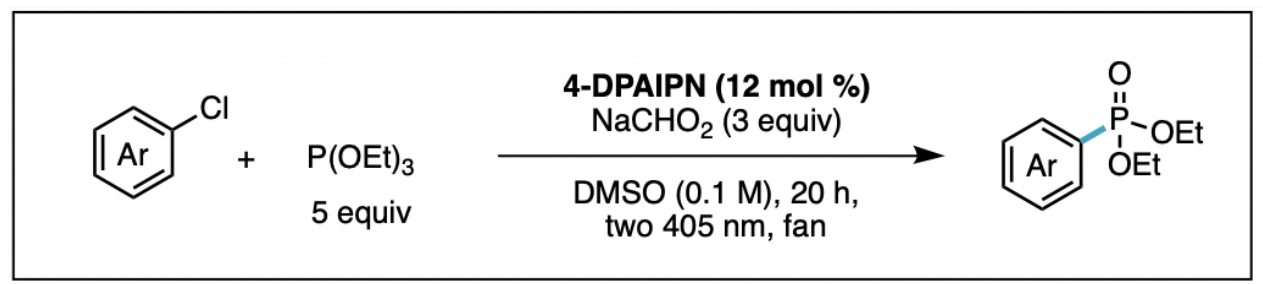

To an oven-dried $10 \mathrm{~mL}$ schlenk tube equipped with a stir bar, 4-DPAIPN (0.048 mmol, $12 \mathrm{~mol}$ $\%$ ) and sodium formate (1.2 mmol, 3 equiv) were added. Aryl chloride ( $0.4 \mathrm{mmol}, 1$ equiv) and triethyl phosphite $(2.0 \mathrm{mmol}, 5$ equiv) were added to the schlenk tube followed by DMSO (4 $\mathrm{mL}, 0.1 \mathrm{M}$ ). The reaction mixture was freeze-pump-thawed then sealed under N2 and stirred and irradiated with two $405 \mathrm{~nm}$ LEDs $(4.5 \mathrm{~cm}$ from glass surface on each side of the tube with fan 
cooling) for 20 hours. After reaction completion, the reaction was quenched with $50 \mathrm{~mL}$ $\mathrm{NaHCO} 3$ (aq) and extracted with $30 \mathrm{~mL}$ EtOAc three times. The combined EtOAc layer was washed with $50 \mathrm{~mL}$ brine then dried over Na2SO4. The mixture was filtered and concentrated in vacuo then purified by flash chromatography with silica.

For NMR analyses: After reaction completion, $\mathrm{CH} 2 \mathrm{Br} 2$ was added as the internal standard to crude reaction mixture. $0.1 \mathrm{~mL}$ aliquot was removed and quenched with $1 \mathrm{~mL}$ water then extracted with $1 \mathrm{~mL} \mathrm{CDCl} 3$. Reactions were analyzed via ${ }^{1} \mathrm{H}$ NMR of the $\mathrm{CDCl} 3$ layer.

\section{General Procedure C - Borylation}

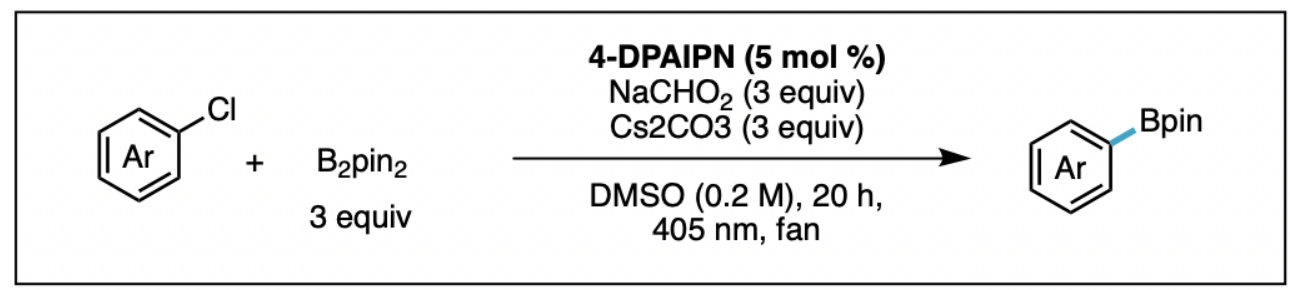

To an oven-dried $10 \mathrm{~mL}$ schlenk tube equipped with stir bar, 4-DPAIPN (0.01 mmol, $2.5 \mathrm{~mol} \%)$, sodium formate (1.2 mmol, 3 equiv), B2pin2 (1.2 mmol, 3 equiv), and $\mathrm{Cs} 2 \mathrm{CO} 3$ (1.2 mmol, 3 equiv) were added. The tube was evacuated and backfilled with $\mathrm{N} 2$ three times. While under active N2, aryl chloride ( $0.4 \mathrm{mmol}, 1$ equiv) was added to the schlenk tube followed by DMSO $(2 \mathrm{~mL}, 0.2 \mathrm{M})$. The schlenk tube was sealed under N2. Stirred and irradiated with two $405 \mathrm{~nm}$ LEDs ( $4.5 \mathrm{~cm}$ from glass surface on each side of the tube with fan cooling) for 20 hours total. At the 6 hour mark, an additional $2.5 \mathrm{~mol} \%$ 4-DPAIPN was added as a stock solution $(2.5 \mathrm{~mol} \%$ 4-DPAIPN dissolved in $400 \mathrm{uL}$ DMSO - then to the reaction vessel, evacuated and backfilled with $\mathrm{N} 2$ on the side arm then while under active N2, added the stock solution). The tube was resealed under N2 and stirred while irradiating for the remaining 14 hours. After reaction completion, the reaction was quenched with $50 \mathrm{~mL} \mathrm{NaHCO} 3$ (aq) and extracted with $30 \mathrm{~mL}$ EtOAc three times. The combined EtOAc layer was washed with $50 \mathrm{~mL}$ brine then dried over $\mathrm{Na} 2 \mathrm{SO}$. The mixture was filtered and concentrated in vacuo then purified by flash chromatography with silica.

For NMR analyses: After reaction completion, $\mathrm{CH} 2 \mathrm{Br} 2$ was added as the internal standard to crude reaction mixture. Took $0.1 \mathrm{~mL}$ aliquot and quenched with $1 \mathrm{~mL}$ water then extracted with $1 \mathrm{~mL} \mathrm{CDCl3}$. Reactions were analyzed via ${ }^{1} \mathrm{H}$ NMR of the $\mathrm{CDCl} 3$ layer. 


\section{General Procedure D - Hydroarylation of Vinyl Carbamate}

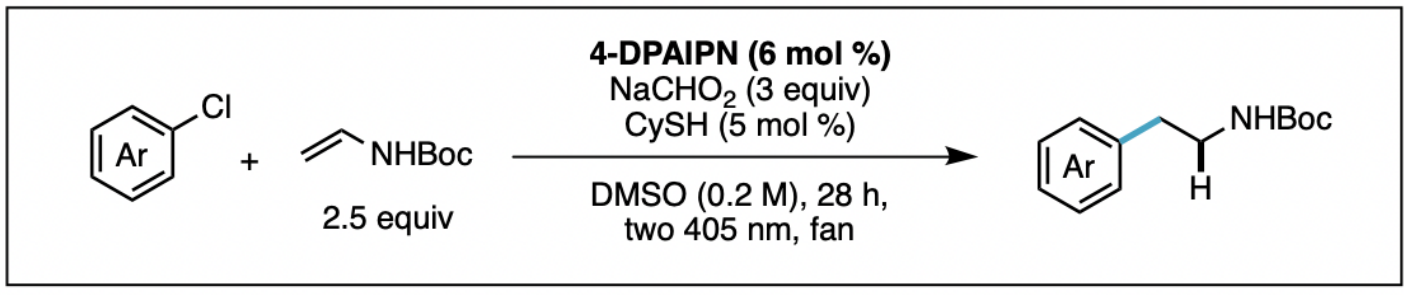

To an oven-dried $10 \mathrm{~mL}$ schlenk tube equipped with a stir bar, 4-DPAIPN (0.012 mmol, 3 mol $\%$ ), sodium formate (1.2 mmol, 3 equiv), and vinyl carbamate (1.0 mmol, 2.5 equiv) were added. The tube was evacuated and backfilled with $\mathrm{N} 2$ three times. While under active N2, added cyclohexylthiol (0.02 mmol, $5 \mathrm{~mol} \%)$ and aryl chloride $(0.4 \mathrm{mmol}, 1$ equiv) to vial then DMSO $(2 \mathrm{~mL}, 0.2 \mathrm{M})$. The tube was sealed under N2 then stirred and irradiated with two $405 \mathrm{~nm}$ lamps (4.5 cm from glass surface on each side with fan cooling) for 28 hours total. At the 6 hour mark, an additional $3 \mathrm{~mol} \%$ 4-DPAIPN was added as a stock solution (3 mol \% 4-DPAIPN dissolved in $400 \mathrm{uL}$ DMSO — then to the reaction vessel, evacuated and backfilled with $\mathrm{N} 2$ on the side arm then while under active N2, added the stock solution). The tube was resealed under N2 and stirred while irradiating for the remaining 22 hours. After reaction completion, the reaction was quenched with $50 \mathrm{~mL} \mathrm{NaHCO} 3$ (aq) and extracted with $30 \mathrm{~mL}$ EtOAc three times. The combined EtOAc layer was washed with $50 \mathrm{~mL}$ brine then dried over Na2SO4. The mixture was filtered and concentrated in vacuo then purified by flash chromatography with silica.

\section{General Procedure E - Hydroarylation of Unactivated Alkenes}

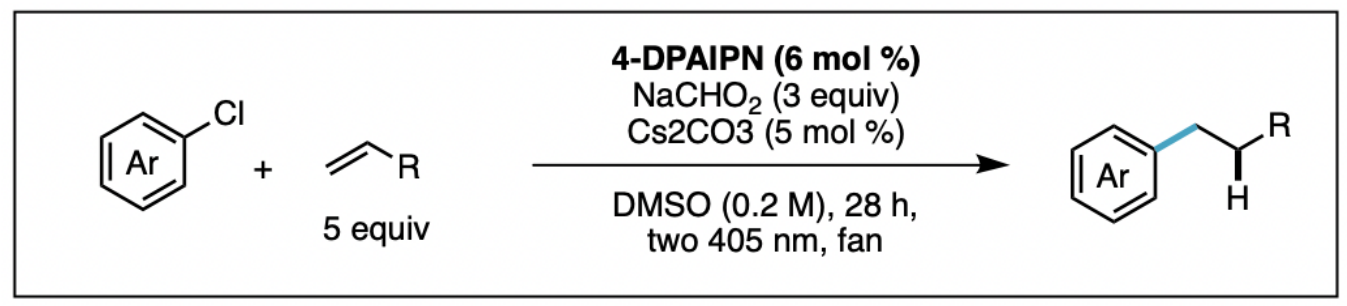

To an oven-dried $10 \mathrm{~mL}$ schlenk tube equipped with a stir bar, 4-DPAIPN (0.012 mmol, $3 \mathrm{~mol}$ $\%$ ) and sodium formate (1.2 mmol, 3 equiv) were added. The tube was evacuated and backfilled with $\mathrm{N} 2$ three times. While under active N2, cyclohexylthiol (0.02 mmol, $5 \mathrm{~mol} \%)$, aryl chloride ( $0.4 \mathrm{mmol}, 1$ equiv), and alkene ( $2.0 \mathrm{mmol}, 5$ equiv) were added to the vial then DMSO ( $2 \mathrm{~mL}$, $0.2 \mathrm{M})$. The tube was sealed under N2 then stirred and irradiated with two $405 \mathrm{~nm}$ lamps $(4.5 \mathrm{~cm}$ from glass surface on each side with fan cooling) for 28 hours total. At the 6 hour mark, an additional $3 \mathrm{~mol} \%$ 4-DPAIPN was added as a stock solution (3 mol \% 4-DPAIPN dissolved in $400 \mathrm{uL}$ DMSO — then to the reaction vessel, evacuated and backfilled with $\mathrm{N} 2$ on the side arm 
then while under active N2, added the stock solution). The tube was resealed under N2 and stirred while irradiating for the remaining 22 hours.

For GC analyses: After reaction completion, mesitylene was added as the internal standard to the crude mixture. $0.1 \mathrm{~mL}$ aliquot was removed from the crude and quenched with $1 \mathrm{~mL}$ water and extracted with $1 \mathrm{~mL}$ diethyl ether. The diethyl ether layer was filtered through a silica pipette plug then ran on the GC.

For NMR analyses: $\mathrm{CH} 2 \mathrm{Br} 2$ was added as the internal standard to crude reaction mixture. 0.1 $\mathrm{mL}$ aliquot was removed and quenched with $1 \mathrm{~mL}$ water then extracted with $1 \mathrm{~mL} \mathrm{CDCl3}$. Took Reactions were analyzed via ${ }^{1} \mathrm{H} \mathrm{NMR}$ of the $\mathrm{CDCl} 3$ layer.

\section{Reaction Optimization}

\section{Dehalogenation}

Following General Procedure A on $0.1 \mathrm{mmol}$ scale, the following parameters were evaluated during optimization of this reaction. Reactions were analyzed via GCMS.

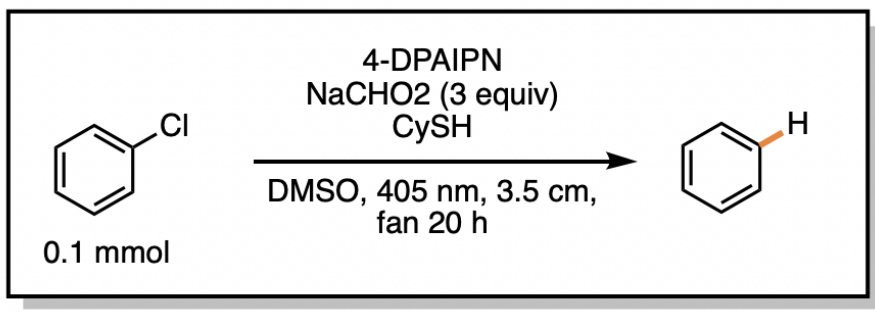

\begin{tabular}{|l|c|}
\hline & PhH \% \\
\hline 0.2 M DMSO, 5 mol \% 4-DPAIPN (two 2.5 mol \% batches) & 62 \\
\hline 0.08 M DMSO, 5 mol \% 4-DPAIPN & 62 \\
\hline 0.08 M DMSO, 10 mol \% 4-DPAIPN & 74 \\
\hline 0.2 M DMSO, 5 mol \% 4-DPAIPN (two 2.5 mol \% batches), no CySH & 57 \\
\hline 0.2 M DMF, 5 mol \% 4-DPAIPN, no CySH & 14 \\
\hline 0.2 M THF, 5 mol \% 4-DPAIPN (two 2.5 mol \% batches), no CySH & 0 \\
\hline
\end{tabular}

Figure S2: Dehalogenation optimization.

\section{Phosphonylation}

Following General Procedure B, the conditions below were used as the initial standard conditions. The following parameters were evaluated during optimization of this reaction. Reactions were analyzed via ${ }^{1} \mathrm{H}$ NMR using $\mathrm{CH} 2 \mathrm{Br} 2$ as the internal standard. 


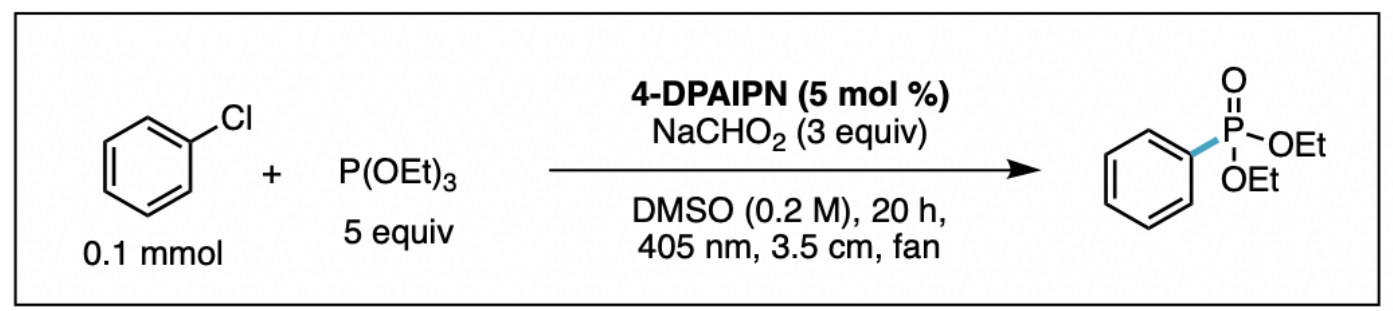

\begin{tabular}{|l|c|}
\hline & prdt \\
\hline standard & 30 \\
\hline 2.5 mol \% 4-DPAIPN & 33 \\
\hline 0.1 M DMSO, 2.5 mol \% 4-DPAIPN & 25 \\
\hline 0.1 M DMSO, 5 mol \% DPA (no batch addition) & 40 \\
\hline 0.1 M DMSO, 10 mol \% DPA & 55 \\
\hline 0.1 M DMSO, 10 mol \% DPA, FPT & 53 \\
\hline 10 eq phos, 2.5 mol \% 4-DPAIPN & 36 \\
\hline 15 eq phos, 2.5 mol \% 4-DPAIPN & 36 \\
\hline 0.067 M DMSO, 10 mol \% 4-DPAIPN & 30 \\
\hline 0.1 M DMSO, 10 mol \% 4-DPAIPN, 10 eq phos & 50 \\
\hline 0.067 M DMSO, 10 mol \% 4-DPAIPN, 10 eq phos & 46 \\
\hline 0.1 M, 5 mol \% 4-DPAIPN, 10 eq phos (no batch addition) & 37 \\
\hline
\end{tabular}

Figure S3: Phosphonylation optimization.

The remainder of optimization for the phosphonylation was performed on $0.4 \mathrm{mmol}$ scale with the following standard conditions.

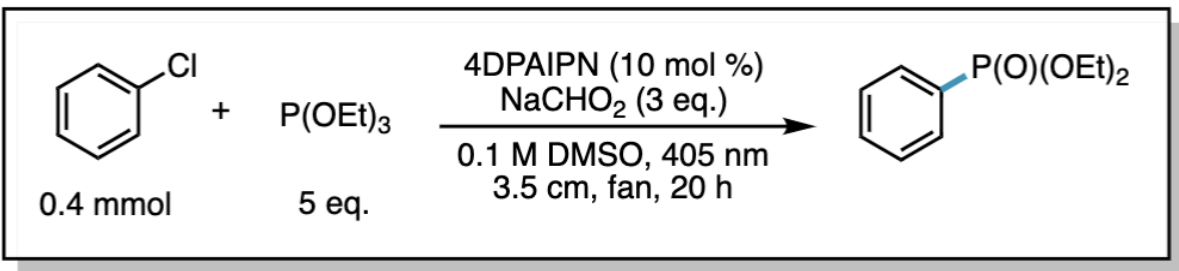

\begin{tabular}{|l|c|}
\hline & prdt \\
\hline standard & 51 \\
\hline 2 lights & 55 \\
\hline photobox & 51 \\
\hline 12 mol \% DPA & 60 \\
\hline 15 mol \% DPA & 61 \\
\hline 12 mol \% DPA, 0.08 M & 50 \\
\hline 15 mol \% DPA, 0.08 M & 63 \\
\hline 12 mol \% DPA, 0.05 M & 47 \\
\hline 15 mol \% DPA, 0.05 M & 52 \\
\hline
\end{tabular}

Figure S4: Phosphonylation optimization on $0.4 \mathrm{mmol}$ scale. 


\section{Borylation}

Following General Procedure $\mathrm{C}$ on $0.1 \mathrm{mmol}$ scale, the following parameters were evaluated during optimization of this reaction. Reactions were analyzed via ${ }^{1} \mathrm{H}$ NMR using $\mathrm{CH} 2 \mathrm{Br} 2$ as the internal standard.

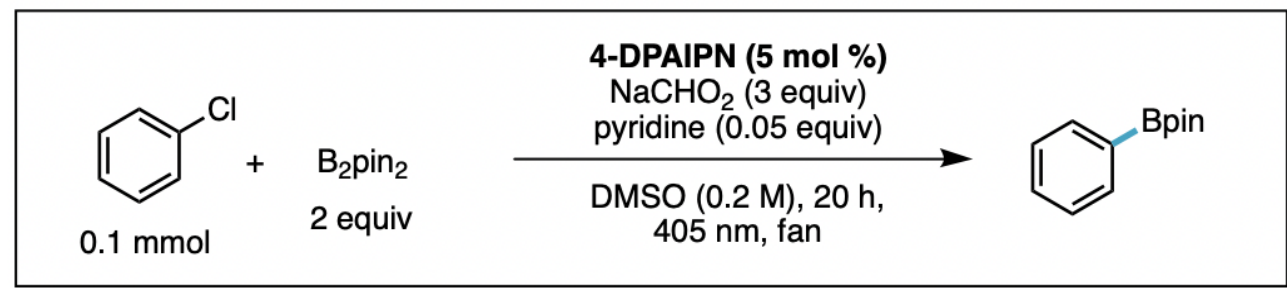

\begin{tabular}{|l|c|c|c|}
\hline & prdt & PhH & prdt/PhH \\
\hline standard & 60 & 20 & 3 \\
\hline 2.5 mol \% 4-DPAIPN & 50 & 15 & 3.33333333 \\
\hline 0 eq pyr & 50 & 28 & 1.78571429 \\
\hline 0.05 eq pyr & 68 & 27 & 2.51851852 \\
\hline 0.5 eq pyr & 68 & 22 & 3.09090909 \\
\hline 1 eq B2pin2 & 54 & 18 & 3 \\
\hline 3 eq B2pin2 & 67 & 25 & 2.68 \\
\hline 4 eq B2pin2 & 67 & 11 & 6.09090909 \\
\hline 5 eq B2pin2 & 70 & 15 & 4.66666667 \\
\hline 0.1 M, 10 mol \% 4-DPAIPN, 3 eq B2pin2, no batch & 60 & 23 & 2.60869565 \\
\hline 0.15 M, 5 mol \% 4-DPAIPN, 3 eq B2pin2 & 68 & 19 & 3.57894737 \\
\hline DMF & 15 & 10 & 1.5 \\
\hline
\end{tabular}

Figure S5: Borylation optimization.

The remainder of borylation optimization was performed with chloroanisole as the substrate because electron-rich substrates were more challenging. 


\begin{tabular}{|l|c|c|c|c|}
\hline & prdt & Ar-H & rsm & prdt/Ar-H \\
\hline standard & 57 & 20 & 26 & 2.85 \\
\hline 0.5 eq pyridine & 54 & 22 & 30 & 2.45455 \\
\hline 0.5 eq DMAP & 58 & 25 & 14 & 2.32 \\
\hline no fan, 5 eq B2pin2, 0.5 eq pyridine & 41 & 9 & 52 & 4.55556 \\
\hline 10 mol \% 4-DPAIPN, 0.08 M DMSO, 0.05 eq pyridine & 50 & 32 & 21 & 1.5625 \\
\hline 10 mol \% 4-DPAIPN, 0.08 M DMSO, 1 eq pyridine & 29 & 20 & 42 & 1.45 \\
\hline 10 mol \% 4-DPAIPN, 0.08 M DMSO, 1 eq DMAP & 45 & 22 & 34 & 2.04545 \\
\hline 10 mol \% 4-DPAIPN, 0.08 M DMSO, 1 eq Cs2CO3 & 51 & 30 & 18 & 1.7 \\
\hline 10 mol \% 4-DPAIPN, 0.08 M DMSO, 1 eq tBuOK & 41 & 29 & 8 & 1.41379 \\
\hline 10 mol \% 4-DPAIPN, 0.08 M DMSO, 1 eq K3PO4 & 37 & 24 & 26 & 1.54167 \\
\hline 10 mol \% 4-DPAIPN, 0.08 M DMSO, 1 eq pyridine, 5 eq B2pin2 & 34 & 9 & 54 & 3.77778 \\
\hline 0.5 eq Cs2CO3 & 41 & 23 & 21 & 1.78261 \\
\hline 1 eq Cs2CO3 & 49 & 20 & 18 & 2.45 \\
\hline 2 eq Cs2CO3 & 61 & 23 & 11 & 2.65217 \\
\hline 3 eq Cs2CO3 & 67 & 29 & 0 & 2.31034 \\
\hline 4 eq Cs2CO4 & 66 & 33 & 0 & 2 \\
\hline 3 eq Cs2CO3 with Cs formate & 63 & 33 & 0 & 1.90909 \\
\hline
\end{tabular}

Figure S6: Borylation optimization with chloroanisole as the substrate.

\section{Hydroarylation of Vinyl Carbamate}

Following General Procedure D on $0.1 \mathrm{mmol} \mathrm{scale}$, the following parameters were evaluated during optimization of this reaction. Reactions were analyzed via GCMS.

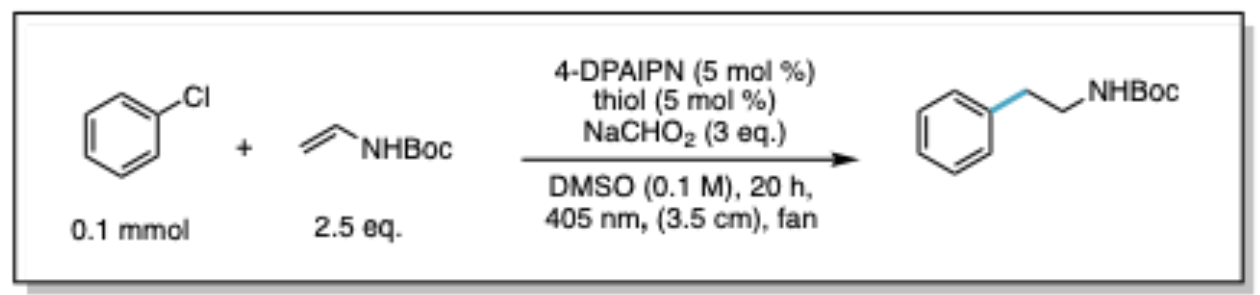

\begin{tabular}{|l|c|c|c|}
\hline catalyst & product \% & product/PhH & conversion \\
\hline NpMI (427 nm) & 10 & 1.3 & 42 \\
\hline NpDI (467) & 0 & NA & 0 \\
\hline DCA (525 nm) & 0 & NA & 0 \\
\hline 4-CzIPN (390 nm) & 14 & 7.7 & 32 \\
\hline tBu-4-CzIPN & 16 & 5.2 & 24 \\
\hline 4-DPAPN & 22 & 5.1 & 41 \\
\hline 4-DPATPN & 17 & 3.4 & 32 \\
\hline 3-CN-3-Ph & 0 & NA & 0 \\
\hline 4-DPAIPN & 55 & 4.2 & 97 \\
\hline
\end{tabular}

Figure S7. Catalyst evaluation for hydroarylation. 


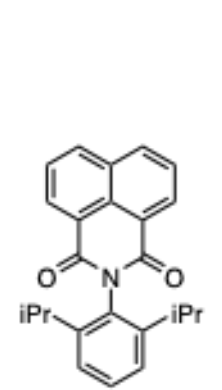<smiles>CC(C)c1cccc(C(C)C)c1N1C(=O)c2ccc3c4c(ccc(c24)C1=O)C(=O)N(c1c(C(C)C)cccc1C(C)C)C3=O</smiles>

NpMI

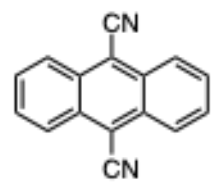

DCA

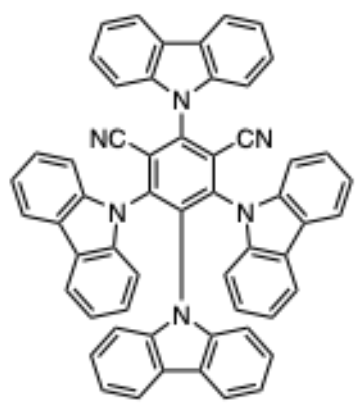

4-CzIPN

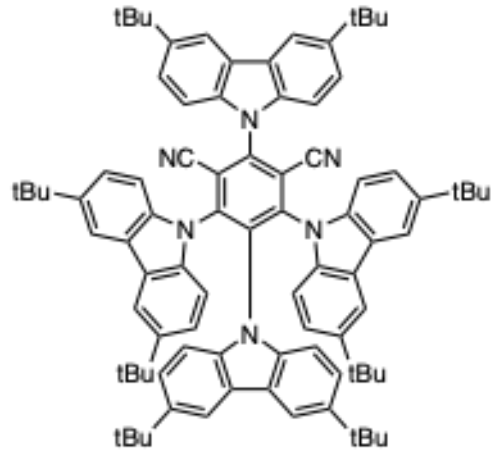

tBu-4-CzIPN<smiles>N#Cc1c(N)c(N)c(P(c2ccccc2)c2ccccc2)c(N)c1N</smiles>

4-DPAPN<smiles>N#Cc1c(Nc2ccccc2)c([PH2+])c([PH2+])c([PH2+])c1[NH+](c1ccccc1)c1ccccc1</smiles>

4-DPATPN<smiles>N#Cc1c(-c2ccccc2)c(C#N)c(-c2ccccc2)c(C#N)c1-c1ccccc1</smiles>

3-CN-3-Ph<smiles>N#Cc1c(N)c(N)c(P(c2ccccc2)c2ccccc2)c(P)c1N</smiles>

4-DPAIPN

Figure S8: Catalyst structures.

\begin{tabular}{|l|c|c|c|}
\hline & yield & prdt/PhH & conversion \\
\hline DMSO & 55 & 2.4 & 90 \\
\hline MeCN & 18 & 1.6 & 46 \\
\hline DMF & 21 & 0.7 & 52 \\
\hline acetone & 4 & 0.5 & 25 \\
\hline HFIP & 0 & -- & 0 \\
\hline DCM & 0 & -- & 0 \\
\hline THF & 0 & $(40 \% \mathrm{PhH})$ & 58 \\
\hline $\mathbf{0 . 0 5} \mathbf{M}$ & 32 & 0.8 & 85 \\
\hline $\mathbf{0 . 1 0} \mathbf{M}$ & 50 & 2.4 & 90 \\
\hline $\mathbf{0 . 2 0} \mathbf{M}$ & 27 & 6.2 & 35 \\
\hline
\end{tabular}

Figure S9: Solvent evaluation for hydroarylation. All solvents tested were run 1:1 with DMSO. 


\begin{tabular}{|l|l|c|c|c|c|}
\hline & & yield & prdt/PhH & conversion & MB \\
\hline \multirow{3}{*}{ thiophenols } & no HAT & 5 & 0.6 & 31 & 81 \\
\cline { 2 - 6 } & 2,6-di-tBu-4-OMe-PhOH & 2 & 0.3 & 20 & 87 \\
\hline \multirow{3}{*}{ alkyl thiols } & PhSH & 41 & 2.4 & 80 & 83 \\
\cline { 2 - 6 } & 4-OMe-PhSH & 53 & 2.4 & 89 & 87 \\
\cline { 2 - 6 } & decanethiol & 54 & 2.1 & 89 & 91 \\
\cline { 2 - 6 } & tert-dodecylthiol & 55 & 2.4 & 90 & 92 \\
\hline
\end{tabular}

Figure S10: Thiol evaluation for hydroarylation.

\begin{tabular}{|l|c|c|c|}
\hline reductant (3 equiv) & prdt & PhH & prdt/PhH \\
\hline DIPEA & 6 & 37 & 0.4 \\
\hline NPh3 & 0 & 0 & -- \\
\hline Na-ascorbate & 0 & 0 & -- \\
\hline Li-formate & 18 & 31 & 0.6 \\
\hline Cs-formate & 53 & 24 & 2.3 \\
\hline K-formate & 33 & 27 & 1.2 \\
\hline Na-formate & 50 & 21 & 2.4 \\
\hline formic acid + NBu3 & 9 & 2 & 4.2 \\
\hline tBuOH & 0 & 0 & -- \\
\hline iPrOH & 0 & 0 & -- \\
\hline H2O & 0 & 0 & -- \\
\hline
\end{tabular}

Figure S11: Reductant evaluation for hydroarylation.

6. Photocatalyst and Reductant Evaluation

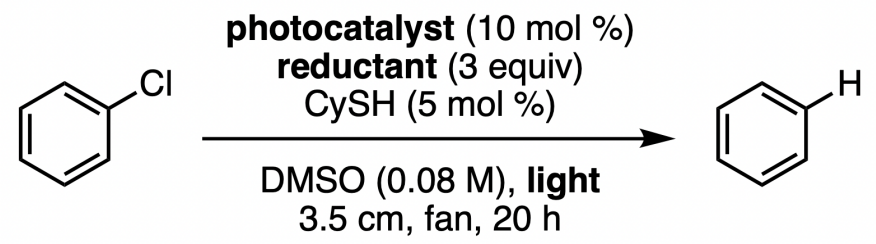

\begin{tabular}{|c|c|c|c|c|}
\hline & 4-DPAIPN & 4-CzIPN & Fluorenone & Phenazine \\
\hline $\mathrm{NEt}_{3}$ & 17 & 16 & 1 & 8 \\
\hline $\mathrm{NBu}_{3}$ & 13 & 16 & 1 & 4 \\
\hline $\mathrm{EtN}(\mathrm{iPr})_{2}$ & 35 & 14 & 2 & 7 \\
\hline $\mathrm{NaCHO}_{2}$ & 70 & 33 & 35 & 6 \\
\hline
\end{tabular}

Figure S12. Catalyst and reductand matrix to unlock potent radical anion reactivity. 
Following General Procedure A except varying the photocatalyst, reductant, and wavelength, the following yields were obtained via GC analysis using mesitylene as the internal standard. The light used for irradiation (4-DPAIPN $=405 \mathrm{~nm}, 4-C z I P N=390 \mathrm{~nm}$, fluorenone $=405 \mathrm{~nm}$, phenazine $=440 \mathrm{~nm}$ ) was determined from the optimal wavelength for the reduced congener of each photocatalyst, discovered in \{Chernowsky, Colleen; Chmiel, Alyah; Wickens, Zachary (2021): Photocatalytic Activity of Diverse Organic Radical Anions: Catalyst Discovery Enables Cleavage of Strong $\mathrm{C}(\mathrm{sp} 2)-\mathrm{N}$ and $\mathrm{C}(\mathrm{sp} 2)-\mathrm{O}$ Bonds. ChemRxiv. Preprint. https://doi.org/10.26434/chemrxiv.14710398.v1\}.

\section{Evaluation of Leaving Groups not Susceptible to XAT}

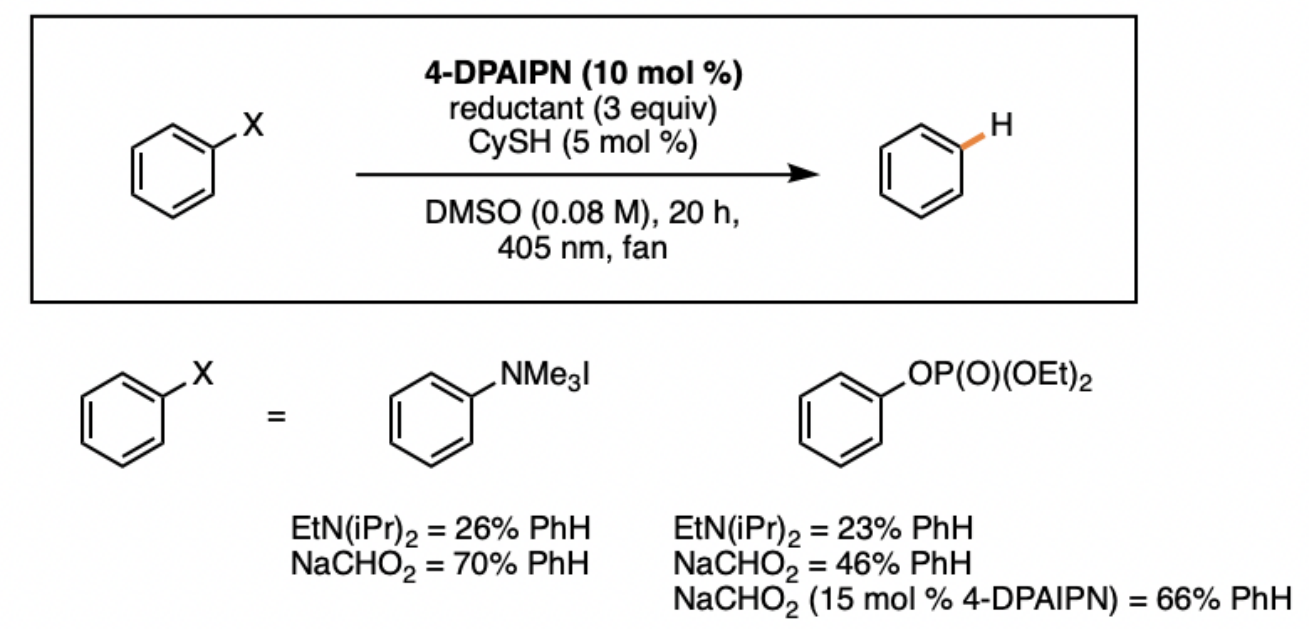

Figure S13. Testing non-halide leaving groups to rule out an XAT mechanism.

Following General Procedure A, the following yields were obtained via GC analysis. The alkyl amine promoted the desired reduction of the anilinium and phosphate in modest yields, supporting an electron-primed mechanism rather than halogen atom transfer (XAT). Furthermore, we see that the reduction becomes much more efficient upon employing sodium formate as the redox activator. Conversion of the phosphate can be increased by employing higher catalyst loading.

\section{Reductants Evaluated with 4-DPAIPN}

Below is a complete list of reductants that were tested with 4-DPAIPN as the photocatalyst, using General Procedure A. For reductants that lacked an H-atom (PPh3, 4-OMe-NPh3, Mn(0)), dimethylformamide was used as a co-solvent to act as an $\mathrm{H}$-atom donor to the aryl radical that would be generated upon single electron reduction. 


\begin{tabular}{|l|c|}
\hline & \% prdt \\
\hline sodium oxalate & 2 \\
\hline PPh3 & 7 \\
\hline 4-OMe-NPh3 & 3 \\
\hline Mn(0) & 1 \\
\hline sodium ascorbate & 2 \\
\hline NEt3 & 17 \\
\hline NBu3 & 13 \\
\hline EtN(iPr)2 & 35 \\
\hline NaCHO2 & 70 \\
\hline
\end{tabular}

Figure S14. Reductants tested with 4-DPAIPN for the dehalogenation of chlorobenzene.

\section{Control Experiments}

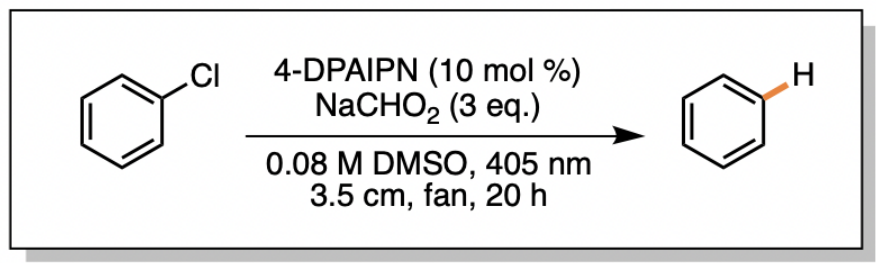

$\begin{array}{ccc}\text { alterations } & \text { prdt } & \text { rsm } \\ \text { none } & 71 & 18 \\ \text { no light } & <2 & 99 \\ \text { no cat } & <2 & 94 \\ \text { no formate } & \text { not detected } & 98\end{array}$

The following control experiments were run using General Procedure A with the following deviations mentioned above. We see that light, catalyst, and formate are required.

\section{Radical Clock Experiment}

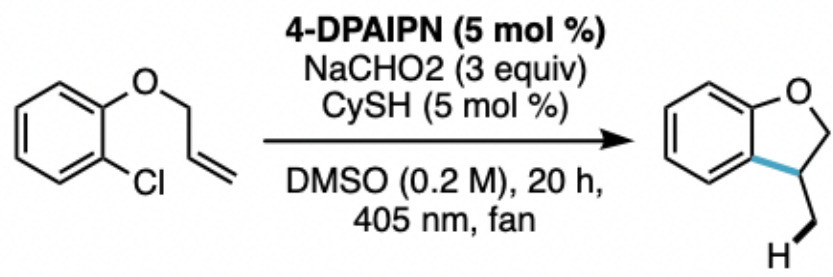

Figure S15. Radical clock experiment to support aryl radical intermediate. 
To an oven-dried $10 \mathrm{~mL}$ schlenk tube equipped with a stir bar, 4-DPAIPN $(0.0025 \mathrm{mmol}, 2.5 \mathrm{~mol}$ $\%)$ and sodium formate $(0.3 \mathrm{mmol}, 3$ equiv) were added. The flask was evacuated and backfilled with $\mathrm{N} 2$ three times. While under active N2 (if N2 pressure is too low, then the reaction mixture was freeze-pump-thawed after addition of all reagents), added cyclohexylthiol $(0.005 \mathrm{mmol}, 5$ mol \%) and aryl chloride $(0.1 \mathrm{mmol}, 1$ equiv) to vial then DMSO $(0.5 \mathrm{~mL}, 0.2 \mathrm{M})$. Sealed tube under N2. The reaction mixture was stirred and irradiated with a $405 \mathrm{~nm}$ lamp $(3.5 \mathrm{~cm}$ from glass surface with fan cooling) for 20 hours total. At the 6 hour mark, an additional $2.5 \mathrm{~mol} \%$ 4-DPAIPN (for a total of $5 \mathrm{~mol} \%$ photocatalyst) was added as a stock solution $(2.5 \mathrm{~mol} \%$ 4-DPAIPN dissolved in $100 \mathrm{uL} \mathrm{DMSO} \mathrm{-} \mathrm{then} \mathrm{to} \mathrm{the} \mathrm{reaction} \mathrm{vessel,} \mathrm{evacuated} \mathrm{and} \mathrm{backfilled}$ with $\mathrm{N} 2$ on the side arm then while under active $\mathrm{N} 2$, added the stock solution). The tube was resealed under $\mathrm{N} 2$ and the mixture stirred under irradiation for the remaining 14 hours. $\mathrm{CH} 2 \mathrm{Br} 2$ (7 $\mathrm{uL}, 0.1 \mathrm{mmol}, 1$ equiv) was added as the internal standard to crude reaction mixture. $0.1 \mathrm{~mL}$ aliquot was removed and quenched with $1 \mathrm{~mL}$ water then extracted with $1 \mathrm{~mL} \mathrm{CDCl3.52 \%} \mathrm{yield}$ was obtained via ${ }^{1} \mathrm{H}$ NMR. NMR consistent with reported spectrum (J. Org. Chem. 2018, 83, 16, 9381-9390). 


\section{High-Throughput Experimentation with Aryl Halide Informer Plate at Merck}

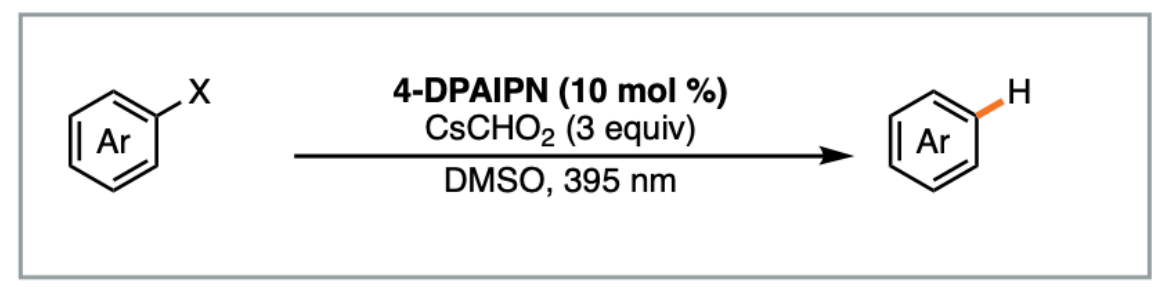

\begin{tabular}{|c|c|c|c|c|c|}
\hline X1 & X2 & X3 & X4 & X5 & X6 \\
\hline X7 & X8 & X9 & X10 & X11 & X12 \\
\hline X13 & X14 & X15 & X16 & X17 & X18 \\
\hline
\end{tabular}
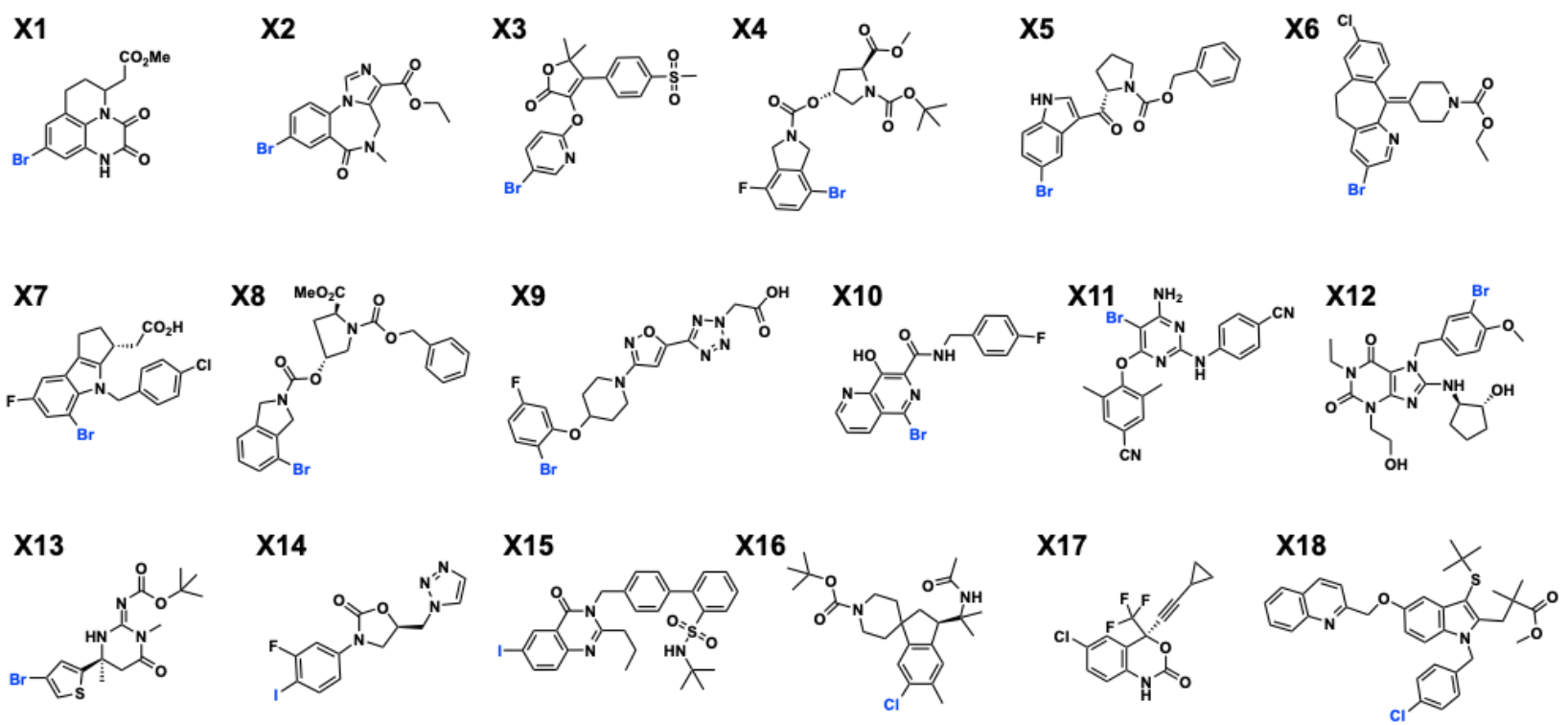

Figure S16. Aryl halide informer plate used in high-throughput experimentation to test the 4-DPAIPN and formate system, in collaboration with Merck.

To a $4 \mathrm{~mL}$ vial equipped with a stir bar, 4-DPAIPN (23.9 mg, $0.03 \mathrm{mmol}$ ) and cesium formate (0.9 mmol, 3 equiv) were added. Under active $\mathrm{N} 2$, DMSO $(3.75 \mathrm{~mL})$ previously sparged with nitrogen for $5 \mathrm{~min}$ was added. The resulting suspension was vigorously stirred for 5-10 min. In a nitrogen inertion box, to each reaction well of a custom plated kit containing $10 \mu \mathrm{mol}$ of the commercially available informers was added $125 \mu \mathrm{L}$ of the suspension containing 4-DPAIPN $(0.8 \mathrm{mg}, 1 \mu \mathrm{mol})$, cesium formate $(5.3 \mathrm{mg}, 30 \mu \mathrm{mol})$. The reaction block was sealed, and the kit was stirred (by action of a tumble stirrer) under an active stream of nitrogen and irradiated with a 
$395 \mathrm{~nm}$ LED plate (Lumidox II, stage 3, $190 \mathrm{~mW} /$ well) equipped with an active cooling base for 8 hours. After completion, each reaction vial was analyzed on an LCMS. The HTE screen afforded hits as depicted in the following graphic showing conversion to the reduction product.

An advantage of using chemical reductants to generate electron-primed catalysts is that it allows for an operationally simple reaction setup as well as allows use of photoredox high-throughput experimentation technology. We demonstrated this using an aryl halide informer plate that contains a unique densely functionalized substrate in each well. Dehalogenation was chosen as the target reaction due to its analytical simplicity. We learned that this electron-primed system can reduce a variety of medicinally-relevant compounds using high-throughput experimentation. These compounds were detected as significant products via LCMS. HTE plate: Lumidox Gen II 24-Position LED Arrays, part no. LUM296DA395. Aryl halide informer plate: https://www.sigmaaldrich.com/US/en/tech-docs/paper/970033

To confirm the aforementioned hits, these reactions were repeated on a $0.1 \mathrm{mmol}$ scale using a modified General Procedure A conducted with a Penn PhD Photoreactor M2 equipped with a $405 \mathrm{~nm}$ light source without cyclohexylthiol unless otherwise noted. See compounds 27-35.

Additionally, a single informer (X2) was reacted on a $0.1 \mathrm{mmol}$ scale using a modified General Procedure E conducted with a Penn PhD Photoreactor M2 equipped with a $405 \mathrm{~nm}$ light source. See compound 36.

\section{Cyclic Voltammetry}

$N$-vinyl carbamate $\left(0.1 M T B A P F_{\curvearrowleft}\right)--E_{\text {red }}=-2.25 \mathrm{~V}$ vs $\mathbf{S C E}$

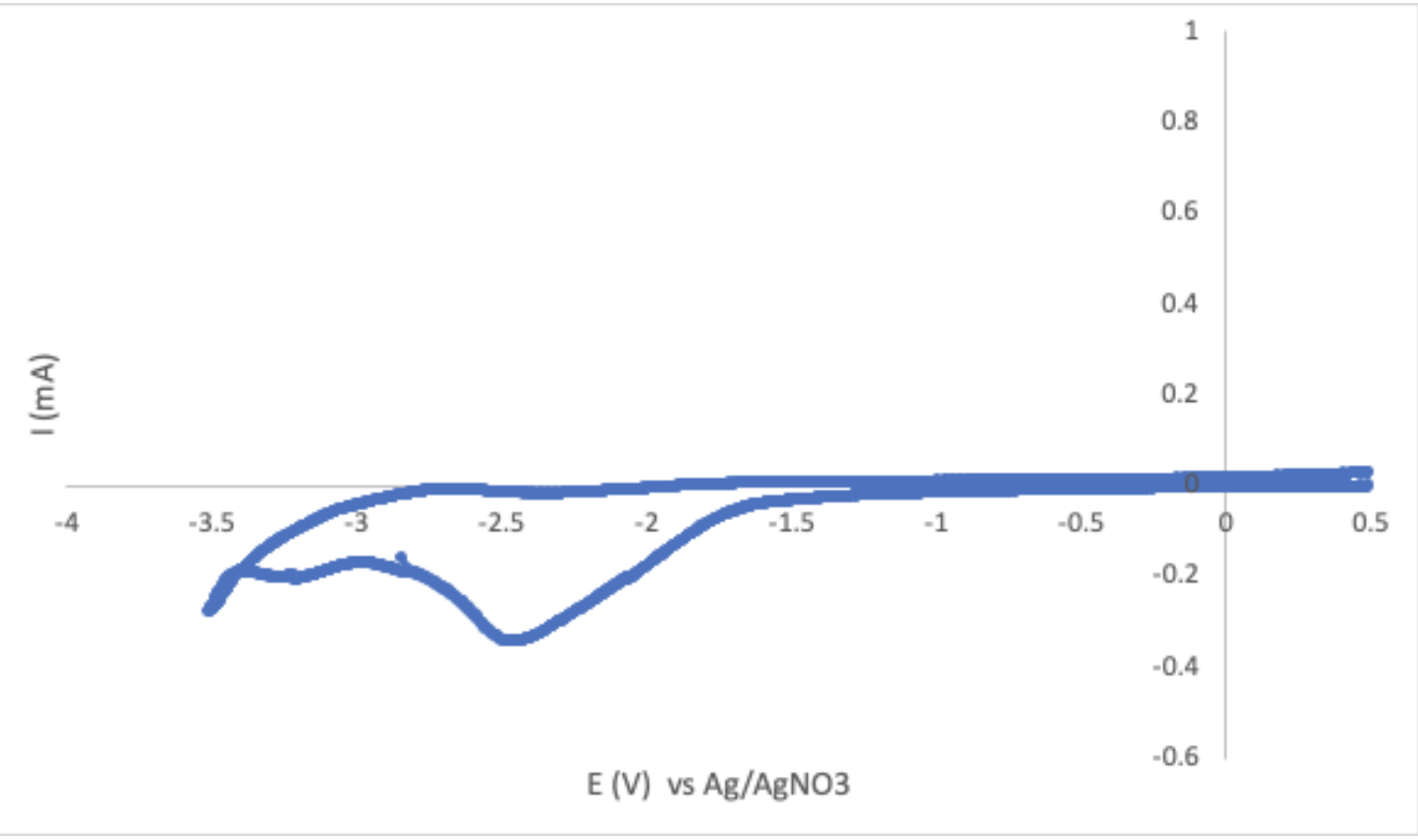


Sodium formate (0.1 M TBAPF6) $-E_{\mathrm{ox}}=+1.25 \mathrm{~V}$ vs SCE

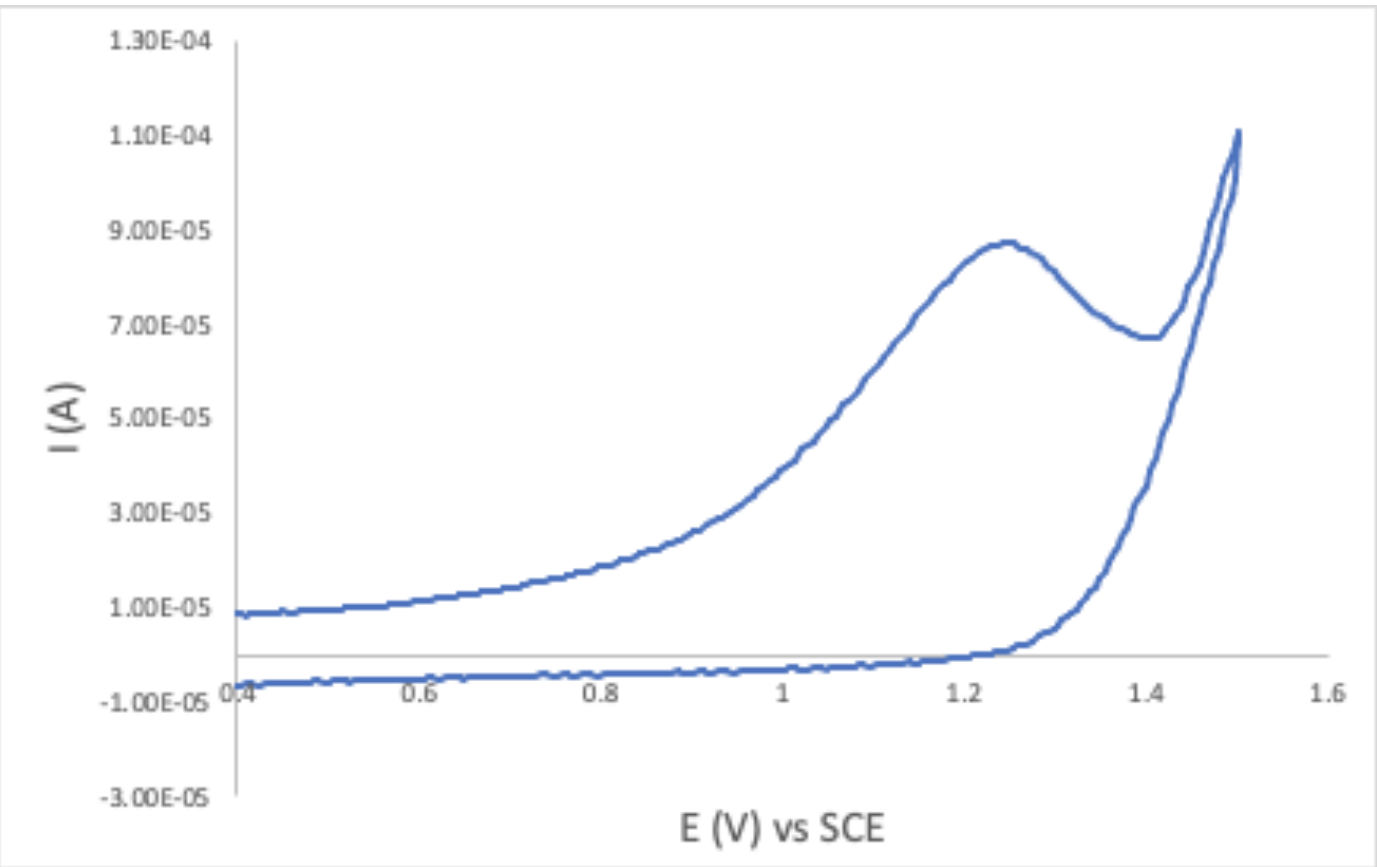

\section{Calibration Curves}

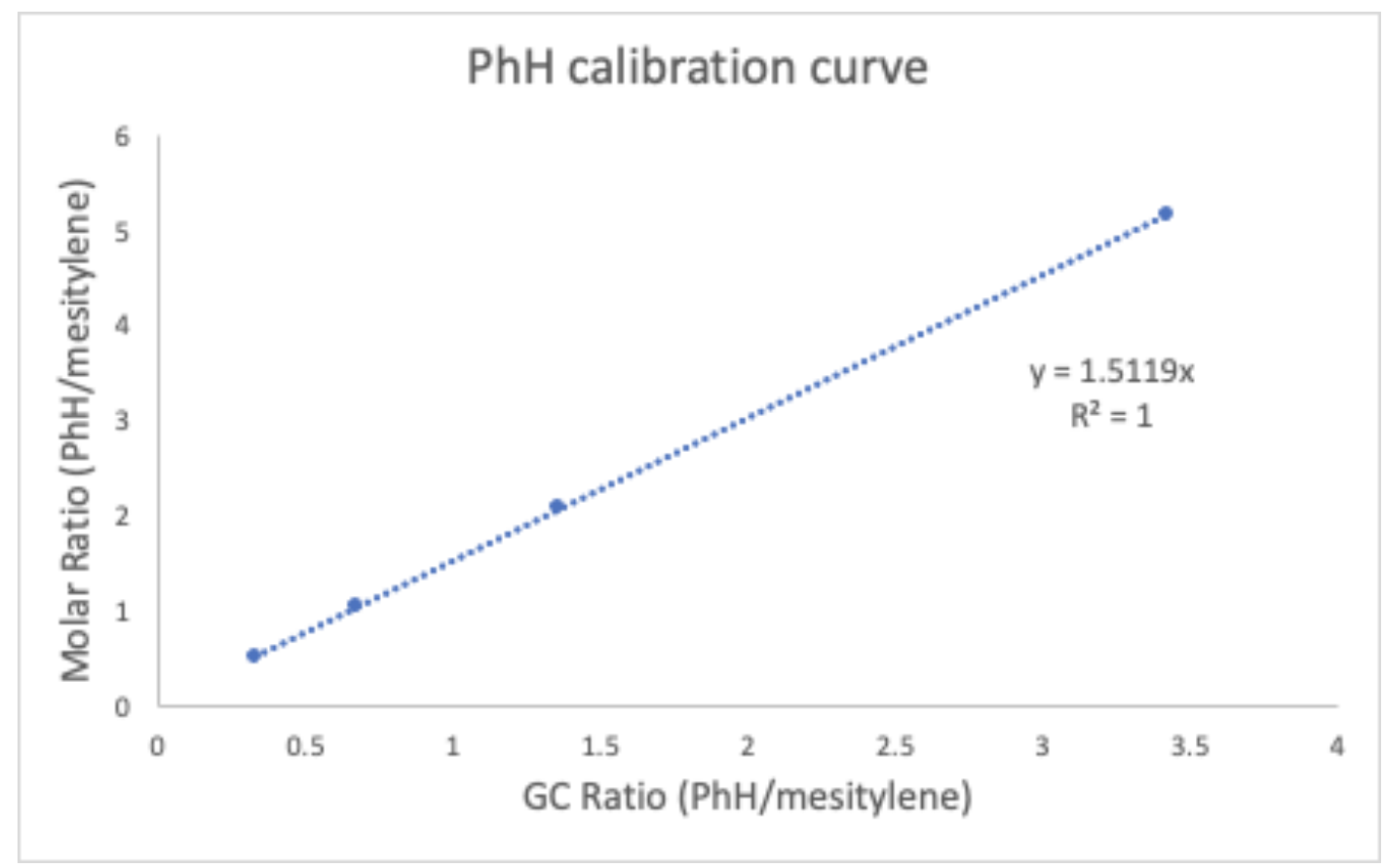



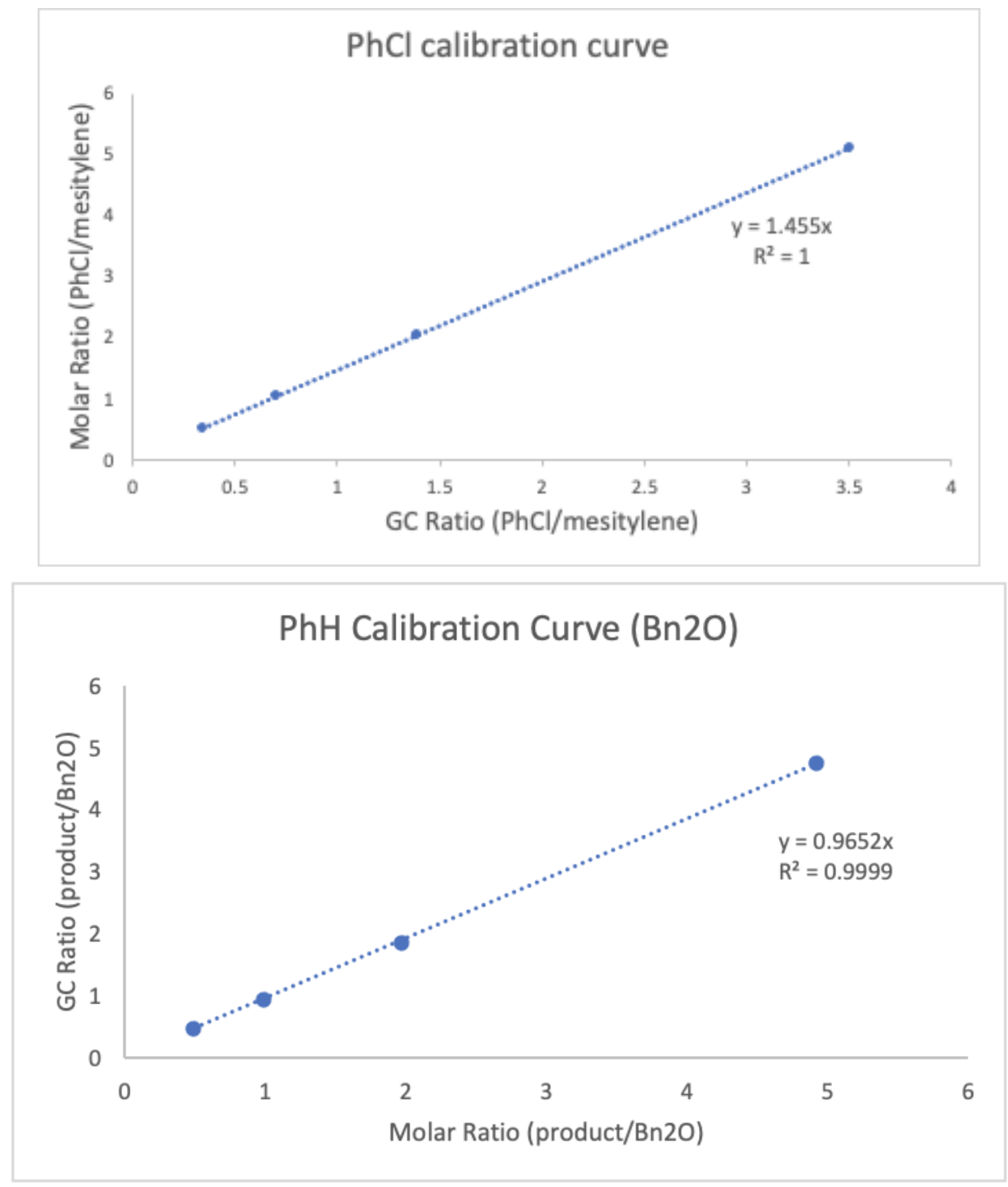

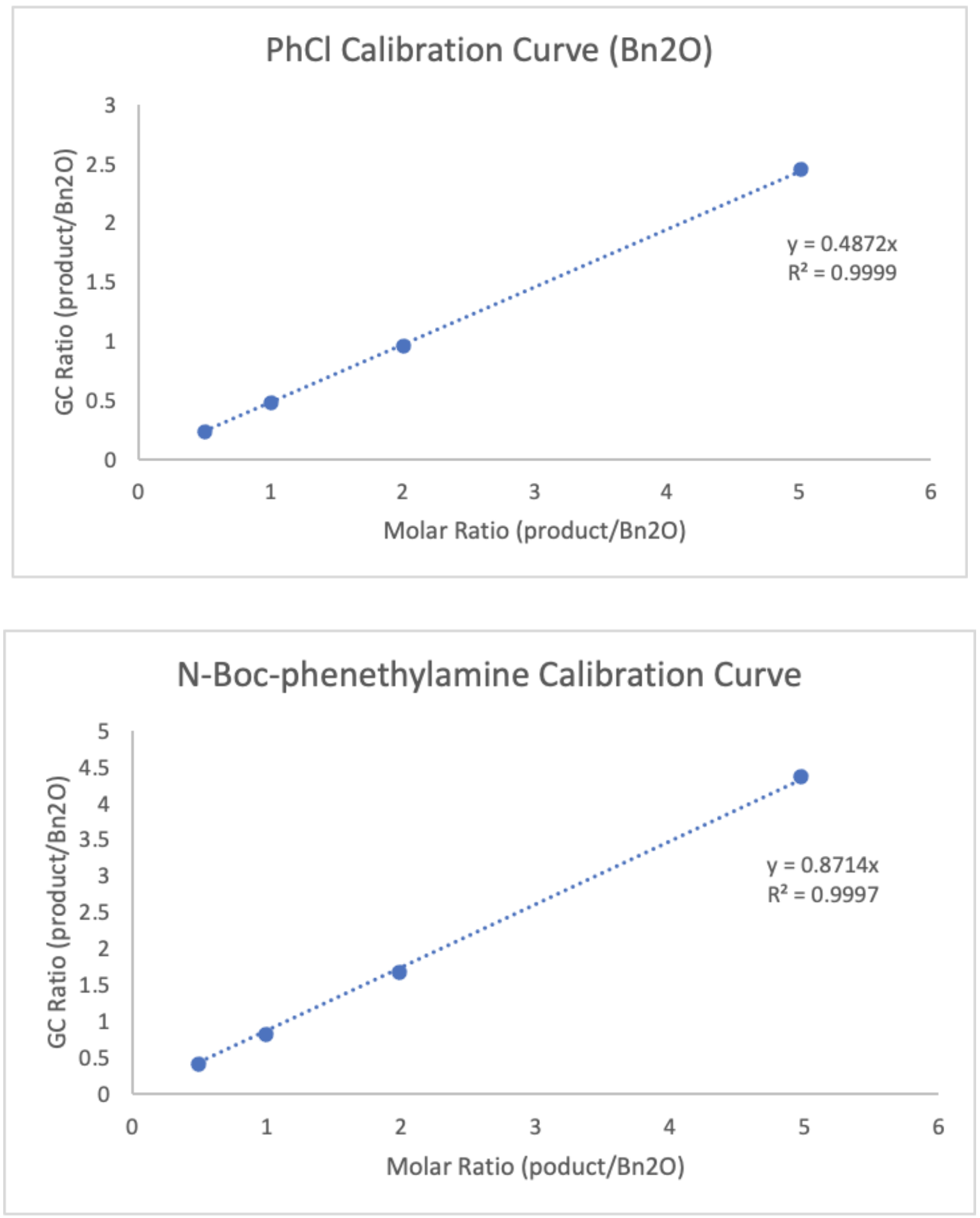

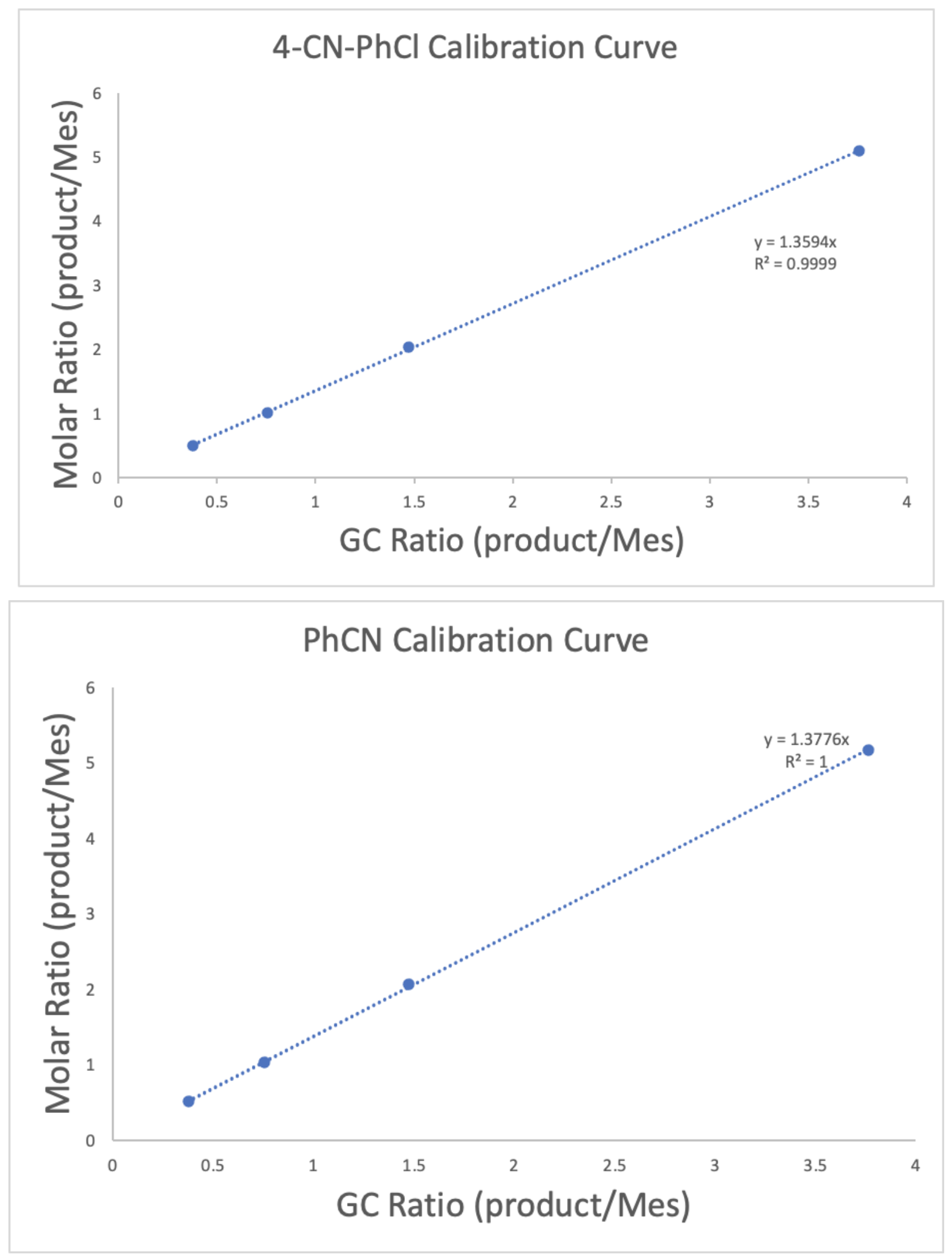

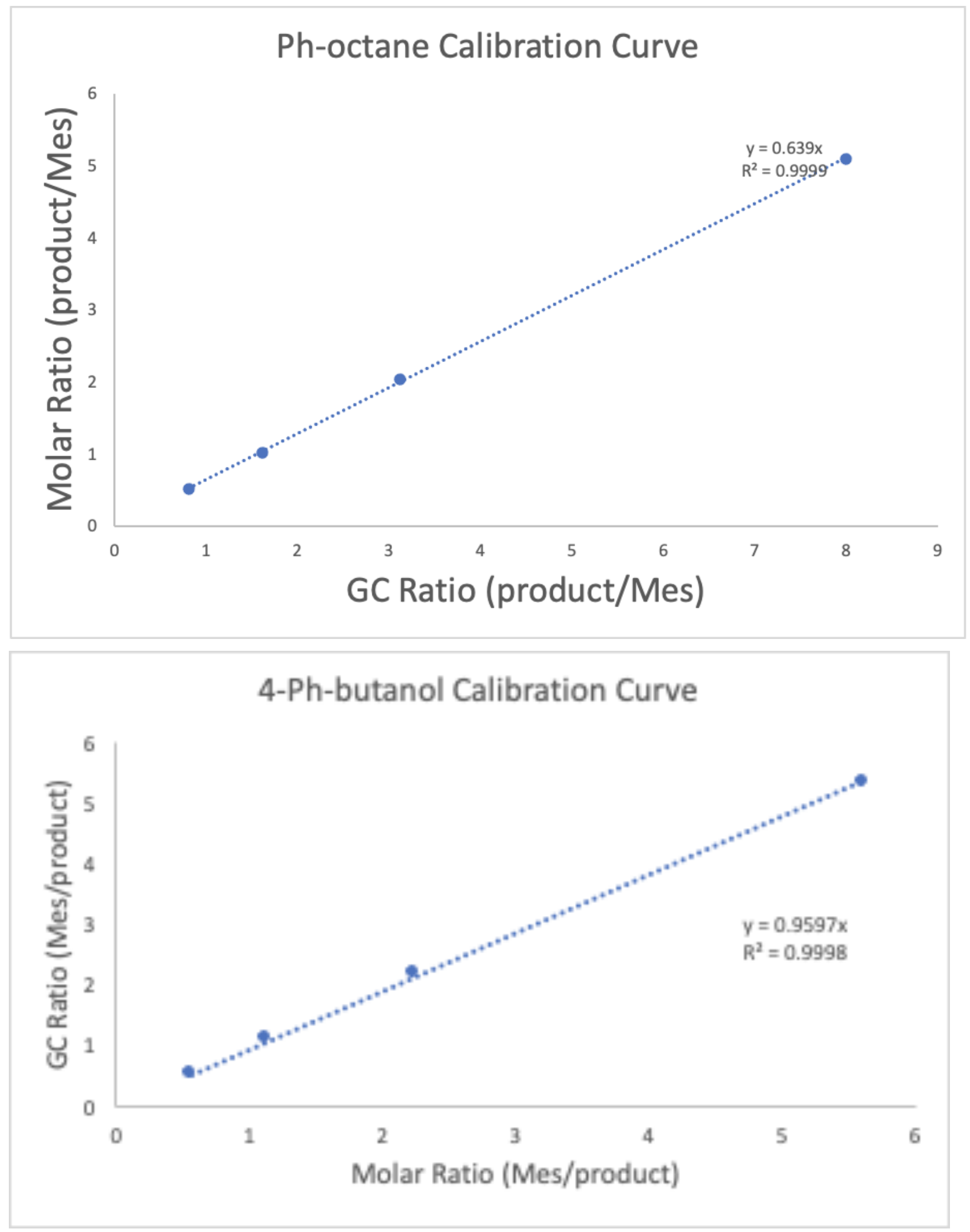


\section{Stern Volmer and UV/Vis Data}

\section{Stern Volmer}

In the glovebox, a $25 \mathrm{uM}$ solution of 4-DPAIPN in DMSO was prepared with a given concentration of the quencher. The samples were irradiated at $435 \mathrm{~nm}$ and emission peak was measured at $525 \mathrm{~nm}$. Quenching of 4-DPAIPN* was observed with tetrabutylammonium (TBA) formate and cyclohexylthiol, however no quenching was observed with chlorobenzene.

Note: TBA-formate was used instead of Na-formate because of poor solubility of the sodium counter ion. TBA-formate was tested as a reductant in the hydroarylation of the vinyl carbamate (General Procedure D) to validate its reactivity. Lower conversion was observed $(65 \%$ conversion) with undesired over-reduction $(\mathrm{PhH})$ as the major by-product $(55 \%)$.

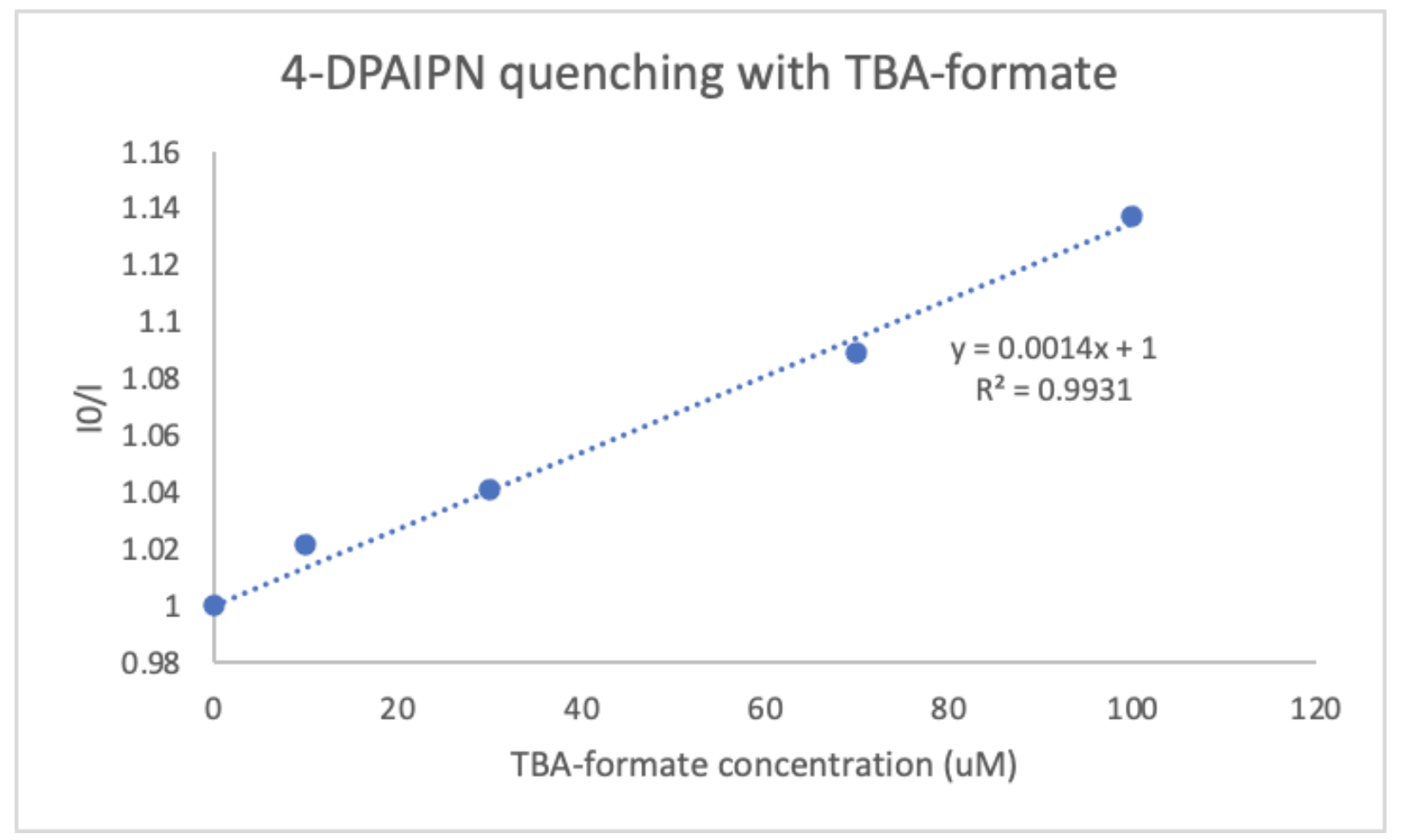

Figure S17. Stern-Volmer quenching of 4-DPAIPN with tetrabutylammonium formate. 


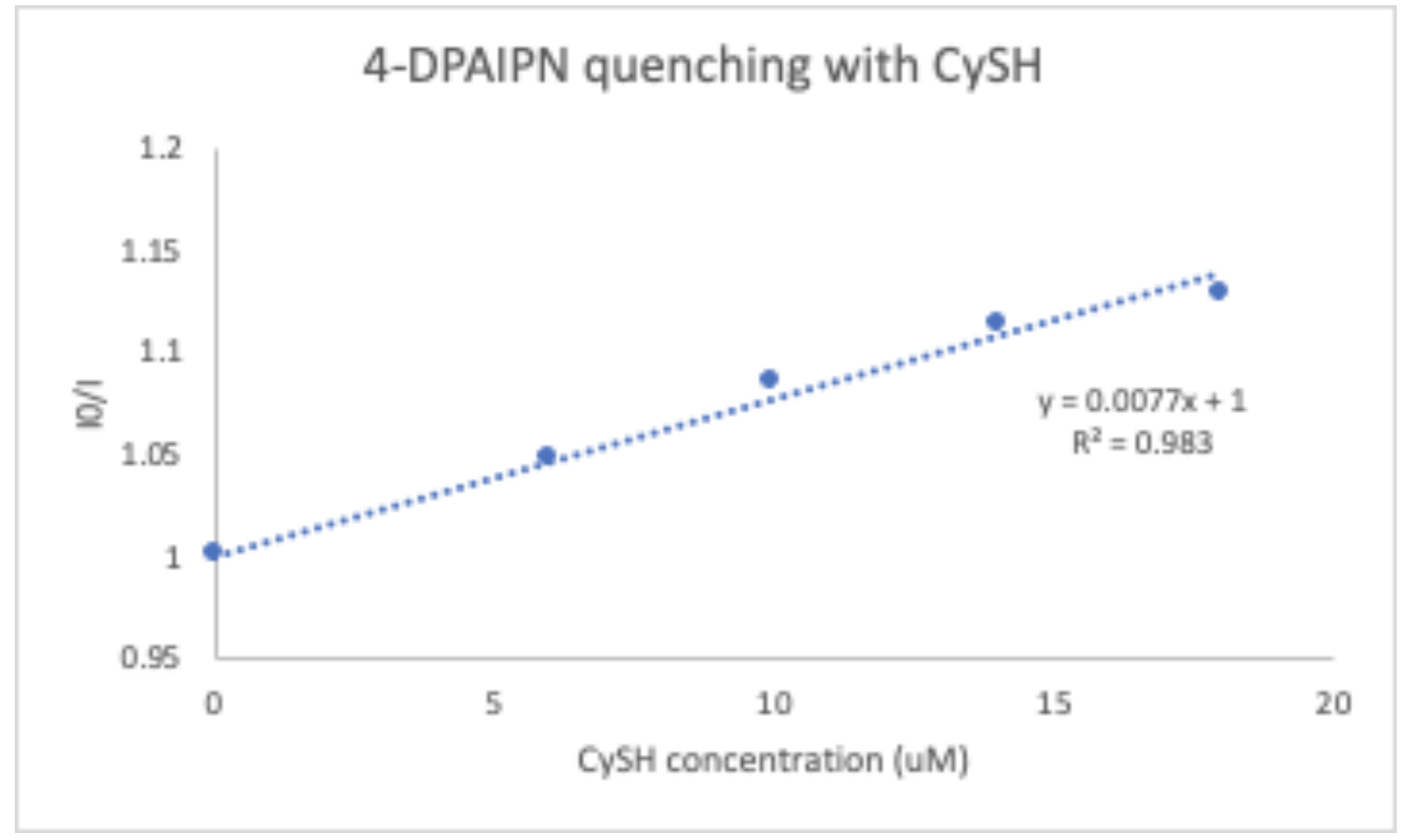

Figure S18. Stern-Volmer quenching of 4-DPAIPN with cyclohexylthiol.

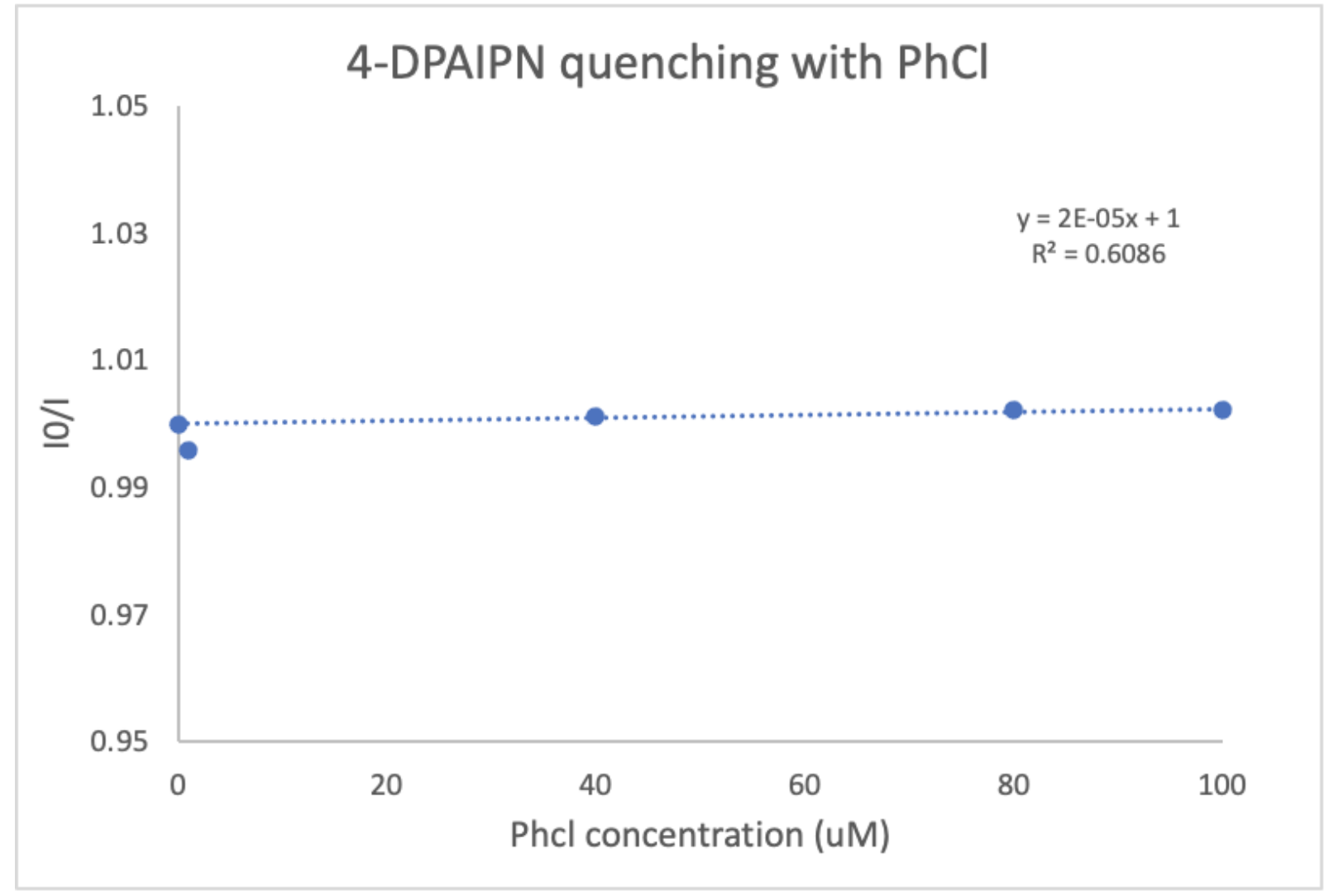

Figure S19. Stern-Volmer quenching of 4-DPAIPN with chlorobenzene. 


\section{UV/vis}

Under argon, a $25 \mathrm{uM}$ solution of 4-DPAIPN and sodium formate in DMSO was prepared. The first UV/vis spectrum was taken. To the sample cuvette, a $405 \mathrm{~nm}$ LED was used to irradiate the mixture for 15 seconds while shaking. Following irradiation, the second UV/vis spectrum was taken which showed 4-DPAIPN - - features grow in. Next, chlorobenzene was added to the cuvette through the septum cap to give a $100 \mathrm{uM}$ solution of chlorobenzene with the catalyst and formate mixture. The third UV/vis spectrum was recorded which showed no change in features, suggesting that 4-DPAIPN•- does not react on this time scale with chlorobenzene in the dark. Finally, the mixture was irradiated for 15 seconds with a $405 \mathrm{~nm}$ LED while shaking. The fourth UV/vis spectrum was taken and showed the 4-DPAIPN features grow in while the 4-DPAIPN $\bullet-$ features shrunk, suggesting that light is required for 4 -DPAIPN $\bullet-$ to reduce chlorobenzene and revert to 4-DPAIPN.

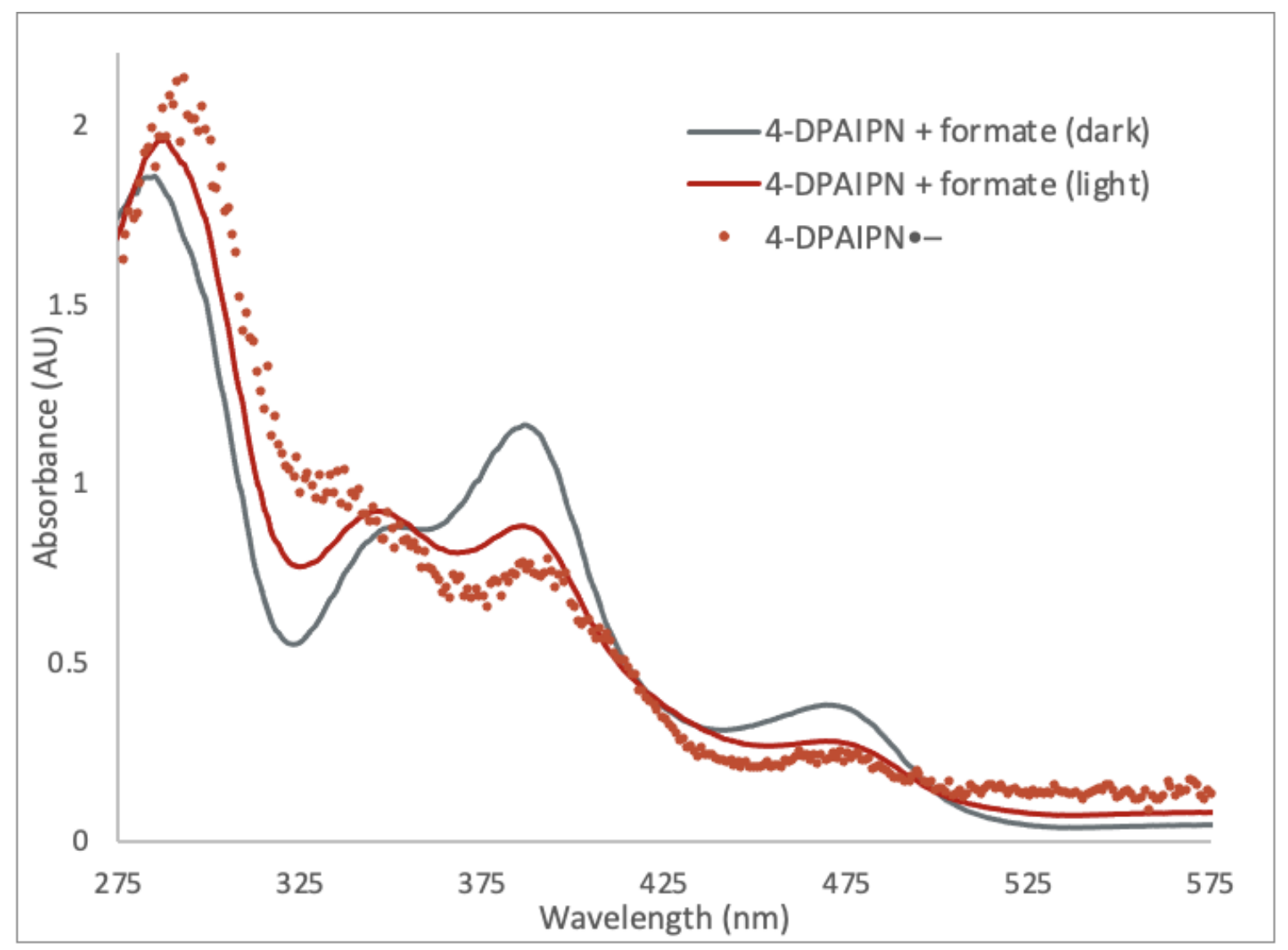

Figure S20. UV/vis of 4-DPAIPN•- generated with formate + light, and electrochemically.

For electrochemically generated 4-DPAIPN:

An oven-dried divided electrochemical cell under N2 was equipped with an electrode assembly consisting of rubber septa as caps with stainless steel wire and RVC for the cathode, a sacrificial zinc anode, and $\mathrm{Ag} / \mathrm{AgNO}_{3}$ reference electrode. TBAPF6 (0.1 M in DMF) was added to the cell 
followed by 4-DPAIPN to make a $25 \mathrm{uM}$ solution. Using a dip-probe, the solution was electrolyzed at $-2 \mathrm{~V}$ vs $\mathrm{Ag} / \mathrm{AgNO}$. The solution changed from bright yellow to dark green/brown/black. The UV/vis spectrum was then recorded.

\section{NMR Experiment for 4-DPAIPN॰- Generation}

In the glovebox, 4-DPAIPN ( $8 \mathrm{mg}, 1 \mathrm{umol})$ and sodium formate $(0.7 \mathrm{mg}, 1 \mathrm{umol})$ were added to a J-young tube, followed by D6-DMSO $(0.4 \mathrm{~mL})$ to give a bright yellow solution. The NMR tube was wrapped in foil during transport then the first NMR spectrum was recorded. The NMR tube was then irradiated with a $405 \mathrm{~nm}$ LED and shaken for 45 seconds until the solution turned brown/black. The NMR spectrum was recorded and revealed significant broadening on the catalyst signals, indicative of a radical species being generated. Finally, the NMR tube was opened to air to presumably oxidize the 4-DPAIPN •- back to neutral 4-DPAIPN. The solution returned to bright yellow and the NMR spectrum was recorded, revealing the neutral 4-DPAIPN features had returned.

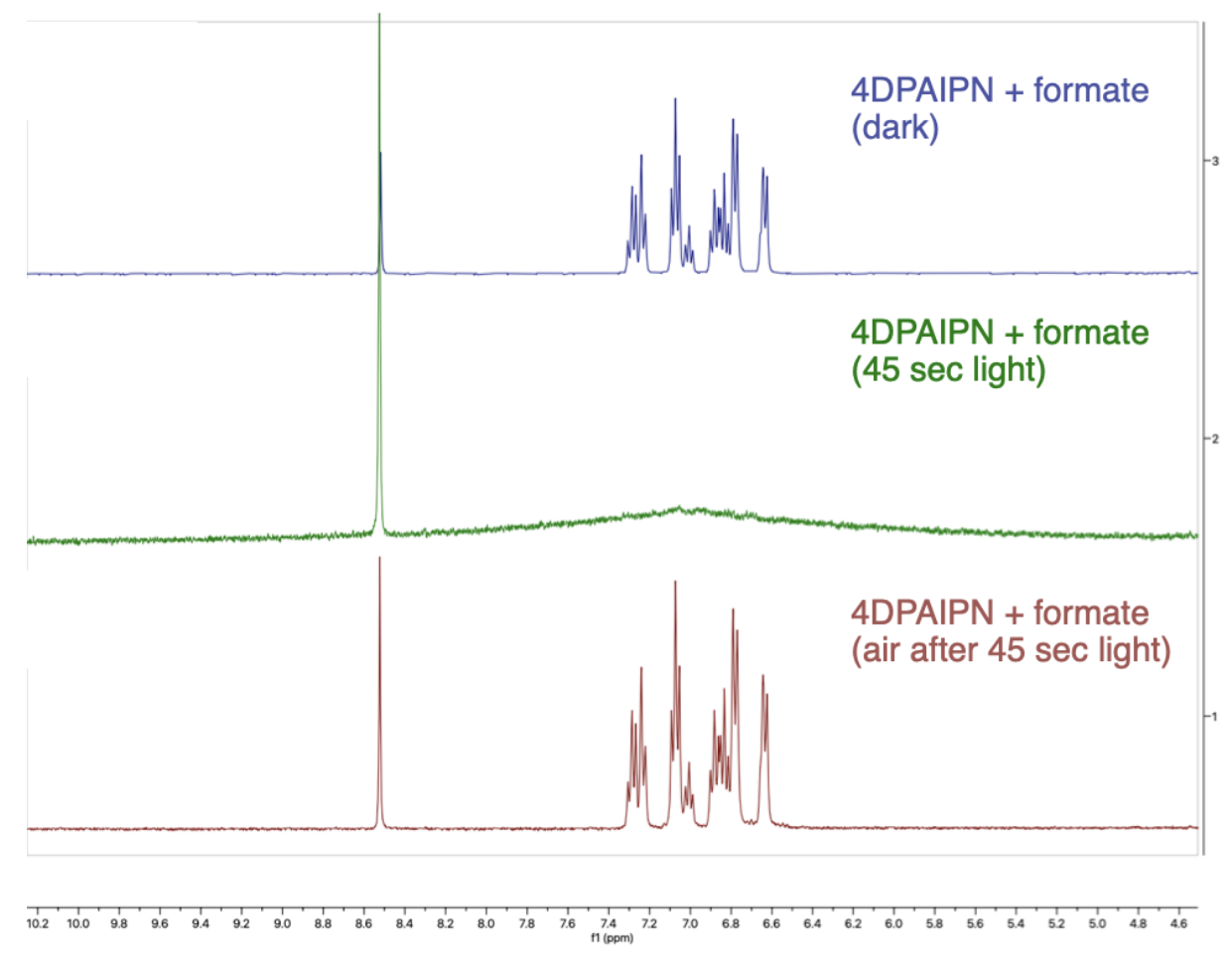

Figure S21: NMR experiment revealing evidence of 4-DPAIPN•- generation in the presence of formate and light. 


\section{Plausible Mechanism for $\mathrm{CO} \mathrm{C}^{-}$- Generation from Thiyl Radical}

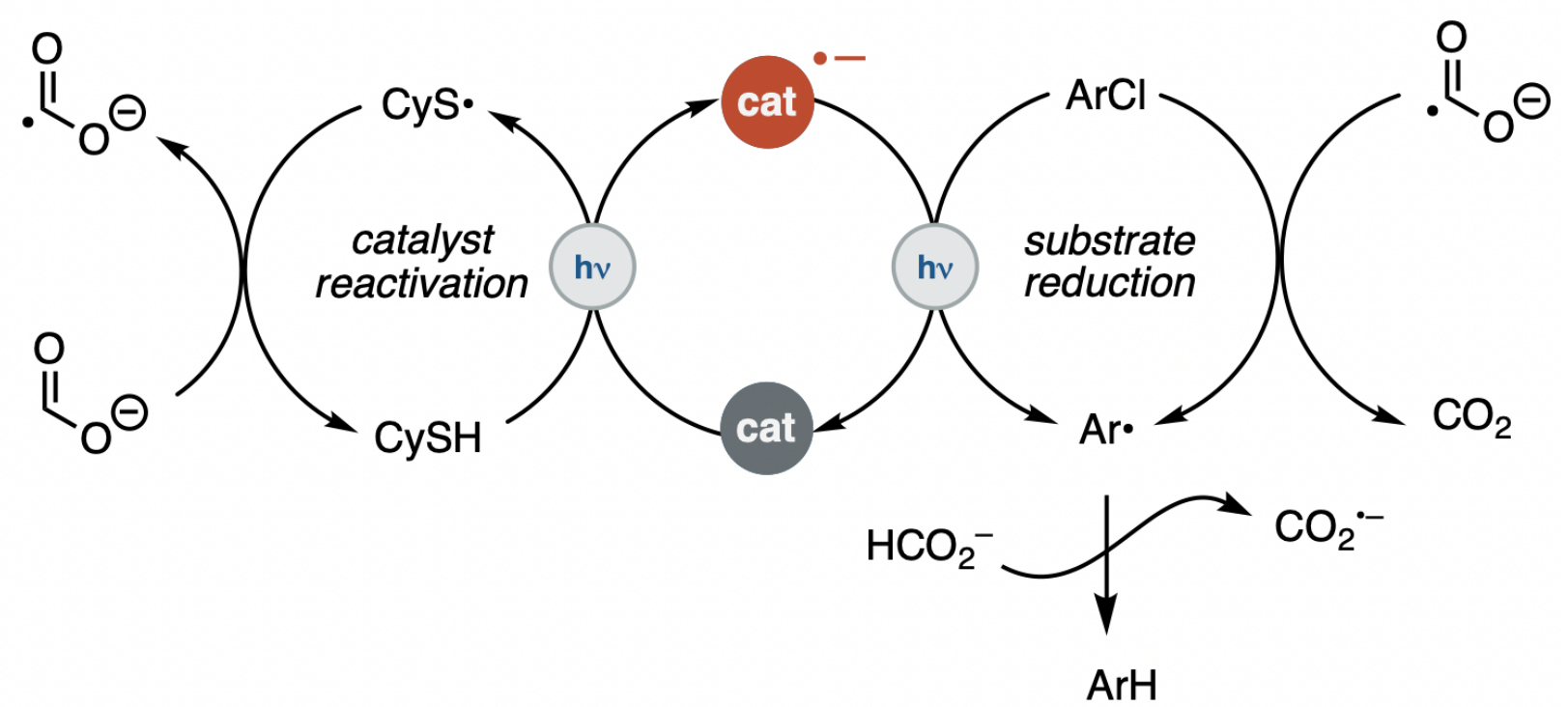

Figure S22. Mechanism of thiol generating CO2•-

Based on quenching in Stern-Volmer experiments, a plausible mechanism when thiol is present in the net-reductive reactions could be oxidation of the thiol by the 4-DPAIPN* followed by electron-transfer/proton-transfer (ETPT) to generate a thiyl radical. That thiyl radical could then abstract an $\mathrm{H} \bullet$ atom from formate to generate the $\mathrm{CO} 2 \bullet$ - that can promote the reaction as shown in Scheme 1. 


\section{Probing Substrate Reduction by $\mathrm{CO}_{2} \bullet-$}
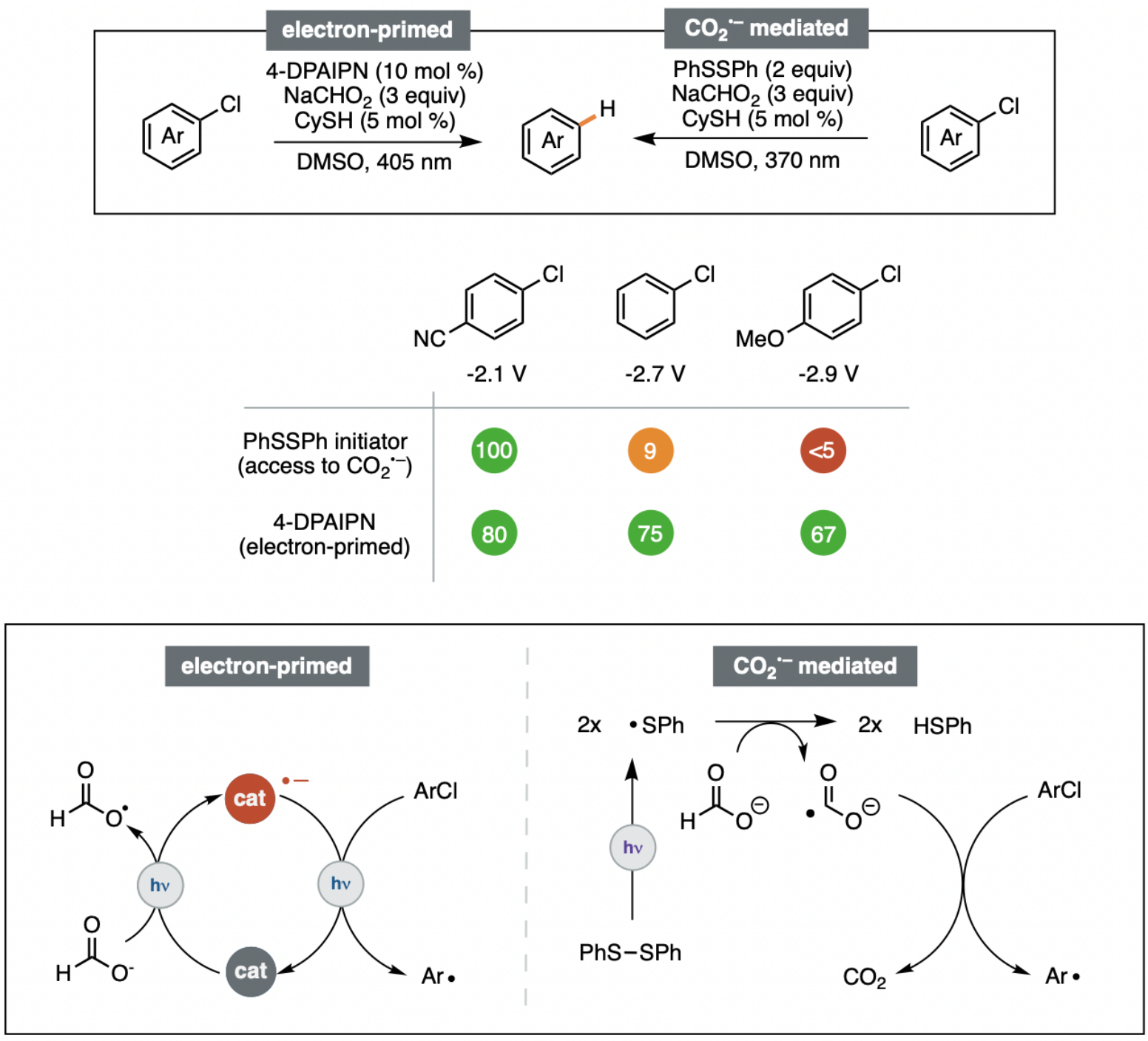

Figure S23. Evidence for $\mathrm{CO}_{2} \bullet$ promoting substrate reduction at milder substrate $E_{\text {red }}$ and electron-primed catalysis promoting substrate reduction at more challenging substrate $E_{\text {red }}$.

In an attempt to discriminate reduction of substrate via 4-DPAIPN radical anion excited state vs. $\mathrm{CO}_{2}$ radical anion, the homolysis of the $\mathrm{S}-\mathrm{S}$ bond of phenyl disulfide was explored as an alternative route to access $\mathrm{CO}_{2} \bullet-$ from formate. Conditions similar to the 4-DPAIPN-promoted reaction (General Procedure A) were used, replacing 4-DPAIPN with phenyl disulfide (2 equiv) and using $370 \mathrm{~nm}$ irradiation to homolyze the $\mathrm{S}-\mathrm{S}$ bond, instead of $405 \mathrm{~nm}$. The reactions were analyzed by measuring conversion of the aryl chloride via GCMS. 


\section{Product Characterization}<smiles>c1ccccc1</smiles>

from $\mathrm{PhCl}$

Benzene (3): 70\% was obtained following General Procedure A, analyzed via GC analysis.<smiles>CC(C)(C)c1ccccc1</smiles>

Tert-butylbenzene (4): $64 \%$ was obtained following General Procedure A, analyzed via ${ }^{1} \mathrm{H}$ NMR analysis. NMR consistent with reported spectrum (J. Am. Chem. Soc. 2013, 135, 2, 624-627).<smiles>COc1ccccc1</smiles>

Anisole (5): 67\% was obtained following General Procedure A, analyzed via ${ }^{1} \mathrm{H}$ NMR analysis. NMR consistent with reported spectrum (Angew. Chem. Int. Ed. 2018, 57, 12906 -12910).<smiles>COc1c(C(C)(C)C)cccc1C(C)(C)C</smiles>

1,3-di-tert-butyl-2-methoxybenzene (6): 92\% was obtained following General Procedure A, analyzed via ${ }^{1} \mathrm{H}$ NMR analysis. NMR consistent with reported spectrum (Tetrahedron, 69, 3, 2013, 1105-1111).<smiles>CCOCc1ccccc1</smiles>

diethyl phenylphosphonate (10): $47 \mathrm{mg}$ (55\%) was obtained as a colorless oil following General Procedure B. Product was isolated via flash chromatography on silica using 2:1 hexanes/acetone. ${ }^{1} \mathbf{H}$ NMR (400 MHz, CDCl3) $\delta 7.81-7.67(\mathrm{~m}, 2 \mathrm{H}), 7.51-7.43(\mathrm{~m}, 1 \mathrm{H}), 7.39$ $(\mathrm{tdd}, \mathrm{J}=8.3,4.2,1.0 \mathrm{~Hz}, 2 \mathrm{H}), 4.19-3.90(\mathrm{~m}, 4 \mathrm{H}), 1.25(\mathrm{t}, \mathrm{J}=7.1 \mathrm{~Hz}, 6 \mathrm{H})$, consistent with reported spectrum (Org. Lett. 2013, 15, 20, 5362-5365). 


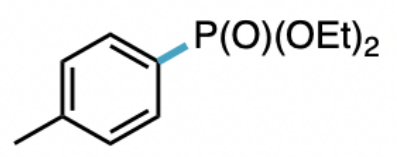

diethyl p-tolylphosphonate (11): $58 \mathrm{mg}(63 \%)$ was obtained as a colorless oil following General Procedure B with the modification that $15 \mathrm{~mol} \%$ 4-DPAIPN was used, first with the addition of $10 \mathrm{~mol} \%$ photocatalyst followed by a batch of $5 \mathrm{~mol} \%$ after 20 hours, giving a total 36 hour reaction time. Product was isolated via flash chromatography on silica using 2:1 hexanes/acetone. ${ }^{1} \mathbf{H}$ NMR $(400 \mathrm{MHz}, \mathrm{CDCl} 3) \delta 7.63(\mathrm{dd}, \mathrm{J}=13.2,8.1 \mathrm{~Hz}, 2 \mathrm{H}), 7.32-7.10(\mathrm{~m}$, $2 \mathrm{H}), 4.19-3.88(\mathrm{~m}, 4 \mathrm{H}), 2.33(\mathrm{~s}, 3 \mathrm{H}), 1.24(\mathrm{t}, \mathrm{J}=7.1 \mathrm{~Hz}, 6 \mathrm{H})$, consistent with reported spectrum (Org. Lett. 2018, 20, 14, 4164-4167).

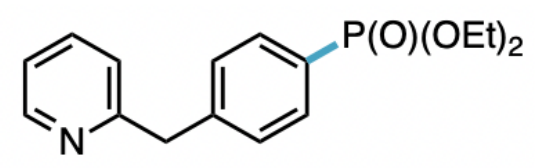

diethyl (4-(pyridin-2-ylmethyl)phenyl)phosphonate (12): $84 \mathrm{mg} \mathrm{(69 \% )} \mathrm{was} \mathrm{obtained} \mathrm{as} \mathrm{a} \mathrm{pale}$ yellow oil following General Procedure B with the modification that 15 mol \% 4-DPAIPN was used, first with the addition of $10 \mathrm{~mol} \%$ photocatalyst followed by a batch of $5 \mathrm{~mol} \%$ after 20 hours, giving a total 36 hour reaction time. Product was isolated via flash chromatography on silica using $20 \% \mathrm{MeOH}$ in DCM. ${ }^{1} \mathbf{H}$ NMR $(400 \mathrm{MHz}, \mathrm{CDCl} 3) \delta 8.55-8.49(\mathrm{~m}, 1 \mathrm{H}), 7.76-$ $7.66(\mathrm{~m}, 2 \mathrm{H}), 7.57$ (td, J = 7.7, $1.9 \mathrm{~Hz}, 1 \mathrm{H}), 7.33$ (dd, J = 8.0,3.9 Hz, 2H), 7.09 (dd, J = 7.8, 2.5 $\mathrm{Hz}, 2 \mathrm{H}), 4.16(\mathrm{~s}, 2 \mathrm{H}), 4.15-3.96(\mathrm{~m}, 4 \mathrm{H}), 1.27(\mathrm{t}, \mathrm{J}=7.1 \mathrm{~Hz}, 6 \mathrm{H}) .{ }^{13} \mathbf{C}$ NMR $(101 \mathrm{MHz}$, CDCl3) $\delta 159.83,149.51,144.26(\mathrm{~d}, \mathrm{~J}=3.2 \mathrm{~Hz}), 136.73,132.11(\mathrm{~d}, \mathrm{~J}=10.3 \mathrm{~Hz}), 129.18(\mathrm{~d}, \mathrm{~J}=$ $15.3 \mathrm{~Hz}), 126.17(\mathrm{~d}, \mathrm{~J}=189.7 \mathrm{~Hz}), 123.28,121.57,62.03(\mathrm{~d}, \mathrm{~J}=5.4 \mathrm{~Hz}), 44.60,16.31$ (d, J = 6.5 $\mathrm{Hz}) .{ }^{31} \mathbf{P}$ NMR $(162 \mathrm{MHz}, \mathrm{CDCl} 3) \delta$ 19.05. HRMS $\left(\mathrm{ESI}^{+}\right) \mathrm{Calc}:[\mathrm{M}+\mathrm{H}]^{+}\left(\mathrm{C}_{16} \mathrm{H}_{20} \mathrm{NO}_{3} \mathrm{P}\right)$ 306.1253 ; measured $306.1247=2.0 \mathrm{ppm}$ difference.

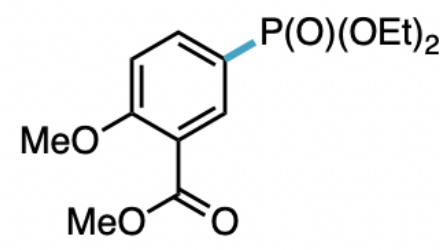

methyl 5-(diethoxyphosphoryl)-2-methoxybenzoate (13): $109 \mathrm{mg}$ (90\%) was obtained as a pale yellow oil following General Procedure B. Product was isolated via flash chromatography on silica using 30-60\% acetone in hexanes. ${ }^{1} \mathbf{H}$ NMR $(400 \mathrm{MHz}, \mathrm{CDCl} 3) \delta 8.15$ (dd, $\mathrm{J}=13.4$, $2.1 \mathrm{~Hz}, 1 \mathrm{H}), 7.85(\mathrm{ddd}, \mathrm{J}=12.5,8.6,2.1 \mathrm{~Hz}, 1 \mathrm{H}), 6.99(\mathrm{dd}, \mathrm{J}=8.6,3.2 \mathrm{~Hz}, 1 \mathrm{H}), 4.15-3.95(\mathrm{~m}$, 4H), $3.89(\mathrm{~s}, 3 \mathrm{H}), 3.83(\mathrm{~s}, 3 \mathrm{H}), 1.25(\mathrm{t}, \mathrm{J}=7.1 \mathrm{~Hz}, 6 \mathrm{H}) .{ }^{13} \mathbf{C} \mathbf{N M R}(101 \mathrm{MHz}, \mathrm{CDCl} 3) \delta 165.67$, $162.03(\mathrm{~d}, \mathrm{~J}=3.3 \mathrm{~Hz}), 137.28(\mathrm{~d}, \mathrm{~J}=11.1 \mathrm{~Hz}), 135.60(\mathrm{~d}, \mathrm{~J}=12.2 \mathrm{~Hz}), 120.32(\mathrm{~d}, \mathrm{~J}=15.5 \mathrm{~Hz})$, $119.65(\mathrm{~d}, \mathrm{~J}=196.4 \mathrm{~Hz}), 111.93(\mathrm{~d}, \mathrm{~J}=15.8 \mathrm{~Hz}), 62.16(\mathrm{~d}, \mathrm{~J}=5.4 \mathrm{~Hz}), 56.19,52.21,16.32$ (d, J 
$=6.5 \mathrm{~Hz}) .{ }^{31} \mathbf{P}$ NMR $(162 \mathrm{MHz}, \mathrm{CDCl} 3) \delta 18.00$. HRMS $\left(\mathrm{ESI}^{+}\right) \mathrm{Calc:}[\mathrm{M}+\mathrm{H}]^{+}\left(\mathrm{C}_{13} \mathrm{H}_{19} \mathrm{O}_{6} \mathrm{P}\right)$ 303.0992; measured 303.0987 $=1.6 \mathrm{ppm}$ difference.

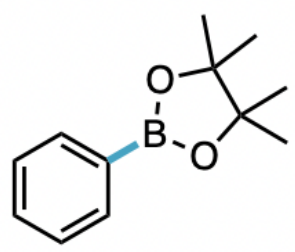

4,4,5,5-tetramethyl-2-phenyl-1,3,2-dioxaborolane (14): $80 \%$ was obtained following General Procedure $\mathrm{C}$, analyzed via ${ }^{1} \mathrm{H}$ NMR analysis. NMR consistent with reported spectrum $(\mathrm{Org}$. Lett. 2012, 14, 17, 4560-4563).<smiles>COc1ccc(B2OC(C)(C)C(C)(C)O2)cc1</smiles>

2-(4-methoxyphenyl)-4,4,5,5-tetramethyl-1,3,2-dioxaborolane (15): $63 \mathrm{mg}$ (67\%) was obtained as a white solid following General Procedure C. Product was isolated via flash chromatography on silica using $10 \%$ ethyl acetate in hexanes. ${ }^{1} \mathbf{H} \mathbf{~ N M R}(400 \mathrm{MHz}, \mathrm{CDCl} 3) \delta$ $7.76(\mathrm{~d}, \mathrm{~J}=8.6 \mathrm{~Hz}, 2 \mathrm{H}), 6.90(\mathrm{~d}, \mathrm{~J}=8.6 \mathrm{~Hz}, 2 \mathrm{H}), 3.83(\mathrm{~s}, 3 \mathrm{H}), 1.34(\mathrm{~s}, 12 \mathrm{H})$, consistent with reported spectrum (Org. Lett. 2012, 14, 17, 4560-4563).<smiles>CC(C)(C)OC(=O)Nc1ccc(B2OC(C)(C)C(C)(C)O2)cc1</smiles>

tert-butyl (4-(4,4,5,5-tetramethyl-1,3,2-dioxaborolan-2-yl)phenyl)carbamate (16): $92 \%$ was obtained following General Procedure C, analyzed via ${ }^{1} \mathrm{H}$ NMR analysis. NMR consistent with reported spectrum (J. Am. Chem. Soc. 2020, 142, 5, 2087-2092).<smiles>CC1(C)OB(c2ccc(N3CCOCC3)cc2)OC1(C)C</smiles> 
4-(4-(4,4,5,5-tetramethyl-1,3,2-dioxaborolan-2-yl)phenyl)morpholine (17): $59 \mathrm{mg}$ (51\%) was obtained as a white solid following General Procedure C. Product was isolated via flash chromatography on silica using $30 \%$ ethyl acetate in hexanes. ${ }^{1} \mathbf{H}$ NMR $(400 \mathrm{MHz}, \mathrm{CDCl} 3) \delta$ $7.73(\mathrm{~d}, \mathrm{~J}=8.6 \mathrm{~Hz}, 2 \mathrm{H}), 6.88(\mathrm{~d}, \mathrm{~J}=8.7 \mathrm{~Hz}, 2 \mathrm{H}), 3.92-3.78(\mathrm{~m}, 4 \mathrm{H}), 3.34-3.17(\mathrm{~m}, 4 \mathrm{H}), 1.33$ (s, 12H), consistent with reported spectrum (Org. Lett. 2016, 18, 11, 2758-2761).

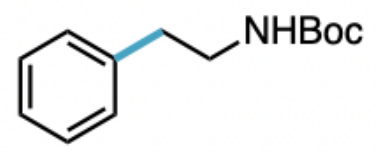

tert-butyl phenethylcarbamate (18): $53 \mathrm{mg}(60 \%)$ was obtained following General Procedure D. Product was isolated via flash chromatography on silica using hexanes ethyl acetate. ${ }^{1} \mathbf{H}$ NMR $(400 \mathrm{MHz}, \mathrm{CDCl} 3) \delta 7.31(\mathrm{dd}, \mathrm{J}=8.0,6.6 \mathrm{~Hz}, 2 \mathrm{H}), 7.20(\mathrm{dd}, \mathrm{J}=8.6,7.1 \mathrm{~Hz}, 3 \mathrm{H}), 4.53(\mathrm{~s}$, $1 \mathrm{H}), 3.38(\mathrm{q}, \mathrm{J}=6.8 \mathrm{~Hz}, 2 \mathrm{H}), 2.80(\mathrm{t}, \mathrm{J}=7.0 \mathrm{~Hz}, 2 \mathrm{H}), 1.44$ (s, 9H), consistent with reported spectrum (Org. Lett. 2019, 21, 8, 2818-2822).

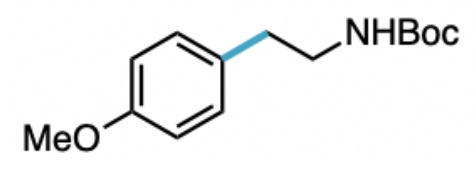

tert-butyl (4-methoxyphenethyl)carbamate (19): $50 \mathrm{mg}$ (50\%) was obtained following General Procedure D. Product was isolated via flash chromatography on silica using hexanes ethyl acetate. ${ }^{1} \mathbf{H}$ NMR $(400 \mathrm{MHz}, \mathrm{CDCl} 3) \delta 7.11(\mathrm{~d}, \mathrm{~J}=8.6 \mathrm{~Hz}, 2 \mathrm{H}), 6.84(\mathrm{~d}, \mathrm{~J}=8.6 \mathrm{~Hz}, 2 \mathrm{H}), 4.52(\mathrm{~s}$, $1 \mathrm{H}), 3.79(\mathrm{~s}, 3 \mathrm{H}), 3.33(\mathrm{t}, \mathrm{J}=6.8 \mathrm{~Hz}, 2 \mathrm{H}), 2.73(\mathrm{t}, \mathrm{J}=7.0 \mathrm{~Hz}, 2 \mathrm{H}), 1.43(\mathrm{~s}, 9 \mathrm{H})$, consistent with reported spectrum (Org. Lett. 2019, 21, 8, 2818-2822).

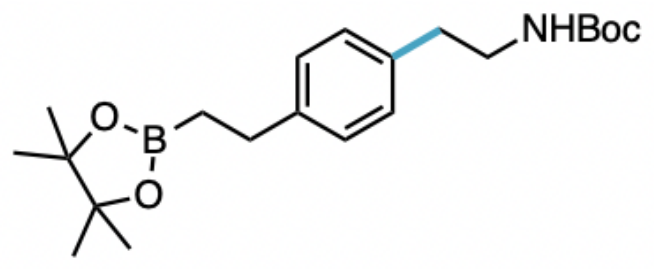

tert-butyl (4-(2-(4,4,5,5-tetramethyl-1,3,2-dioxaborolan-2-yl)ethyl)phenethyl)carbamate (20): $64 \%$ was obtained following General Procedure D. The product was partially purified on silica using hexanes ethyl acetate to verify product identity. ${ }^{1} \mathbf{H} \mathbf{~ N M R}(400 \mathrm{MHz}, \mathrm{CDCl} 3) \delta 7.08$ $(\mathrm{d}, \mathrm{J}=7.8 \mathrm{~Hz}, 2 \mathrm{H}), 7.01(\mathrm{~d}, \mathrm{~J}=7.7 \mathrm{~Hz}, 2 \mathrm{H}), 3.28(\mathrm{~d}, \mathrm{~J}=8.7 \mathrm{~Hz}, 2 \mathrm{H}), 2.66(\mathrm{dt}, \mathrm{J}=12.4,7.5 \mathrm{~Hz}$, 4H), 1.36 (s, 9H), 1.15 (s, 12H), 1.06 (t, J = 8.2 Hz, 2H). ${ }^{13} \mathbf{C}$ NMR (126 MHz, CDCl3) $\delta 155.89$, 142.50, 136.02, 128.61, 128.21, 83.09, 63.63, 41.83, 38.80, 35.73, 34.25, 29.53, 28.42, 24.80. HRMS (ESI $\left.{ }^{+}\right)$Calc: $[\mathrm{M}+\mathrm{Na}]^{+}\left(\mathrm{C}_{21} \mathrm{H}_{34} \mathrm{BNO}_{4}\right) 398.2477$; measured $398.2469=2.0 \mathrm{ppm}$ difference. 


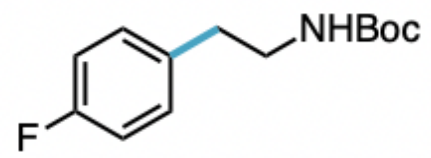

tert-butyl (4-fluorophenethyl)carbamate (21): 66\% was obtained following General Procedure $\mathrm{D}$ and was analyzed via NMR analysis. The product was partially purified on silica using hexanes ethyl acetate to verify product identity. ${ }^{1} \mathrm{H}$ NMR was consistent with reported spectrum (Molecules 2016, 21(9), 1160).<smiles>CC(C)(C)NCCc1ccc(C#N)cc1</smiles>

tert-butyl (4-cyanophenethyl)carbamate (22): $63 \mathrm{mg}$ (64\%) was obtained following General Procedure D. Product was isolated via flash chromatography on silica using hexanes ethyl acetate. ${ }^{1} \mathbf{H}$ NMR $(400 \mathrm{MHz}, \mathrm{CDCl} 3) \delta 7.60(\mathrm{~d}, \mathrm{~J}=8.0 \mathrm{~Hz}, 2 \mathrm{H}), 7.30(\mathrm{~d}, \mathrm{~J}=8.0 \mathrm{~Hz}, 2 \mathrm{H}), 3.39$ $(\mathrm{d}, \mathrm{J}=7.0 \mathrm{~Hz}, 2 \mathrm{H}), 2.87(\mathrm{t}, \mathrm{J}=7.0 \mathrm{~Hz}, 2 \mathrm{H}), 1.43(\mathrm{~s}, 9 \mathrm{H})$, consistent with reported spectrum $(J$. Med. Chem. 2018, 61, 18, 8457-8467).<smiles>CCOCOC[PH2+]Cc1ccc(CCNC(=O)OCc2ccccc2)cc1</smiles>

tert-butyl (4-((diethoxyphosphoryl)methyl)phenethyl)carbamate (23): $89 \mathrm{mg}$ (60\%) was obtained following General Procedure D. Product was isolated via flash chromatography on silica using hexanes ethyl acetate. ${ }^{1} \mathbf{H}$ NMR $(400 \mathrm{MHz}, \mathrm{CDCl} 3) \delta 7.24(\mathrm{dd}, \mathrm{J}=8.1,2.5 \mathrm{~Hz}, 2 \mathrm{H})$, $7.13(\mathrm{~d}, \mathrm{~J}=7.8 \mathrm{~Hz}, 2 \mathrm{H}), 4.51(\mathrm{~s}, 1 \mathrm{H}), 4.10-3.95(\mathrm{~m}, 4 \mathrm{H}), 3.36(\mathrm{~d}, \mathrm{~J}=6.7 \mathrm{~Hz}, 2 \mathrm{H}), 3.12(\mathrm{~d}, \mathrm{~J}=$ $21.5 \mathrm{~Hz}, 2 \mathrm{H}), 2.77(\mathrm{t}, \mathrm{J}=7.1 \mathrm{~Hz}, 2 \mathrm{H}), 1.43(\mathrm{~s}, 9 \mathrm{H}), 1.24(\mathrm{t}, \mathrm{J}=7.1 \mathrm{~Hz}, 6 \mathrm{H})$, consistent with reported spectrum (Angew. Chem. Int. Ed. 2021, 60, 2393-2397).

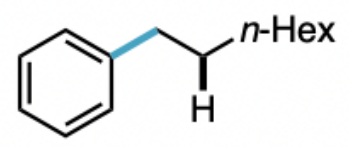

1-phenyloctane (24): 72\% was obtained following General Procedure E and analyzed via GC. 
<smiles>OCCCc1ccccc1</smiles>

4-phenylbutan-1-ol (25): 80\% was obtained following General Procedure E and analyzed via GC.<smiles>N#CC=CCc1ccc(C#N)cc1</smiles>

4-octylbenzonitrile (26): 61\% was obtained following General Procedure E and analyzed via NMR analysis. Product confirmed with ${ }^{1} \mathrm{H}$ NMR of partial purification, consistent with reported spectrum (J. Org. Chem. 2013, 78, 15, 7436-7444). HRMS (ESI ${ }^{+}$Calc: $[\mathrm{M}+\mathrm{H}]^{+}\left(\mathrm{C}_{15} \mathrm{H}_{21} \mathrm{~N}\right)$ 216.1747; measured $216.1744=1.3$ ppm difference.<smiles></smiles>

methyl 2-(2,3-dioxo-2,3,6,7-tetrahydro-1H,5H-pyrido[1,2,3-de]quinoxalin-5-yl)acetate (27): From X1, $16 \mathrm{mg}$ (58\%) was obtained following General Procedure A with the modification that a Penn $\mathrm{PhD}$ Photoreactor M2 equipped with a $405 \mathrm{~nm}$ light source was used to irradiate and no cyclohexylthiol was added. Product was isolated via mass-directed reversed phase chromatography using MeCN/H2O with an NH4OH modifier. ${ }^{1} \mathbf{H}$ NMR (600 MHz, DMSO-d6) $\delta 11.82(\mathrm{~s}, 1 \mathrm{H}), 7.09-7.05(\mathrm{~m}, 1 \mathrm{H}), 7.03-7.00(\mathrm{~m}, 1 \mathrm{H}), 7.00-6.98(\mathrm{~m}, 1 \mathrm{H}), 5.16-5.08(\mathrm{~m}$, $1 \mathrm{H}), 3.62(\mathrm{~s}, 3 \mathrm{H}), 3.00-2.89(\mathrm{~m}, 1 \mathrm{H}), 2.82-2.74(\mathrm{~m}, 1 \mathrm{H}), 2.67-2.56(\mathrm{~m}, 2 \mathrm{H}), 2.15-2.07(\mathrm{~m}$, 1H), 1.91 (tt, J = 13.9, 4.6 Hz, 1H). ${ }^{13} \mathbf{C}$ NMR (151 MHz, DMSO-d6) $\delta 170.77,154.19,153.55$, $125.64,124.41,123.25,123.10,122.56,113.46,51.69,47.04,34.96,22.75,21.08$. HRMS (ESI+) Calc: $[\mathrm{M}+\mathrm{H}]+(\mathrm{C} 14 \mathrm{H} 14 \mathrm{~N} 2 \mathrm{O} 4)$ 275.1032; measured $275.1035=1.1 \mathrm{ppm}$ difference.<smiles>CCOC(=O)c1ncn2c1CN(C)C(=O)c1ccccc1-2</smiles>

ethyl 5-methyl-6-oxo-5,6-dihydro-4H-benzo[f]imidazo[1,5-a][1,4]diazepine-3-carboxylate (28): From X2, $13 \mathrm{mg}(45 \%)$ was obtained as a white solid following General Procedure A with 
the modification that a Penn PhD Photoreactor M2 equipped with a $405 \mathrm{~nm}$ light source was used to irradiate and no cyclohexylthiol was added. Product was isolated via mass-directed reversed phase chromatography using $\mathrm{MeCN} / \mathrm{H} 2 \mathrm{O}$ with an $\mathrm{NH} 4 \mathrm{OH}$ modifier. ${ }^{1} \mathbf{H}$ NMR (600 MHz, DMSO-d6) $\delta 8.37$ (s, 1H), 7.93 - $7.89(\mathrm{~m}, 1 \mathrm{H}), 7.76-7.72(\mathrm{~m}, 2 \mathrm{H}), 7.61-7.55(\mathrm{~m}, 1 \mathrm{H})$, $4.98(\mathrm{~s}, 1 \mathrm{H}), 4.47(\mathrm{~s}, 1 \mathrm{H}), 4.32(\mathrm{~s}, 2 \mathrm{H}), 3.10(\mathrm{~s}, 3 \mathrm{H}), 1.33(\mathrm{t}, \mathrm{J}=7.1 \mathrm{~Hz}, 3 \mathrm{H})$; consistent with reported spectrum (Organic and Biomolecular Chemistry, 2011, 9, 24, 8346-8355). ${ }^{13}$ C NMR (151 MHz, DMSO-d6) $\delta$ 165.74, 162.37, 136.42, 135.51, 132.68, 131.83, 131.73, 128.57, $128.16, \quad 127.63,122.82,60.10,42.00,35.06$, 14.22. HRMS (ESI+) Calc: $[M+H]+$ (C15H15N3O3) 286.1191; measured 286.1190 $=-0.3$ ppm difference.

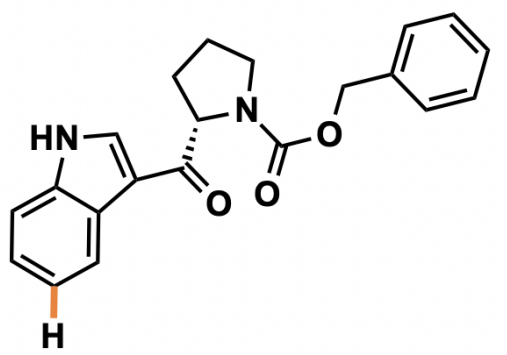

benzyl (S)-2-(1H-indole-3-carbonyl)pyrrolidine-1-carboxylate (29): From X5, $10 \mathrm{mg}$ (22\%) was obtained as a white solid following General Procedure A with the modification that a Penn PhD Photoreactor M2 equipped with a $405 \mathrm{~nm}$ light source was used to irradiate and $8 \mathrm{~mol} \%$ cyclohexylthiol was added. Product was isolated via mass-directed reversed phase chromatography using $\mathrm{MeCN} / \mathrm{H} 2 \mathrm{O}$ with an $\mathrm{NH} 4 \mathrm{OH}$ modifier. Compound is a roughly 1:1 mixture of two rotamers with distinct NMR signals. Peaks observed are reported (not assigned). ${ }^{1}$ H NMR (600 MHz, DMSO-d6) $\delta 12.02(\mathrm{~d}, \mathrm{~J}=12.6 \mathrm{~Hz}, 1 \mathrm{H}), 8.44(\mathrm{dd}, \mathrm{J}=15.2,3.1 \mathrm{~Hz}, 1 \mathrm{H})$, $8.20(\mathrm{dd}, \mathrm{J}=30.8,7.4 \mathrm{~Hz}, 1 \mathrm{H}), 7.51-7.47(\mathrm{~m}, 1 \mathrm{H}), 7.38(\mathrm{~d}, \mathrm{~J}=4.6 \mathrm{~Hz}, 2 \mathrm{H}), 7.36-7.29(\mathrm{~m}$, $1 \mathrm{H}), 7.26-7.17(\mathrm{~m}, 2 \mathrm{H}), 7.12-7.06(\mathrm{~m}, 1 \mathrm{H}), 7.01(\mathrm{t}, \mathrm{J}=7.6 \mathrm{~Hz}, 1 \mathrm{H}), 5.22$ (ddd, J = 30.3, 8.6, $3.5 \mathrm{~Hz}, 1 \mathrm{H}), 5.12-5.02(\mathrm{~m}, 1 \mathrm{H}), 5.02-4.87(\mathrm{~m}, 1 \mathrm{H}), 3.57-3.47(\mathrm{~m}, 2 \mathrm{H}), 2.45-2.28(\mathrm{~m}, 1 \mathrm{H})$, 1.95 - $1.81(\mathrm{~m}, 3 \mathrm{H}) .{ }^{13} \mathbf{C}$ NMR (151 MHz, DMSO-d6) $\delta 193.65,193.25,153.83,153.76,137.17$, $136.87,136.54,136.51,133.87,133.85,128.40,127.87,127.75,127.44,127.23,126.67,125.75$, $125.68,122.94,122.91,121.85,121.79,121.39,121.35,113.73,113.63,112.15,112.14,65.75$, $65.59,61.95,61.53,47.27,46.61,31.84,30.77,23.99,23.18$. HRMS (ESI+) Calc: [M+H]+ (C21H20N2O3) 349.1552; measured 349.1557 = 1.4 ppm difference. 


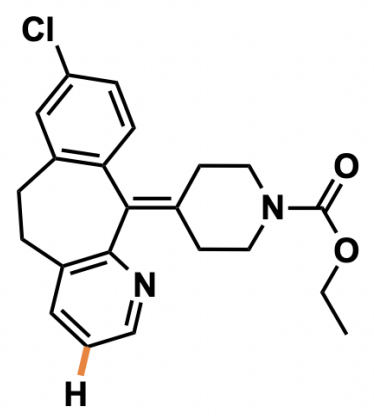

Ethyl 4-(8-chloro-5,6-dihydro-11H-benzo[5,6]cyclohepta[1,2-b]pyridin-11-ylidene) piperidine-1-carboxylate (30): From X6, $13 \mathrm{mg}$ (33\%) was obtained as an off-white solid following General Procedure A with the modification that a Penn PhD Photoreactor M2 equipped with a $405 \mathrm{~nm}$ light source was used to irradiate and no cyclohexylthiol was added. Product was isolated via mass-directed reversed phase chromatography using $\mathrm{MeCN} / \mathrm{H} 2 \mathrm{O}$ with an NH4OH modifier. ${ }^{1} \mathbf{H}$ NMR (600 MHz, DMSO-d6) $\delta 8.34$ (dd, J = 4.6, 1.3 Hz, 1H), $7.60-$ $7.55(\mathrm{~m}, 1 \mathrm{H}), 7.30(\mathrm{~d}, \mathrm{~J}=2.0 \mathrm{~Hz}, 1 \mathrm{H}), 7.25-7.17(\mathrm{~m}, 2 \mathrm{H}), 7.09(\mathrm{~d}, \mathrm{~J}=8.2 \mathrm{~Hz}, 1 \mathrm{H}), 4.03(\mathrm{q}, \mathrm{J}=$ $7.1 \mathrm{~Hz}, 2 \mathrm{H}), 3.67-3.55(\mathrm{~m}, 2 \mathrm{H}), 3.33-3.24(\mathrm{~m}, 2 \mathrm{H}), 3.23-3.12(\mathrm{~m}, 2 \mathrm{H}), 2.81$ (dq, J = 13.2, $6.1 \mathrm{~Hz}, 2 \mathrm{H}), 2.37-2.24(\mathrm{~m}, 2 \mathrm{H}), 2.23-2.11(\mathrm{~m}, 2 \mathrm{H}), 1.17(\mathrm{t}, \mathrm{J}=7.1 \mathrm{~Hz}, 3 \mathrm{H})$; consistent with reported spectrum (Journal of Organic Chemistry, 1989. 54, 9, 2242-2244). ${ }^{13}$ C NMR (151 MHz, DMSO-d6) $\delta 156.80,154.54,146.37,140.18,137.84,137.48,136.48,133.47,133.25$, 131.62, 130.70, 128.96, 125.69, 122.39, 60.69, 44.39, 44.31, 30.96, 30.55, 30.28, 30.18, 14.60. HRMS (ESI+) Calc: $[\mathrm{M}+\mathrm{H}]+(\mathrm{C} 22 \mathrm{H} 23 \mathrm{ClN} 2 \mathrm{O} 2) 383.1526$; measured $383.1533=1.8 \mathrm{ppm}$ difference.

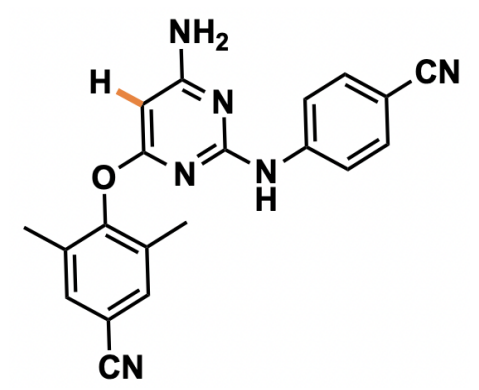

4-((6-amino-2-((4-cyanophenyl)amino)pyrimidin-4-yl)oxy)-3,5-dimethylbenzonitrile $\quad(31)$ : From X11, $22 \mathrm{mg}$ (61\%) was obtained following General Procedure A with the modification that a Penn $\mathrm{PhD}$ Photoreactor M2 equipped with a $405 \mathrm{~nm}$ light source was used to irradiate and no cyclohexylthiol was added. Product was isolated via mass-directed reversed phase chromatography using $\mathrm{MeCN} / \mathrm{H} 2 \mathrm{O}$ with an $\mathrm{NH} 4 \mathrm{OH}$ modifier. ${ }^{1} \mathbf{H}$ NMR (600 MHz, DMSO-d6) $\delta 9.54(\mathrm{~s}, 1 \mathrm{H}), 7.71(\mathrm{~s}, 2 \mathrm{H}), 7.65$ (d, J = 8.3 Hz, 2H), 7.46 (d, J = 8.8 Hz, 2H), 6.77 (s, 2H), 5.46 (s, 1H), 2.12 (s, 6H); consistent with reported spectrum (Organic Process Research and Development, 2010, 14, 3, 657-660). ${ }^{13}$ C NMR (151 MHz, DMSO-d6) $\delta 168.16,166.41,158.86$, 153.90, 145.32, 132.93, 132.52, 132.45, 119.63, 118.69, 117.99, 108.01, 101.66, 78.66, 15.81. 
HRMS (ESI+) Calc: $[\mathrm{M}+\mathrm{H}]+(\mathrm{C} 20 \mathrm{H} 16 \mathrm{N6O}) 357.1464$; measured $357.1474=2.7 \mathrm{ppm}$ difference.

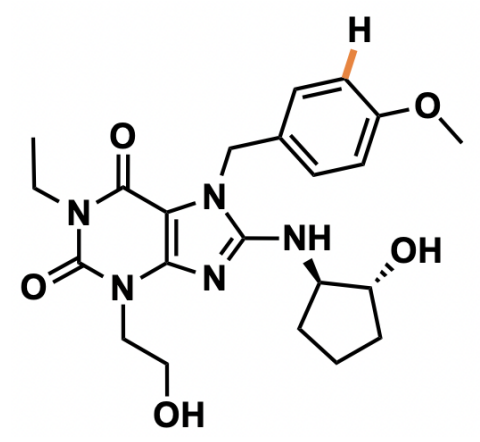

1-ethyl-8-(((1R,2R)-2-hydroxycyclopentyl)amino)-3-(2-hydroxyethyl)-7-(4-methoxybenzyl)3,7-dihydro-1H-purine-2,6-dione (32): From X12, $23 \mathrm{mg}$ (53\%) was obtained following General Procedure A with the modification that a Penn PhD Photoreactor M2 equipped with a $405 \mathrm{~nm}$ light source was used to irradiate and no cyclohexylthiol was added. Product was isolated via mass-directed reversed phase chromatography using $\mathrm{MeCN} / \mathrm{H} 2 \mathrm{O}$ with an $\mathrm{NH} 4 \mathrm{OH}$ modifier. ${ }^{1} \mathbf{H}$ NMR (600 MHz, DMSO-d6) $\delta 7.23(\mathrm{~d}, \mathrm{~J}=8.3 \mathrm{~Hz}, 2 \mathrm{H}), 6.94(\mathrm{~d}, \mathrm{~J}=6.6 \mathrm{~Hz}, 1 \mathrm{H})$, $6.87(\mathrm{~d}, \mathrm{~J}=8.2 \mathrm{~Hz}, 2 \mathrm{H}), 5.25(\mathrm{~s}, 2 \mathrm{H}), 4.84-4.75(\mathrm{~m}, 2 \mathrm{H}), 3.98(\mathrm{t}, \mathrm{J}=6.4 \mathrm{~Hz}, 3 \mathrm{H}), 3.87(\mathrm{dq}, \mathrm{J}=$ 13.8, $6.5 \mathrm{~Hz}, 3 \mathrm{H}), 3.70(\mathrm{~s}, 3 \mathrm{H}), 3.62(\mathrm{q}, \mathrm{J}=5.9 \mathrm{~Hz}, 2 \mathrm{H}), 2.05(\mathrm{dq}, \mathrm{J}=13.4,7.6 \mathrm{~Hz}, 1 \mathrm{H}), 1.84$ $(\mathrm{dq}, \mathrm{J}=14.2,6.8 \mathrm{~Hz}, 1 \mathrm{H}), 1.64(\mathrm{ddt}, \mathrm{J}=21.7,13.6,7.4 \mathrm{~Hz}, 2 \mathrm{H}), 1.52-1.40(\mathrm{~m}, 2 \mathrm{H}), 1.08(\mathrm{t}, \mathrm{J}=$ $6.9 \mathrm{~Hz}, 3 \mathrm{H}) .{ }^{13} \mathrm{C}$ NMR $(151 \mathrm{MHz}$, DMSO-d6) $\delta$ 158.62, 153.45, 152.55, 150.42, 148.67, 129.22, $128.82,113.86,101.19,76.10,61.49,57.80,55.05,44.63,44.61,35.13,32.43,29.90,20.53$, 13.34. HRMS (ESI+) Calc: $[\mathrm{M}+\mathrm{H}]+(\mathrm{C} 22 \mathrm{H} 29 \mathrm{~N} 5 \mathrm{O} 5) 444.2247$; measured $444.2253=1.3 \mathrm{ppm}$ difference.

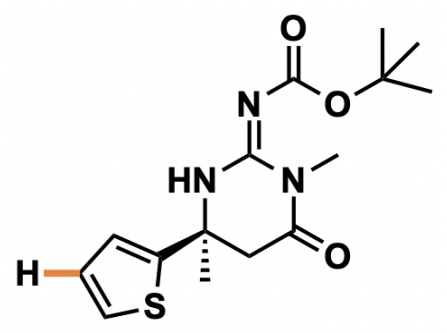

tert-butyl (S,Z)-(1,4-dimethyl-6-oxo-4-(thiophen-2-yl)tetrahydropyrimidin-2(1H)-ylidene) carbamate (33): From X13, $12 \mathrm{mg}(38 \%)$ was obtained as a yellow oil following General Procedure A with the modification that a Penn PhD Photoreactor M2 equipped with a $405 \mathrm{~nm}$ light source was used to irradiate and no cyclohexylthiol was added. Product was isolated via mass-directed reversed phase chromatography using $\mathrm{MeCN} / \mathrm{H} 2 \mathrm{O}$ with an $\mathrm{NH} 4 \mathrm{OH}$ modifier. ${ }^{1} \mathbf{H}$ NMR (600 MHz, DMSO-d6) $\delta 10.05(\mathrm{~s}, 1 \mathrm{H}), 7.46(\mathrm{~d}, \mathrm{~J}=5.0 \mathrm{~Hz}, 1 \mathrm{H}), 7.06-7.03(\mathrm{~m}, 1 \mathrm{H}), 7.00$ $(\mathrm{dd}, \mathrm{J}=4.9,3.7 \mathrm{~Hz}, 1 \mathrm{H}), 3.24-3.12(\mathrm{~m}, 2 \mathrm{H}), 3.04(\mathrm{~s}, 3 \mathrm{H}), 1.70(\mathrm{~s}, 3 \mathrm{H}), 1.43(\mathrm{~s}, 9 \mathrm{H}) .{ }^{13} \mathbf{C}$ NMR (151 MHz, DMSO-d6) $\delta$ 167.63, 163.12, 156.84, 148.47, 127.51, 125.37, 124.09, 78.57, 52.88, 
44.54, 31.31, 29.64, 27.92. HRMS (ESI+) Calc: [M+H]+ (C15H21N3O3S) 324.1382; measured $324.1379=-0.9$ ppm difference.

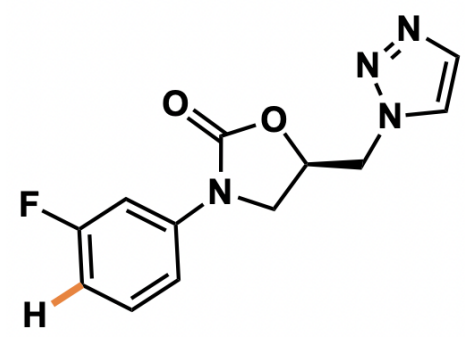

(R)-5-((1H-1,2,3-triazol-1-yl)methyl)-3-(3-fluorophenyl)oxazolidin-2-one (34): From X14, 16 mg $(42 \%)$ was obtained as a white solid following General Procedure A with the modification that a Penn PhD Photoreactor M2 equipped with a $405 \mathrm{~nm}$ light source was used to irradiate and no cyclohexylthiol was added. Product was isolated via mass-directed reversed phase chromatography using $\mathrm{MeCN} / \mathrm{H} 2 \mathrm{O}$ with an $\mathrm{NH} 4 \mathrm{OH}$ modifier. Alternatively, on a $0.022 \mathrm{mmol}$ scale, $2.9 \mathrm{mg}(50 \%)$ was obtained as a white solid following General Procedure A with the same modifications as mentioned above. ${ }^{1} \mathbf{H}$ NMR (600 MHz, DMSO-d6) $\delta 8.17$ (d, J = 0.8 Hz, 1H), $7.77-7.75(\mathrm{~m}, 1 \mathrm{H}), 7.46-7.39(\mathrm{~m}, 2 \mathrm{H}), 7.26(\mathrm{dd}, \mathrm{J}=8.3,1.5 \mathrm{~Hz}, 1 \mathrm{H}), 6.96(\mathrm{td}, \mathrm{J}=8.2,2.3 \mathrm{~Hz}$, $1 \mathrm{H}), 5.15(\mathrm{dq}, \mathrm{J}=10.9,5.4 \mathrm{~Hz}, 1 \mathrm{H}), 4.84(\mathrm{~d}, \mathrm{~J}=5.2 \mathrm{~Hz}, 2 \mathrm{H}), 4.25(\mathrm{t}, \mathrm{J}=9.2 \mathrm{~Hz}, 1 \mathrm{H}), 3.91(\mathrm{dd}, \mathrm{J}$ $=9.3,5.7 \mathrm{~Hz}, 1 \mathrm{H}) .{ }^{13} \mathrm{C}$ NMR $(151 \mathrm{MHz}, \mathrm{DMSO}-\mathrm{d} 6) \delta 162.22(\mathrm{~d}, \mathrm{~J}=241.8 \mathrm{~Hz}), 153.44,139.78$ $(\mathrm{d}, \mathrm{J}=11.0 \mathrm{~Hz}), 133.41,130.65(\mathrm{~d}, \mathrm{~J}=9.5 \mathrm{~Hz}), 125.87,113.73,110.17(\mathrm{~d}, \mathrm{~J}=21.1 \mathrm{~Hz}), 105.07$ $(\mathrm{d}, \mathrm{J}=26.9 \mathrm{~Hz}), 70.93,51.70,47.02$. HRMS (ESI+) Calc: $[\mathrm{M}+\mathrm{H}]+(\mathrm{C} 12 \mathrm{H} 11 \mathrm{FN} 4 \mathrm{O} 2)$ 263.0944; measured $263.0945=0.3 \mathrm{ppm}$ difference.

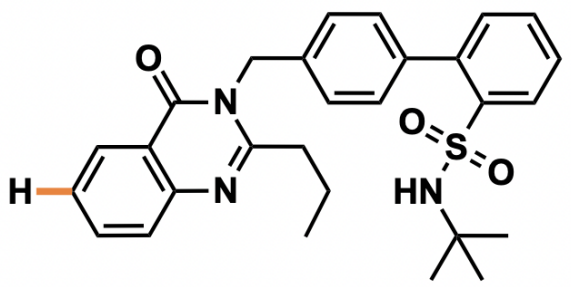

N-(tert-butyl)-4'-

((4-oxo-2-propylquinazolin-3(4H)-yl)methyl)-[1,1'-biphenyl]-2sulfonamide (35): From X15, $19 \mathrm{mg}$ (39\%) was obtained following General Procedure A with the modification that a Penn PhD Photoreactor M2 equipped with a $405 \mathrm{~nm}$ light source was used to irradiate and no cyclohexylthiol was added. Product was isolated via mass-directed reversed phase chromatography using $\mathrm{MeCN} / \mathrm{H} 2 \mathrm{O}$ with an $\mathrm{NH} 4 \mathrm{OH}$ modifier. ${ }^{1} \mathbf{H}$ NMR (600 MHz, DMSO-d6) $\delta 8.18(\mathrm{~d}, \mathrm{~J}=7.9 \mathrm{~Hz}, 1 \mathrm{H}), 8.03$ (d, J = $7.9 \mathrm{~Hz}, 1 \mathrm{H}), 7.83$ (t, J = $7.7 \mathrm{~Hz}, 1 \mathrm{H})$, $7.65(\mathrm{~d}, \mathrm{~J}=8.2 \mathrm{~Hz}, 1 \mathrm{H}), 7.61(\mathrm{t}, \mathrm{J}=7.4 \mathrm{~Hz}, 1 \mathrm{H}), 7.54(\mathrm{q}, \mathrm{J}=7.8 \mathrm{~Hz}, 2 \mathrm{H}), 7.38$ (d, J = 6.9 Hz, 2H), 7.29 (d, J = 7.6 Hz, 1H), $7.21(\mathrm{~d}, \mathrm{~J}=7.3 \mathrm{~Hz}, 2 \mathrm{H}), 6.54(\mathrm{~s}, 1 \mathrm{H}), 5.45(\mathrm{~s}, 2 \mathrm{H}), 2.77$ (t, J = 7.0 $\mathrm{Hz}, 2 \mathrm{H}), 1.76(\mathrm{~h}, \mathrm{~J}=7.2 \mathrm{~Hz}, 2 \mathrm{H}), 0.96-0.94(\mathrm{~m}, 9 \mathrm{H}), 0.94-0.91$ (m, 3H). ${ }^{13} \mathbf{C}$ NMR (151 MHz, DMSO-d6) $\delta 161.66,157.31,146.99,142.07,139.58,138.80,135.78,134.54,132.58$, $131.76,129.65,128.05,127.74,126.89,126.50,126.45,125.58,119.85,53.35,45.39,35.79$, 
29.30, 19.41, 13.56. HRMS (ESI+) Calc: $[\mathrm{M}+\mathrm{H}]+(\mathrm{C} 28 \mathrm{H} 31 \mathrm{~N} 3 \mathrm{O} 3 \mathrm{~S})$ 490.2164; measured $490.2172=1.6 \mathrm{ppm}$ difference.<smiles>CCOC(=O)c1ncn2c1CN(C)C(=O)c1cc(CCNC(=O)OCc3ccccc3)ccc1-2</smiles>

ethyl8-(2-((tert-butoxycarbonyl)amino)ethyl)-5-methyl-6-oxo-5,6-dihydro-4H-benzo[f]imid azo[1,5-a][1,4]diazepine-3-carboxylate (36): From X2, $13 \mathrm{mg}(29 \%)$ was obtained as a white solid following General Procedure E with the modification that a Penn PhD Photoreactor M2 equipped with a $405 \mathrm{~nm}$ light source was used to irradiate and $8 \mathrm{~mol} \%$ cyclohexylthiol was added. In the reaction, an additional $4.4 \mathrm{mg}(15 \%)$ of the reduction product was obtained as a white solid. Product was isolated via mass-directed reversed phase chromatography using $\mathrm{MeCN} / \mathrm{H} 2 \mathrm{O}$ with an $\mathrm{NH} 4 \mathrm{OH}$ modifier. ${ }^{1} \mathbf{H}$ NMR $(600 \mathrm{MHz}, \mathrm{DMSO}-\mathrm{d} 6) \delta 8.33(\mathrm{~s}, 1 \mathrm{H}), 7.73(\mathrm{~s}$, 1H), $7.66(\mathrm{~d}, \mathrm{~J}=8.2 \mathrm{~Hz}, 1 \mathrm{H}), 7.59-7.53(\mathrm{~m}, 1 \mathrm{H}), 6.93(\mathrm{t}, \mathrm{J}=5.4 \mathrm{~Hz}, 1 \mathrm{H}), 4.98(\mathrm{~s}, 1 \mathrm{H}), 4.41(\mathrm{~s}$, 1H), 4.32 (s, 2H), 3.20 (q, J = 6.8 Hz, 2H), 3.10 (s, 3H), 2.81 (t, J = 7.1 Hz, 2H), $1.36(\mathrm{~s}, 9 \mathrm{H})$, $1.33(\mathrm{t}, \mathrm{J}=7.1 \mathrm{~Hz}, 3 \mathrm{H}) .{ }^{13} \mathrm{C}$ NMR $(151 \mathrm{MHz}$, DMSO-d6) $\delta 165.75,162.37,155.57,139.82$, $136.31,135.36,132.97,131.75,130.06,128.31,127.54,122.74,77.61,60.08,42.01,41.13$, 35.09, 34.67, 28.23, 14.23. HRMS (ESI+) Calc: $[\mathrm{M}+\mathrm{H}]+(\mathrm{C} 22 \mathrm{H} 28 \mathrm{~N} 4 \mathrm{O} 5)$ 429.2138; measured $429.2146=1.8 \mathrm{ppm}$ difference. 


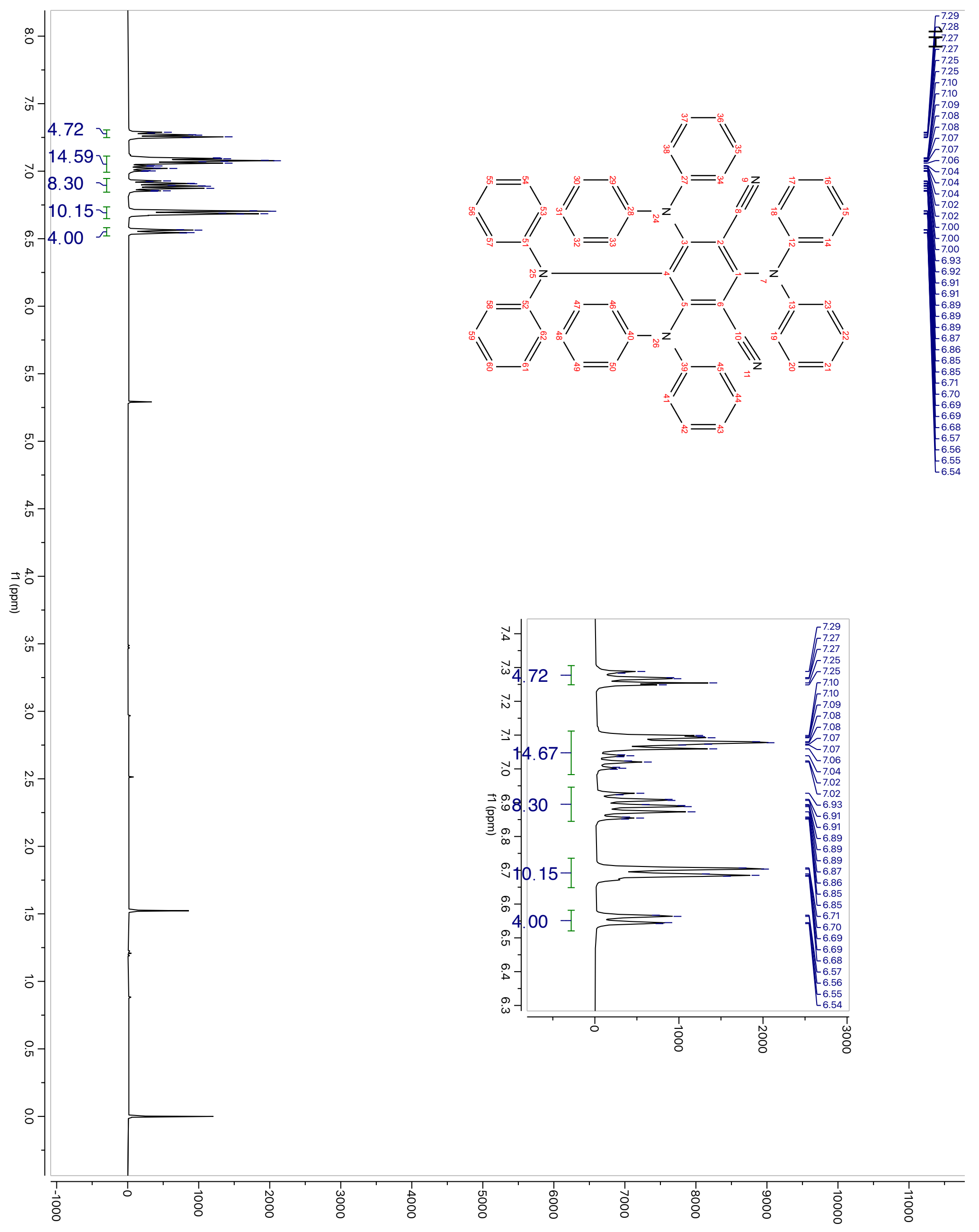




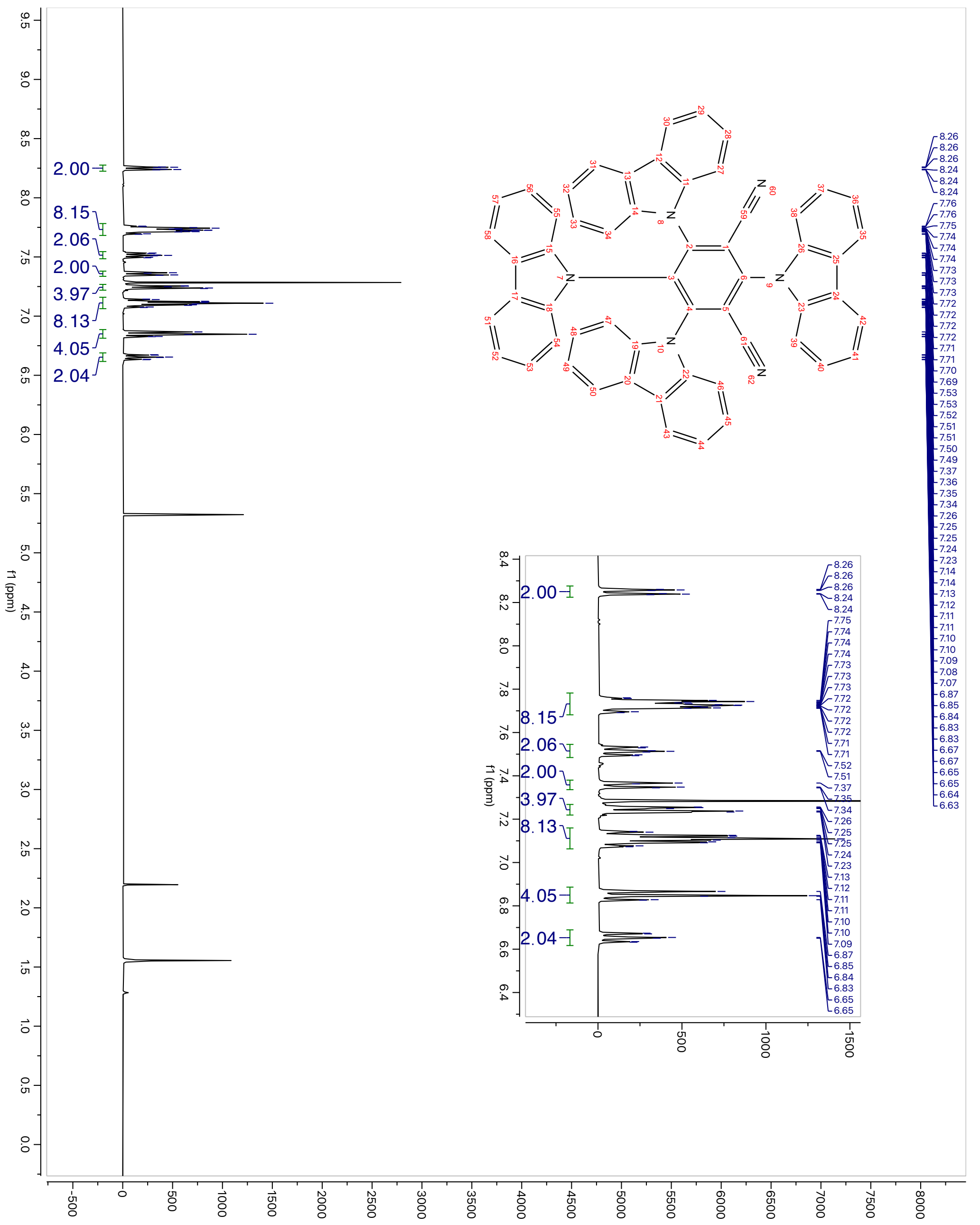




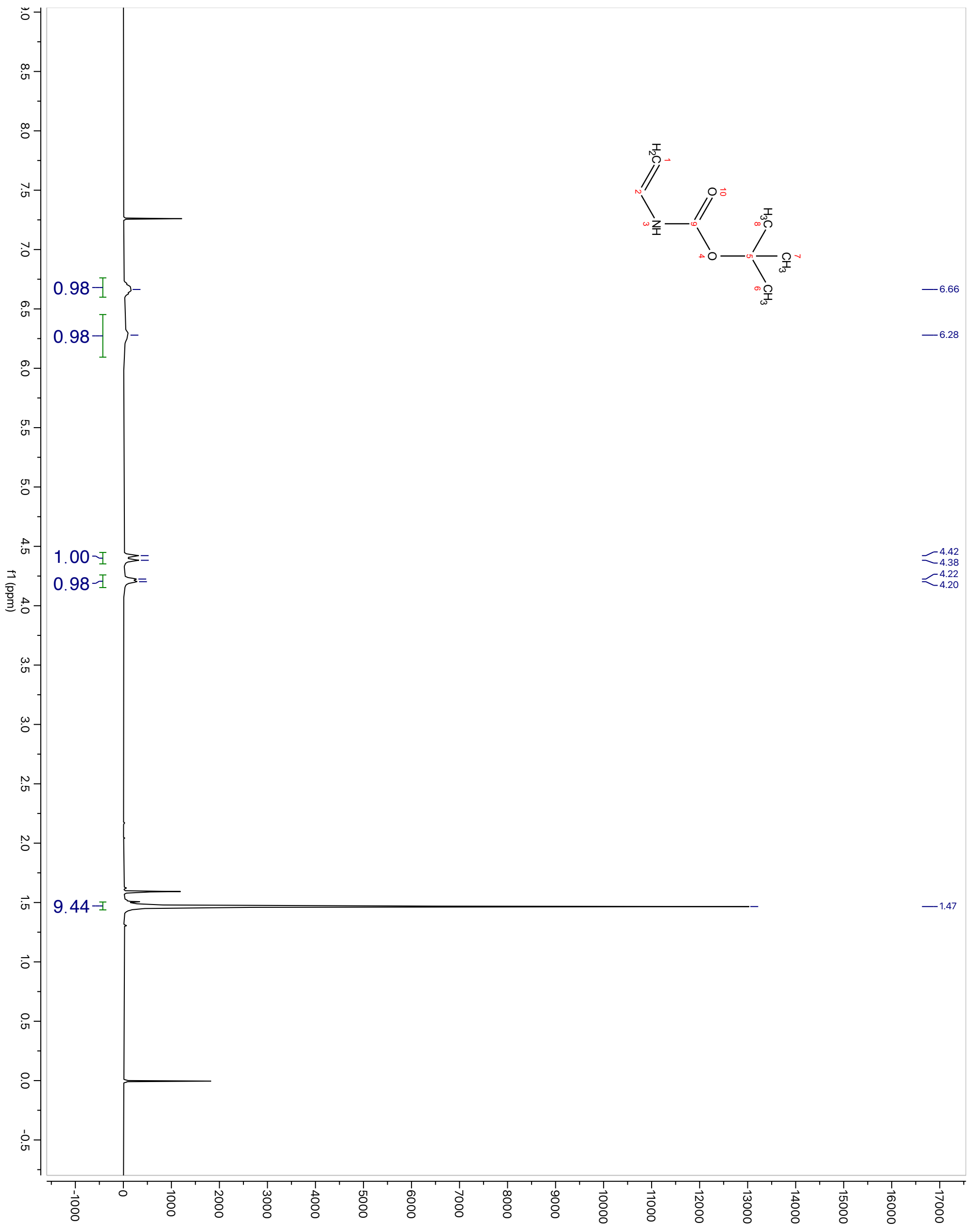




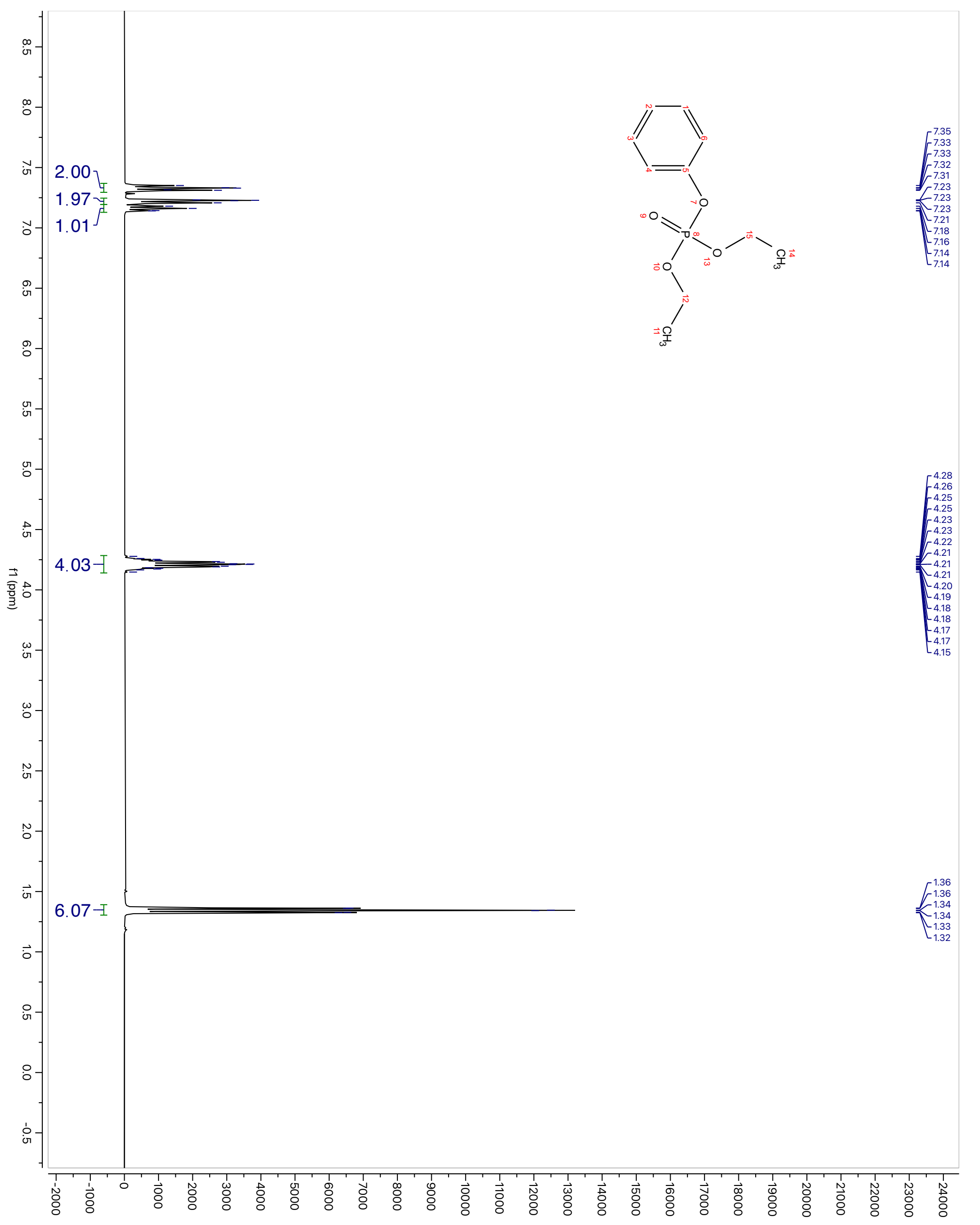




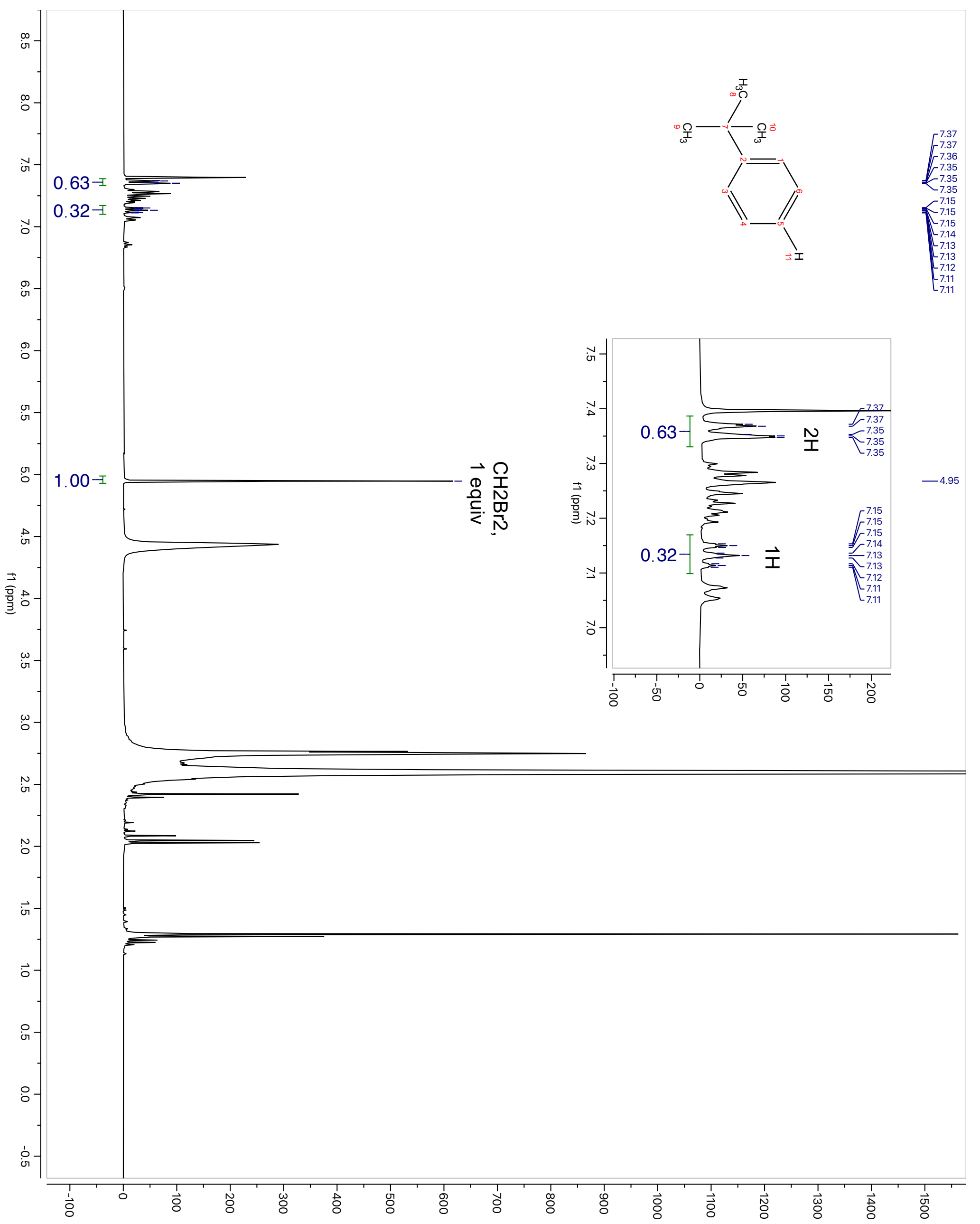




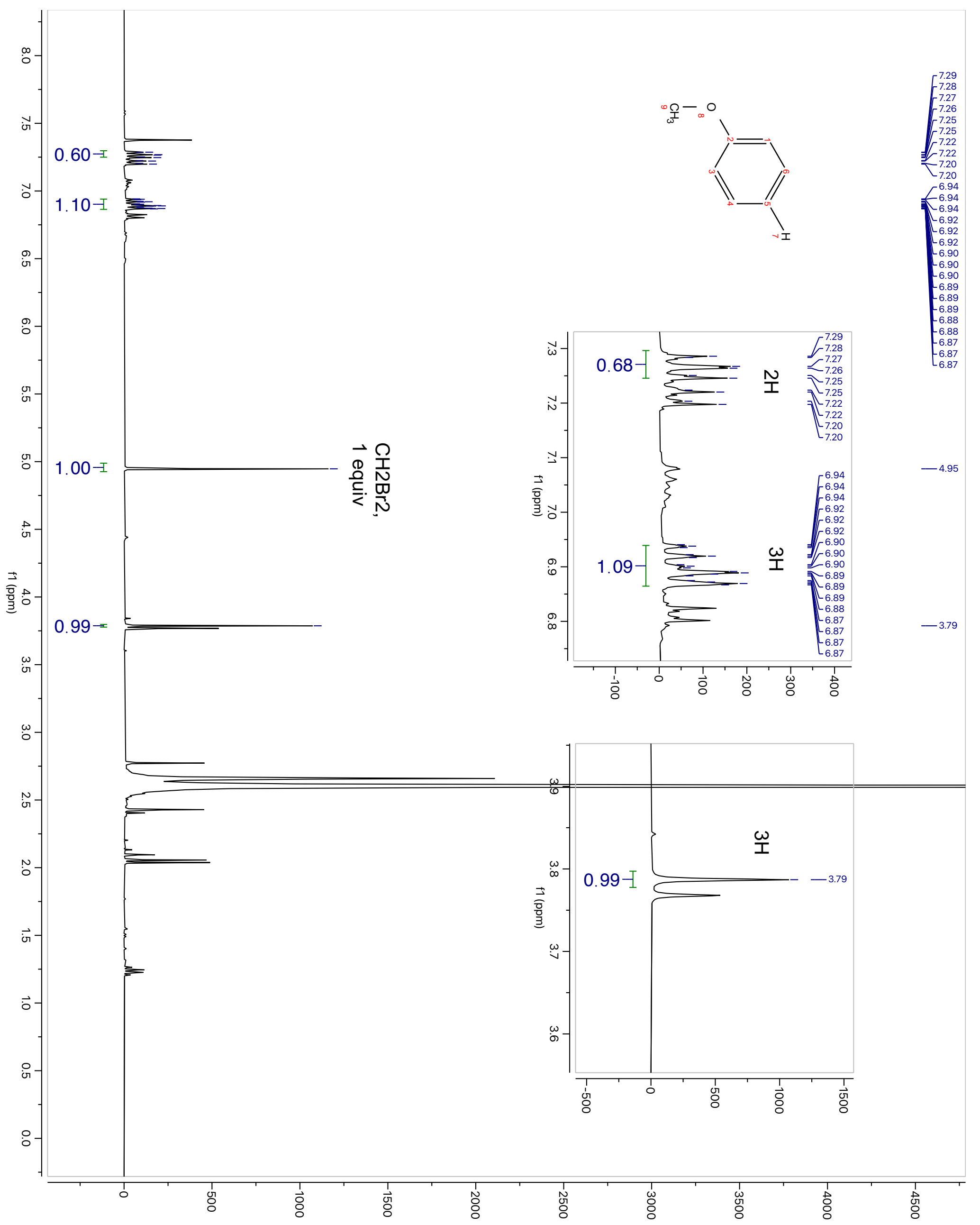




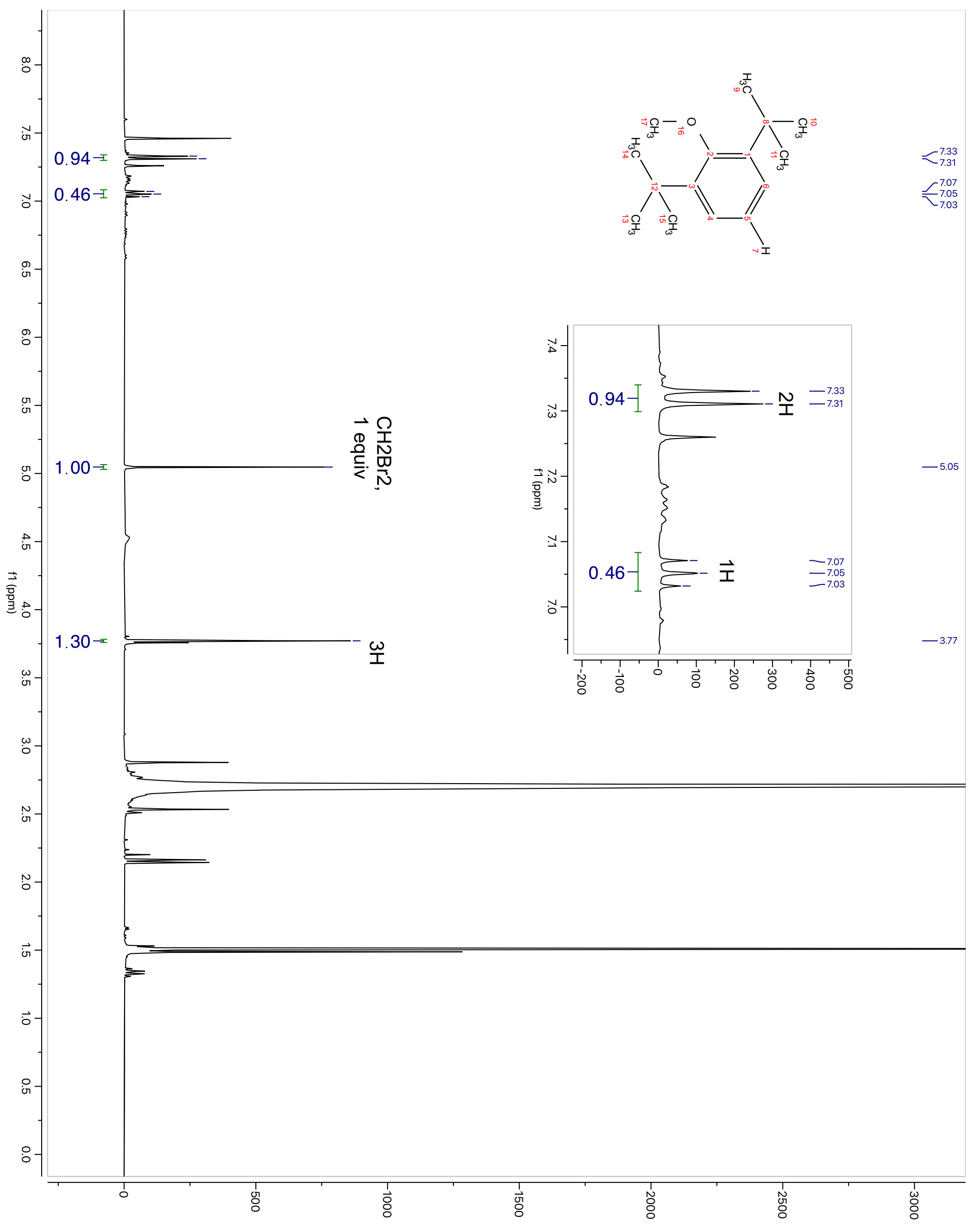




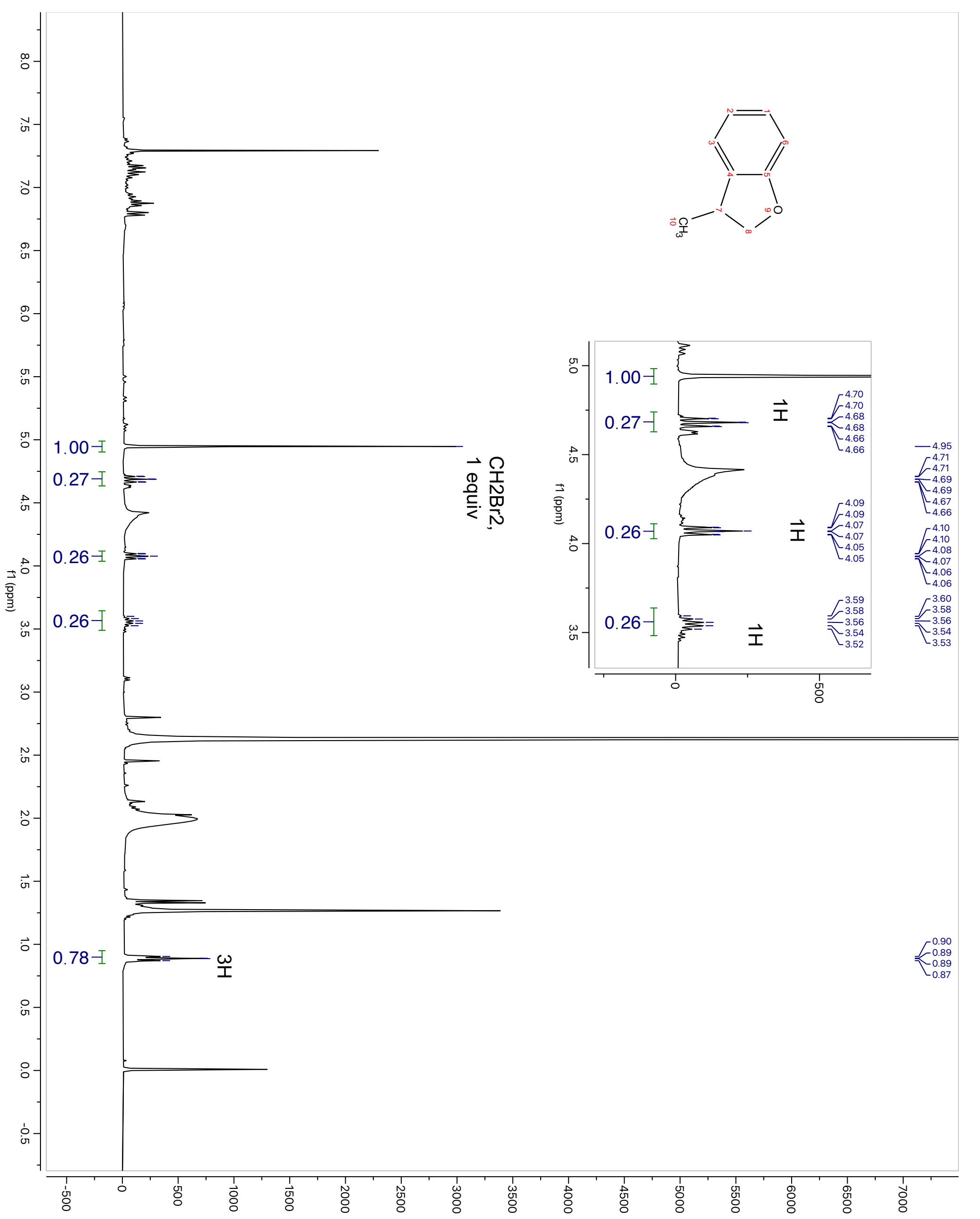




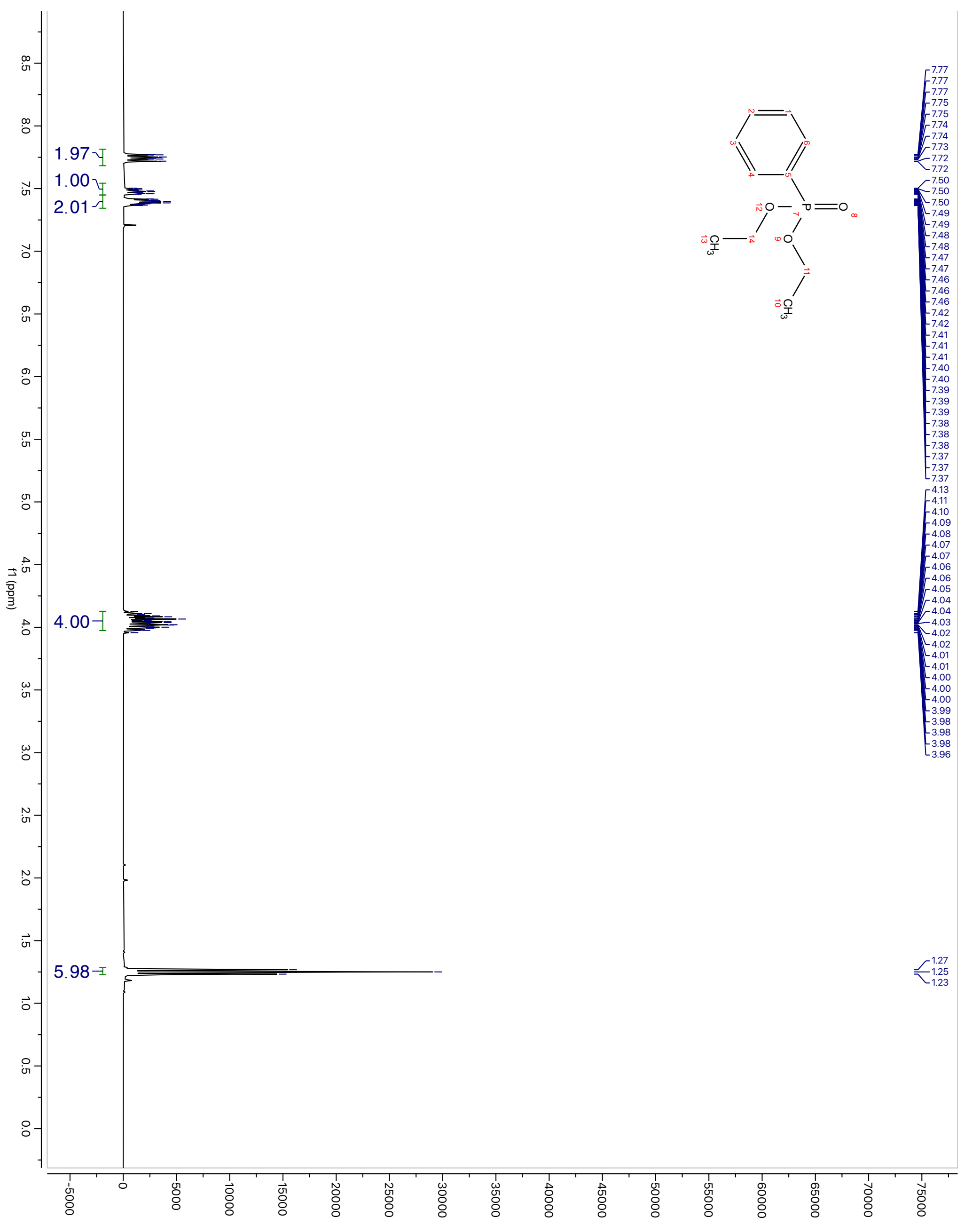




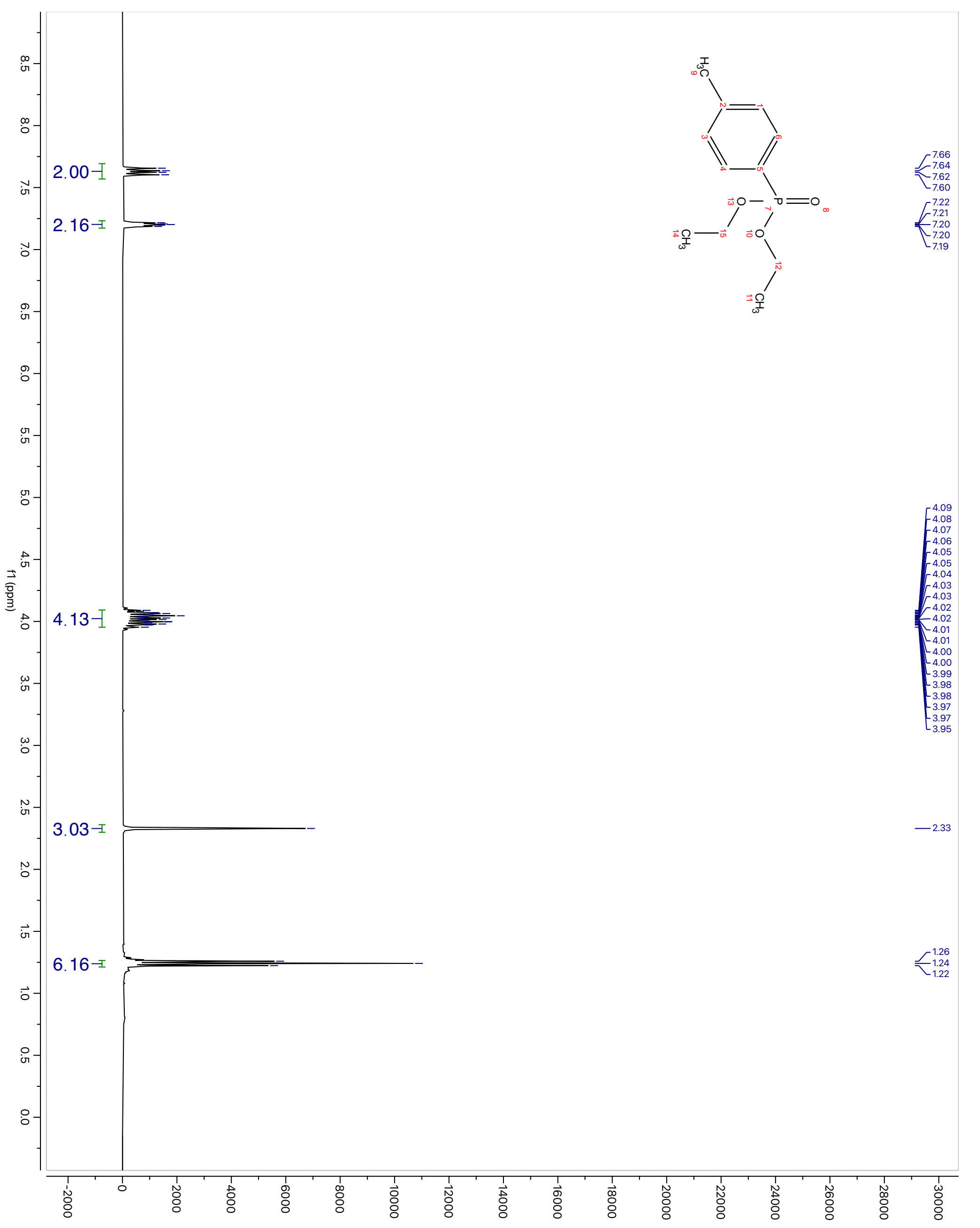




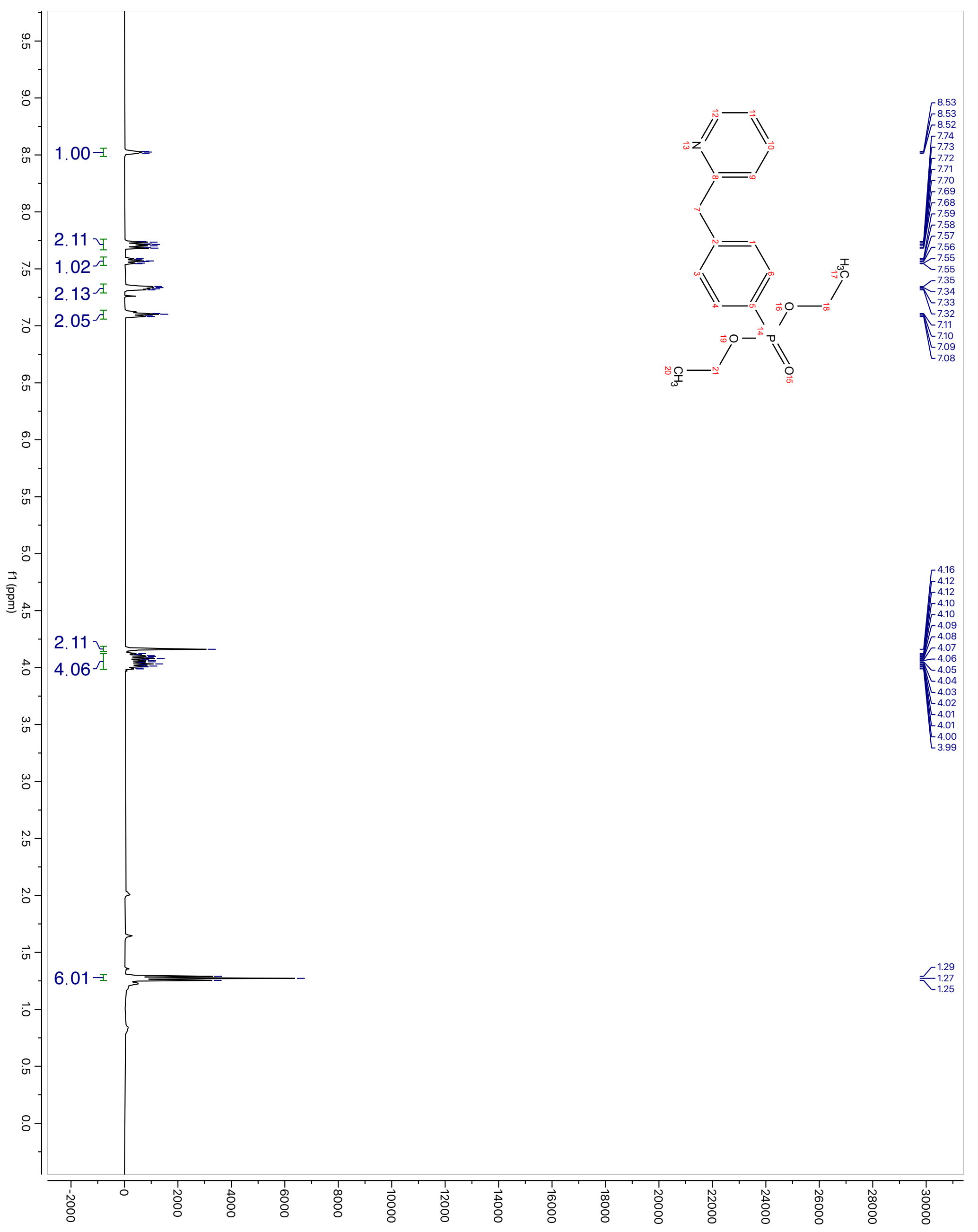




$$
\mathbb{E}^{E^{\prime}}
$$




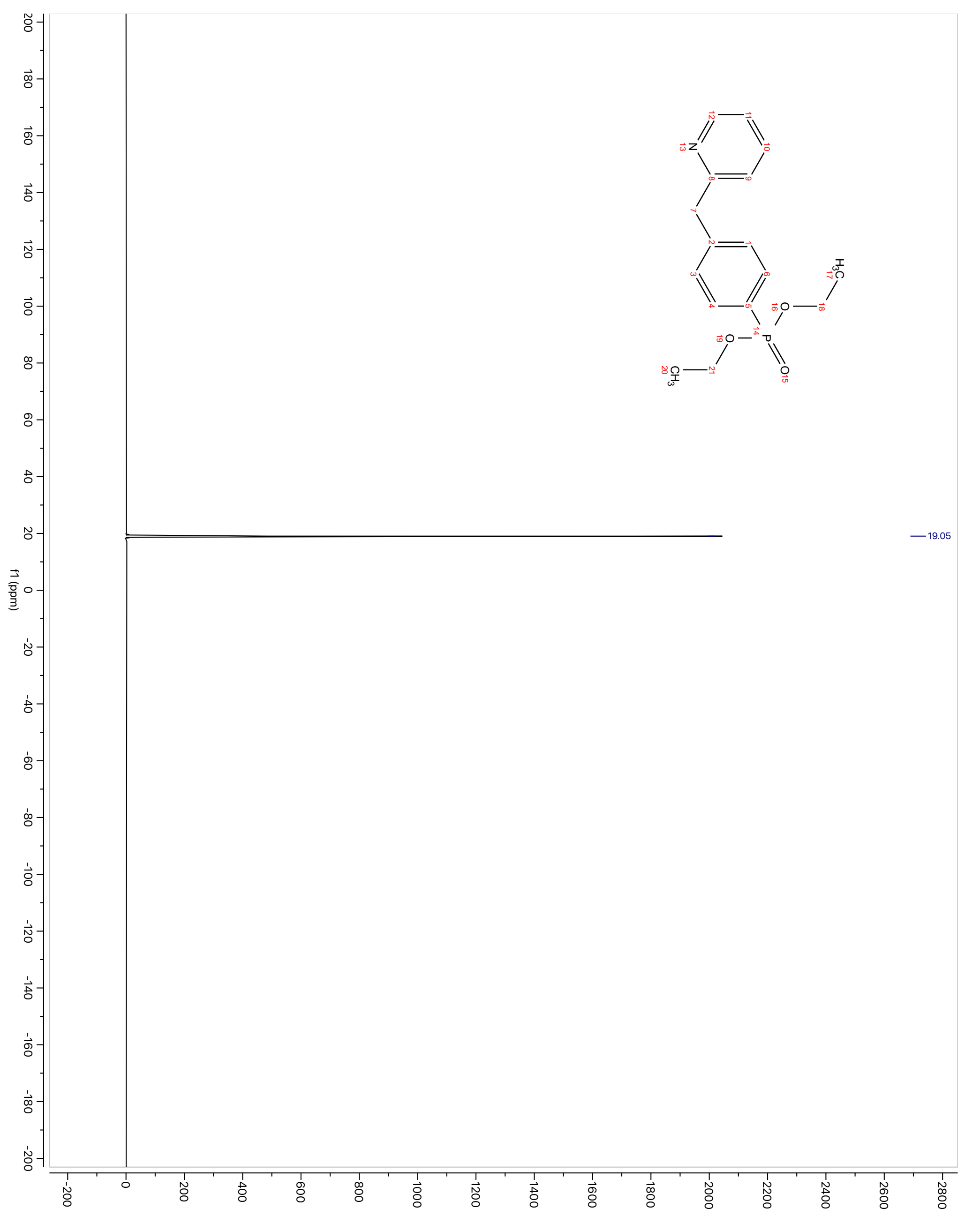




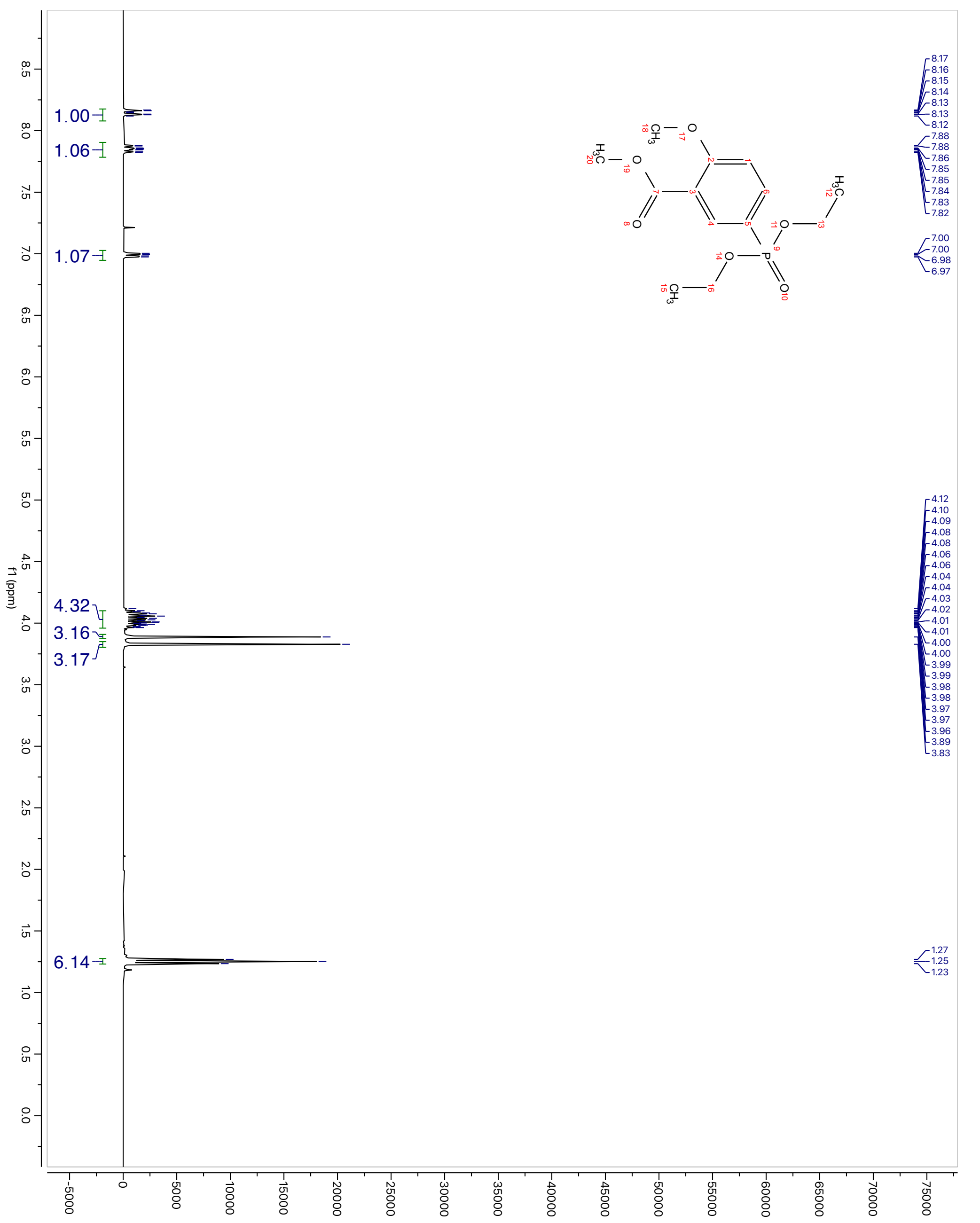




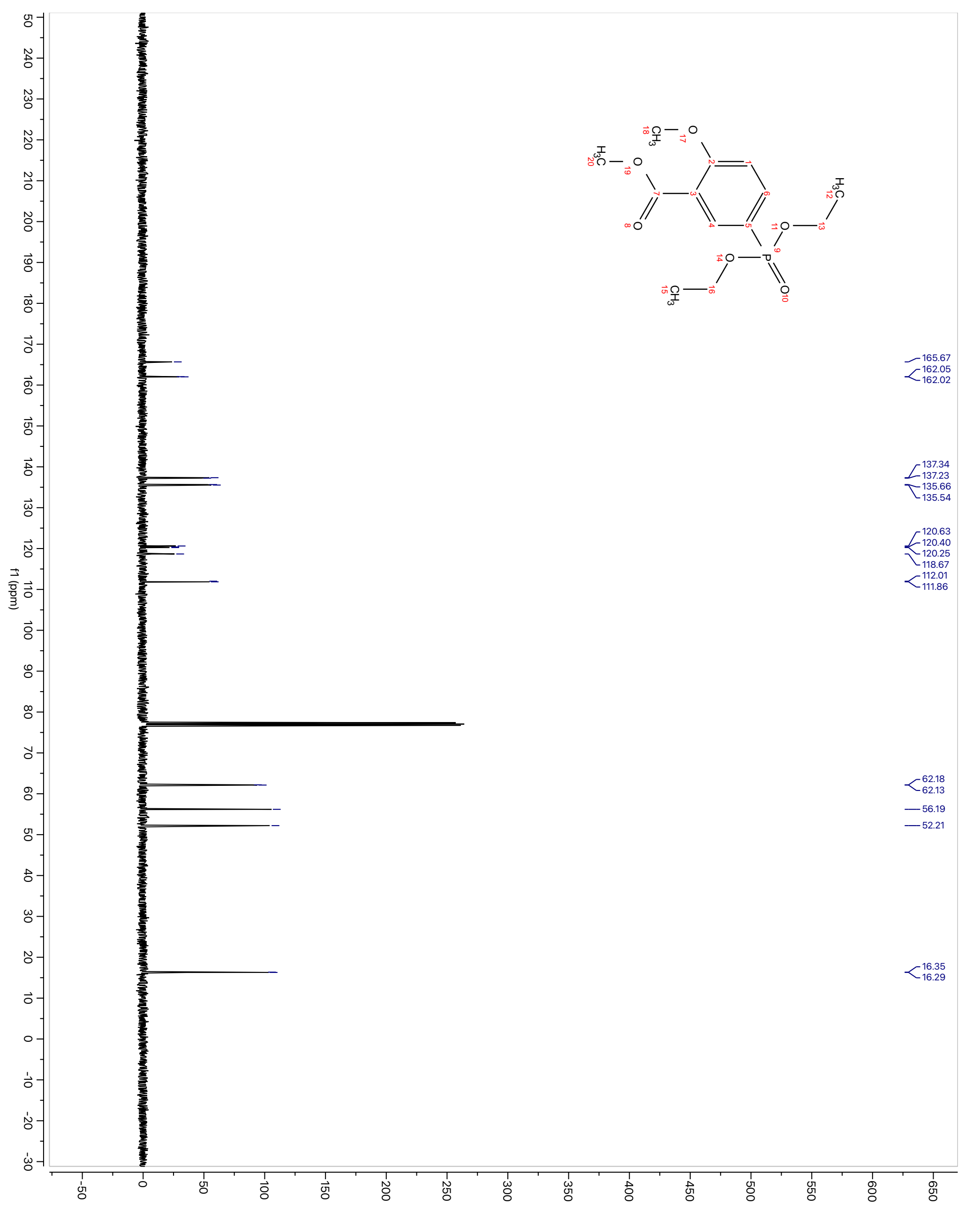




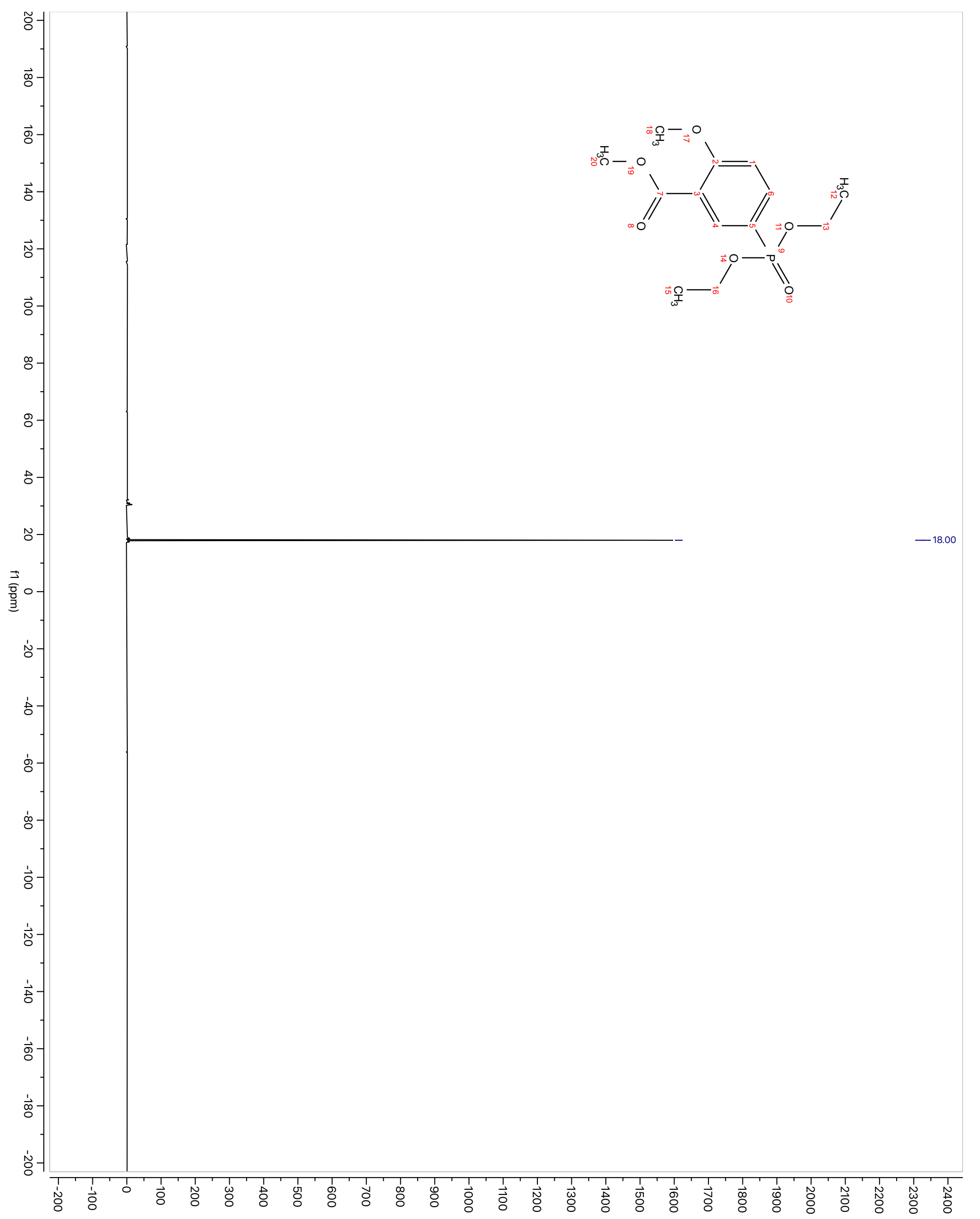




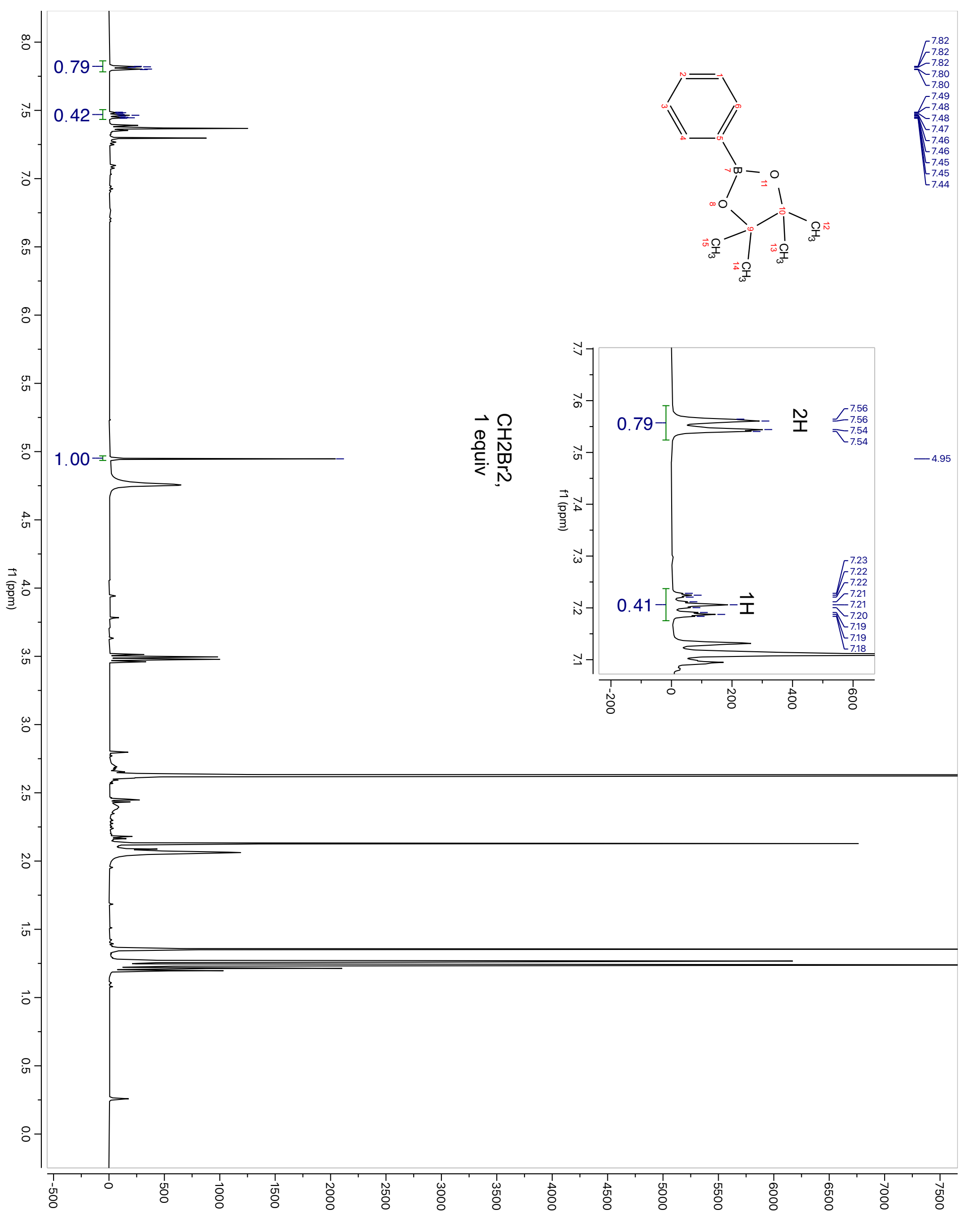




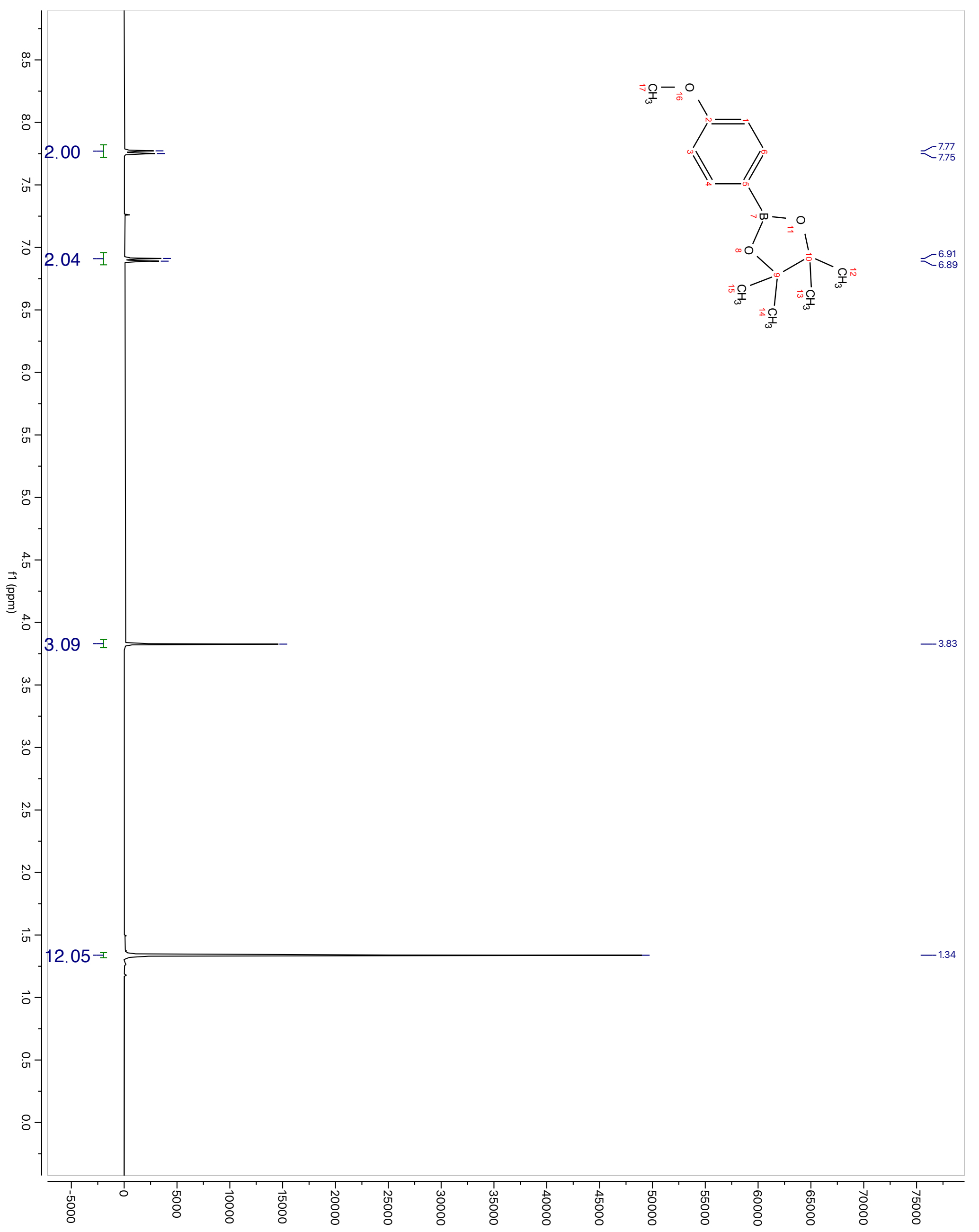




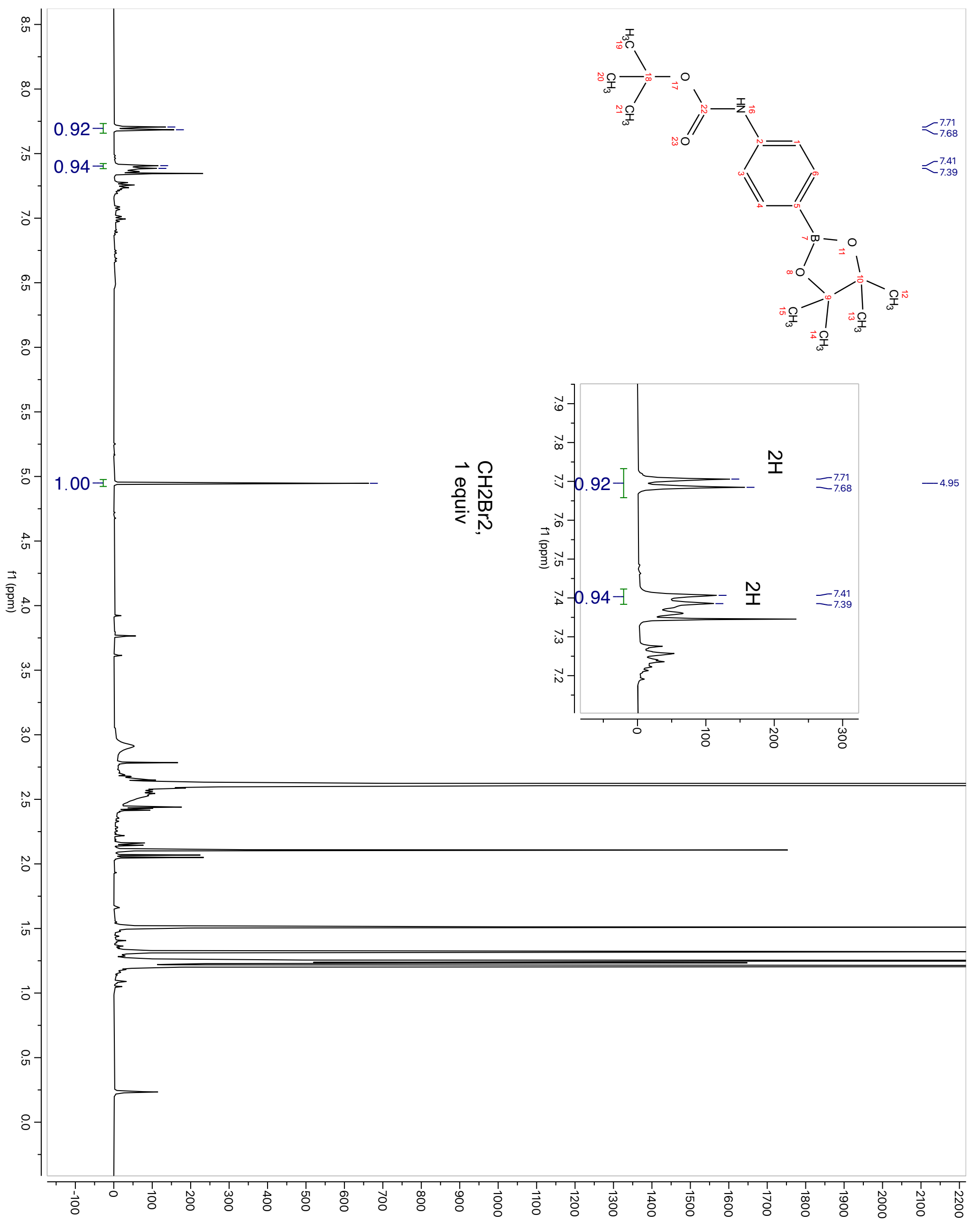




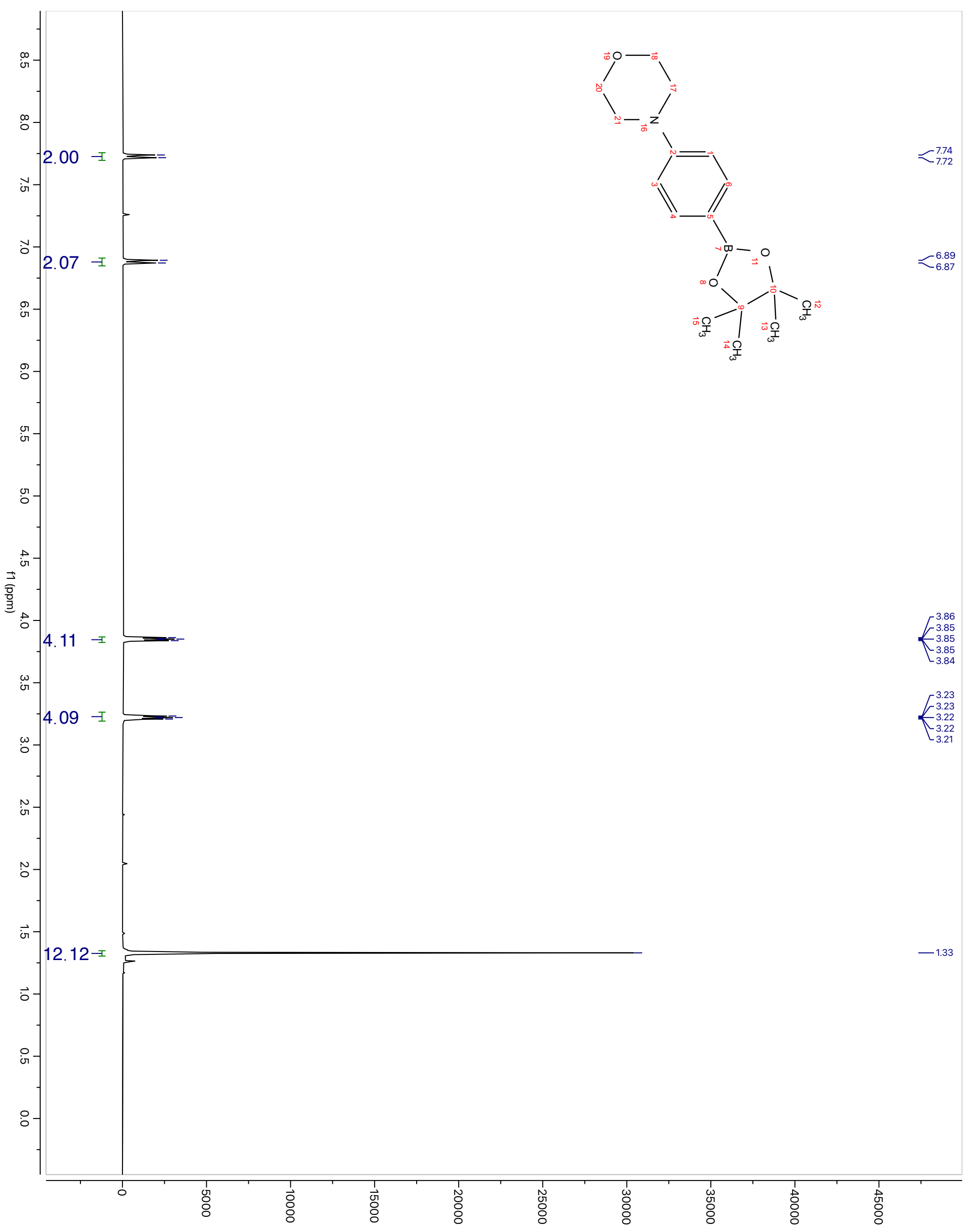




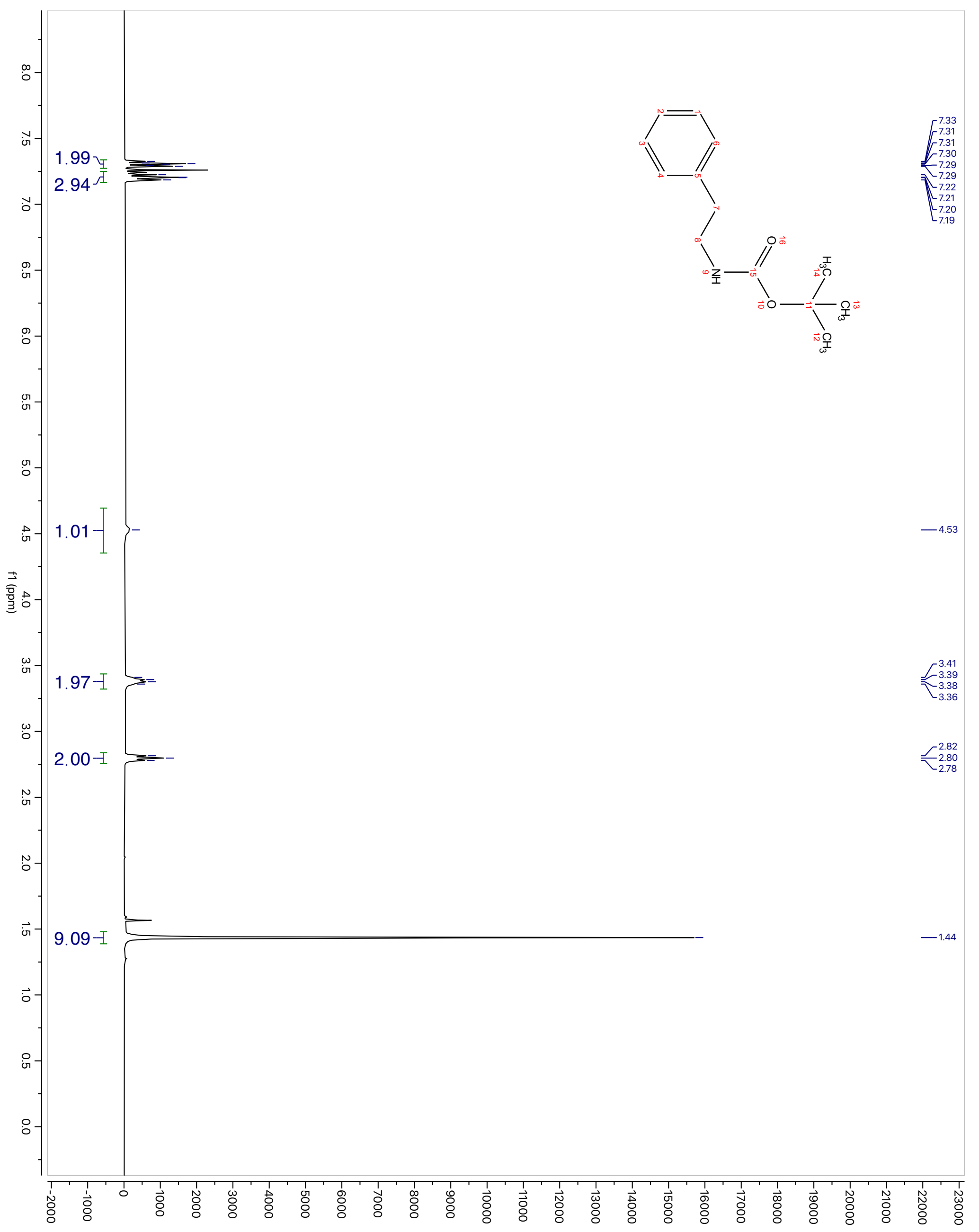




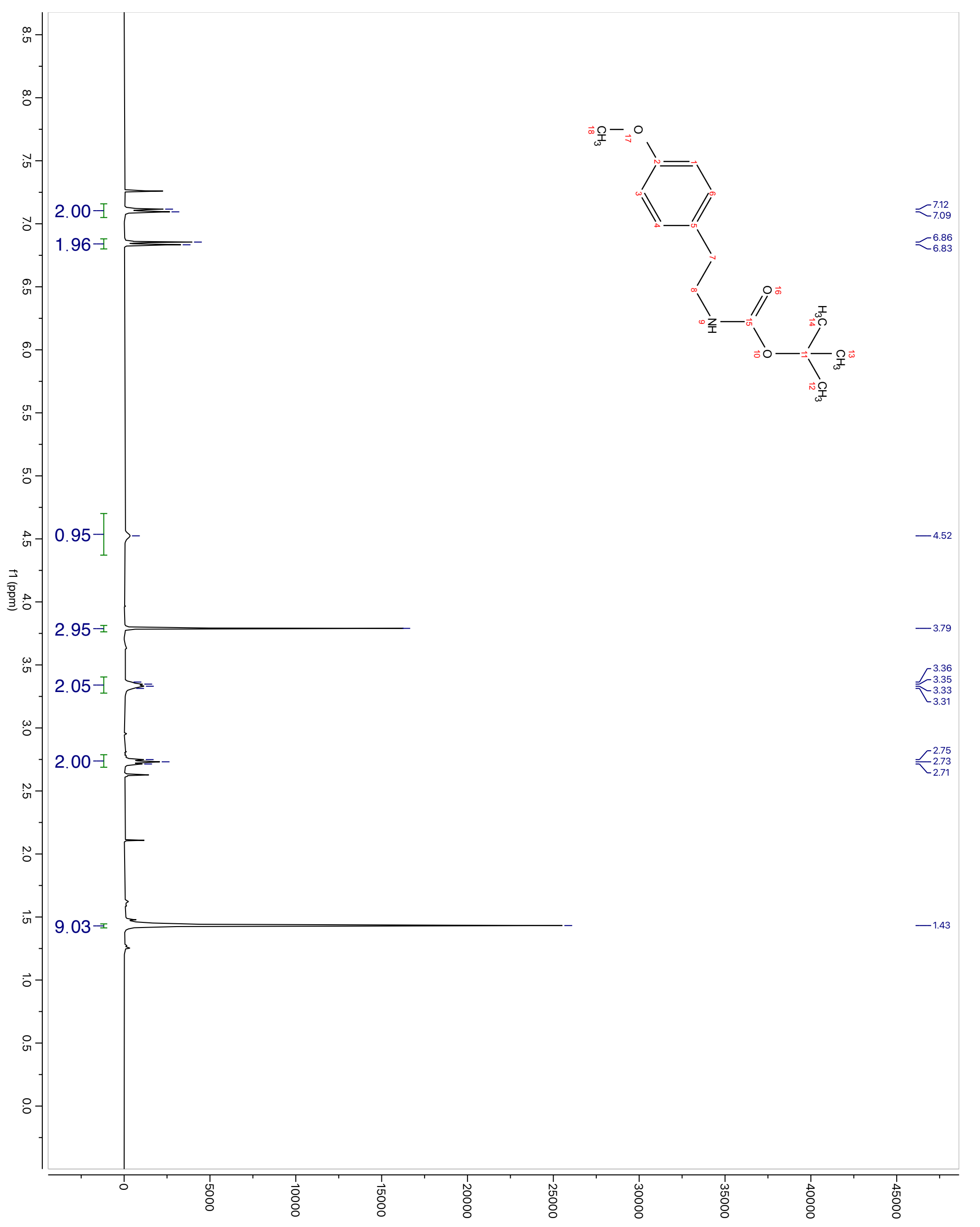




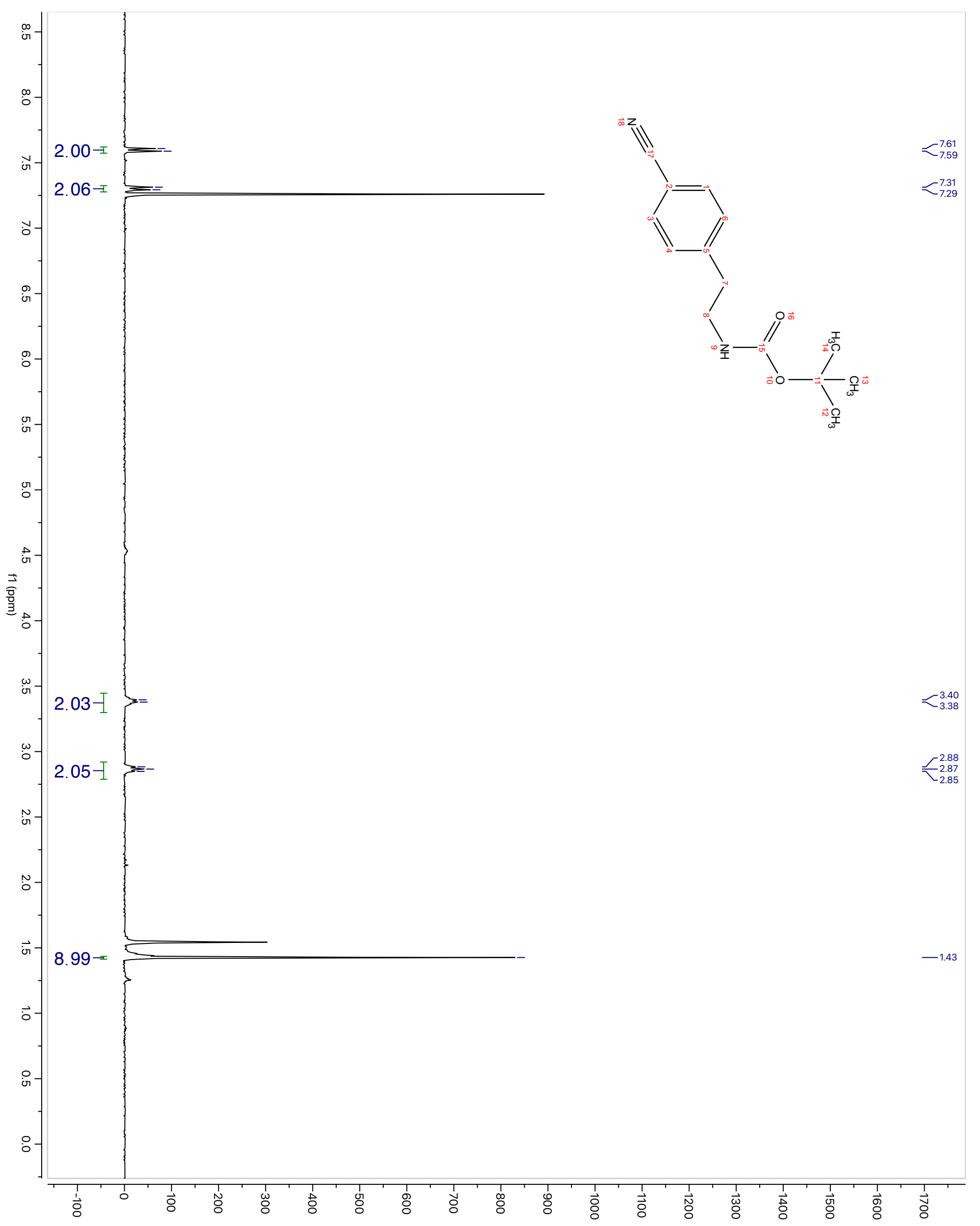




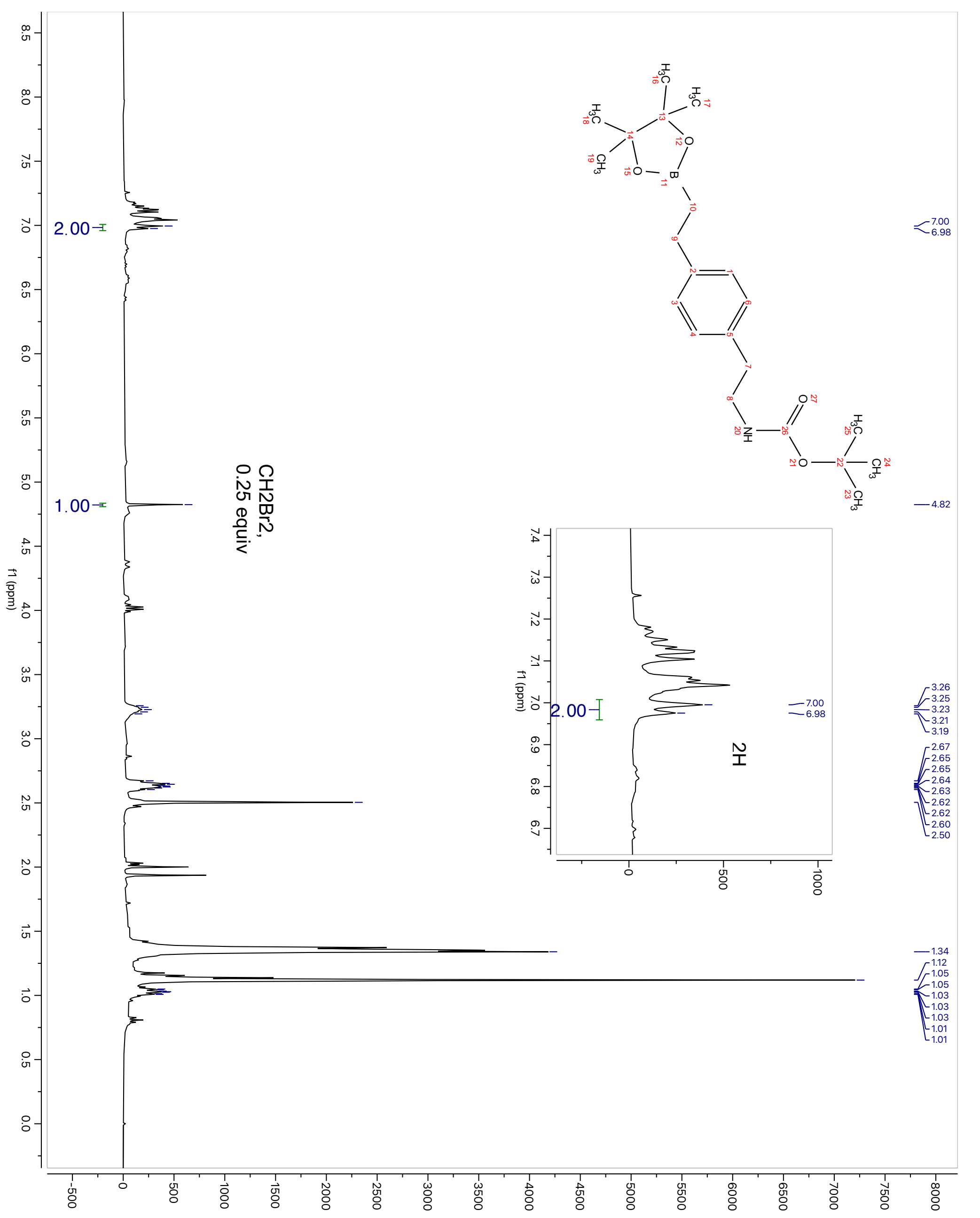




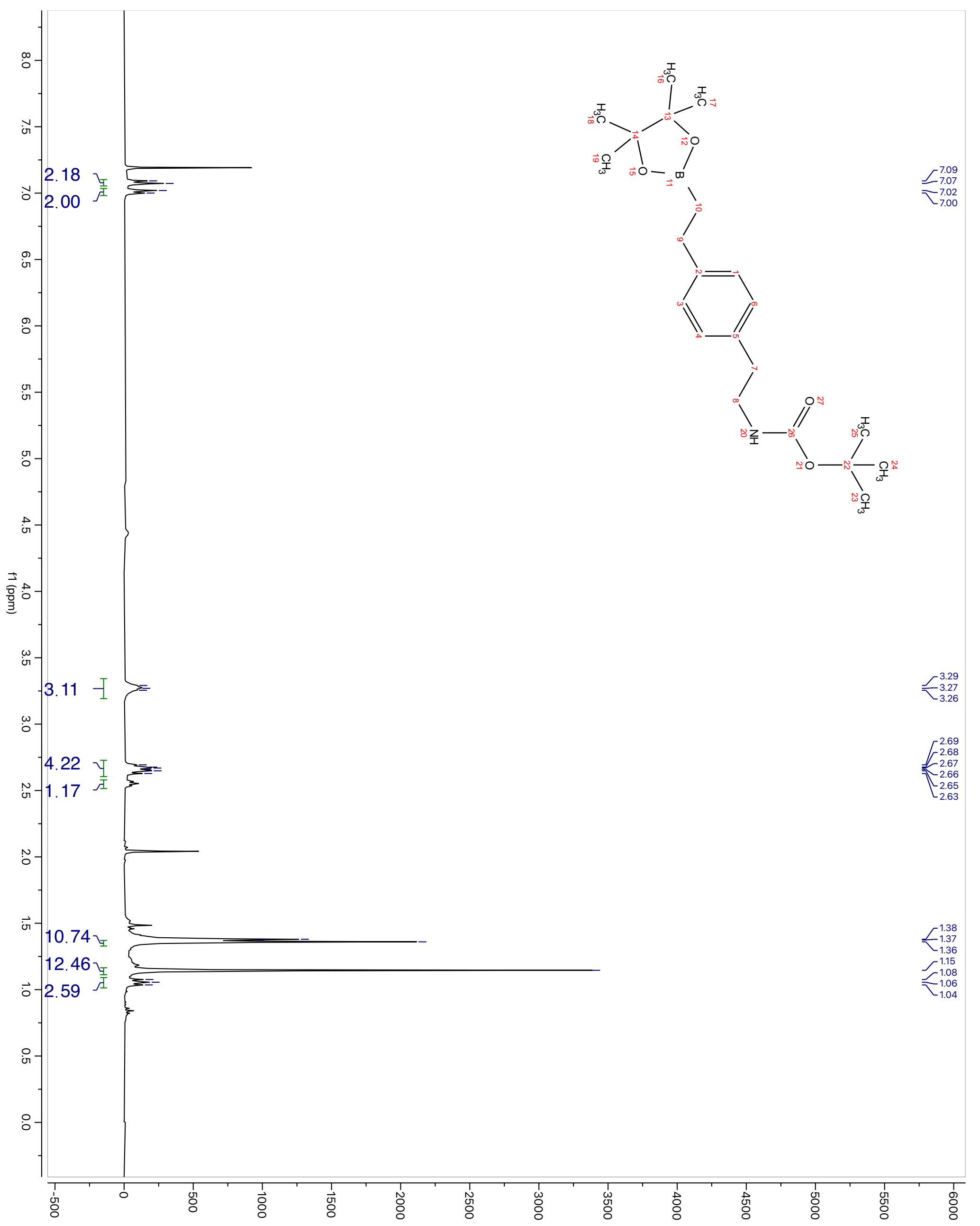




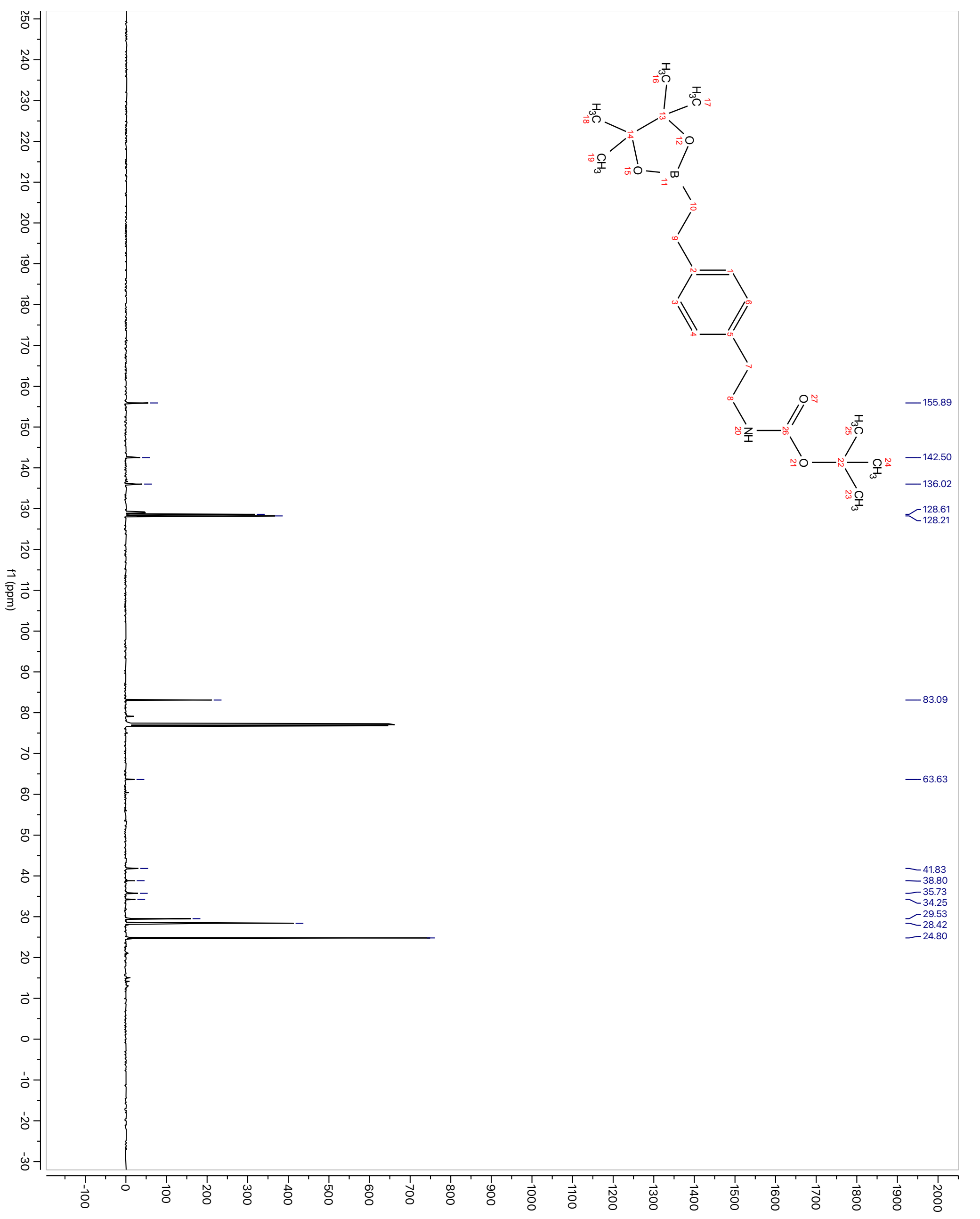




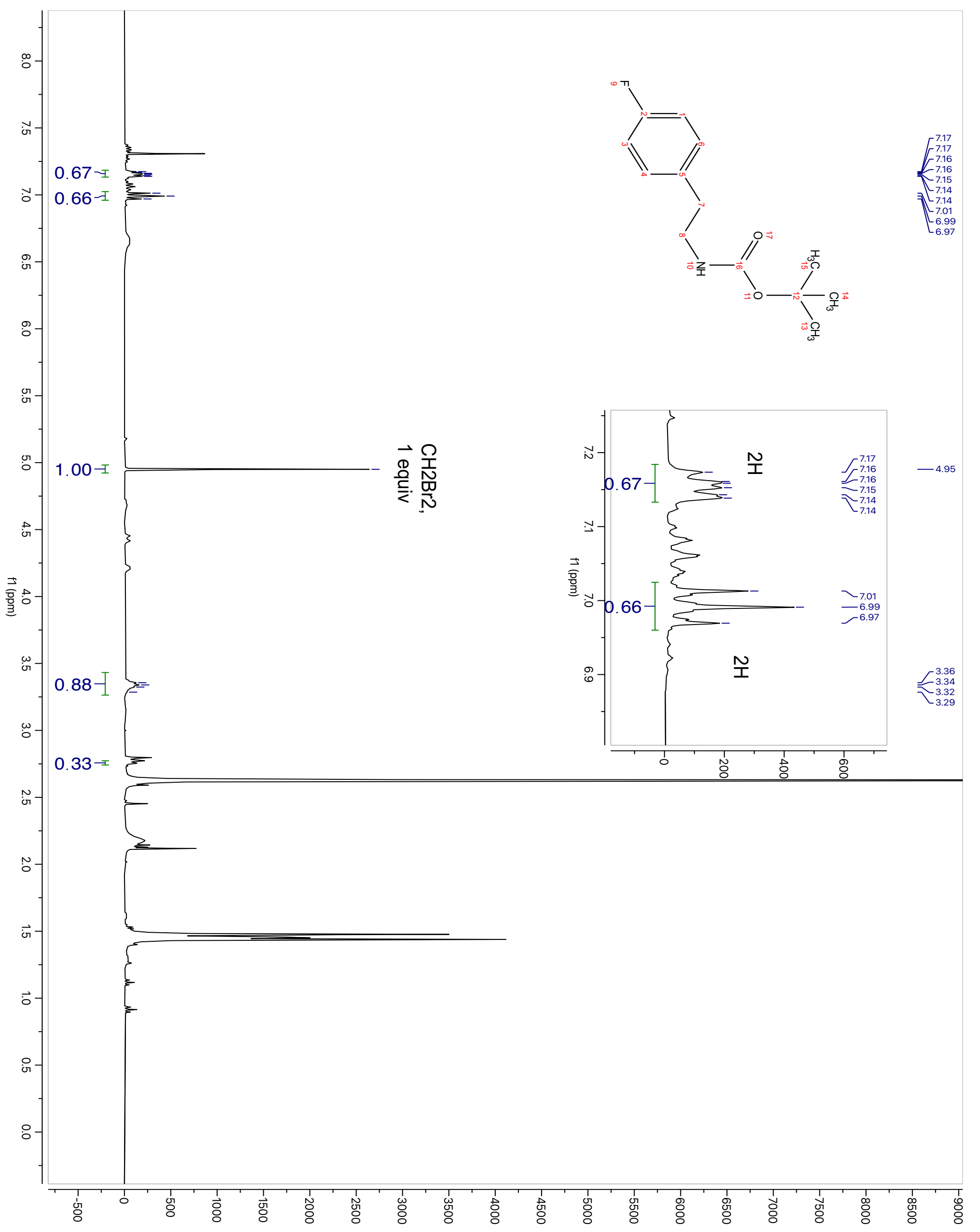




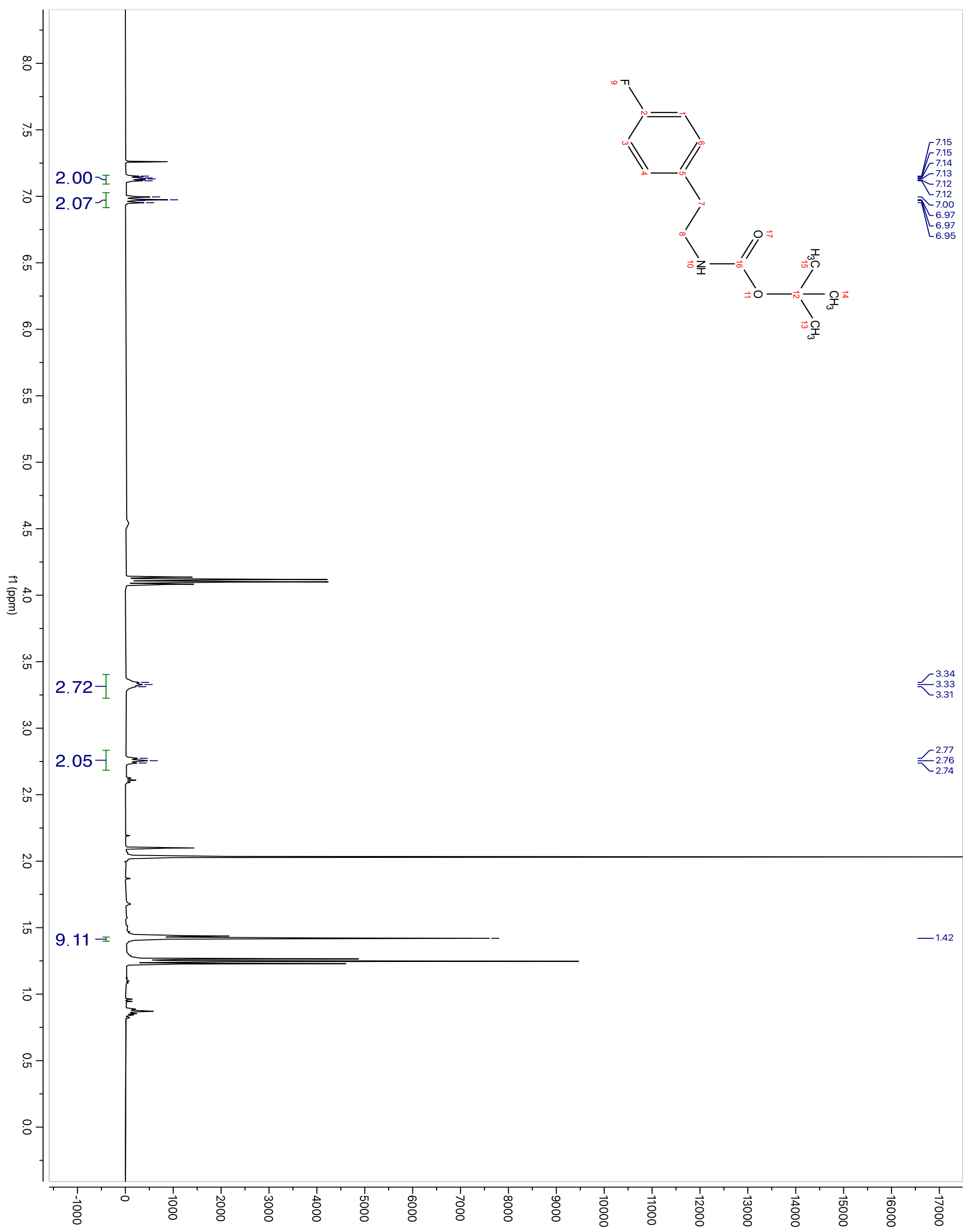




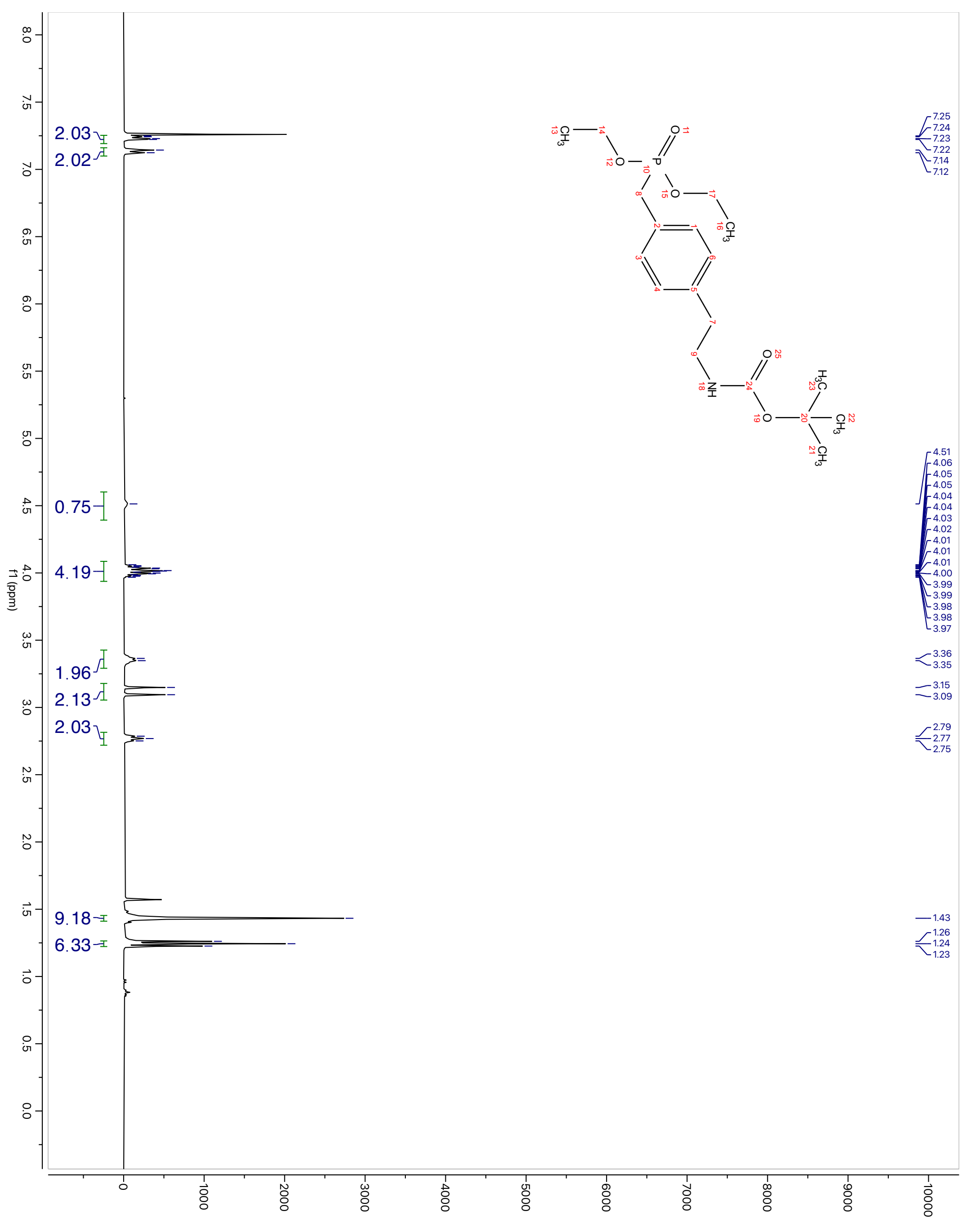




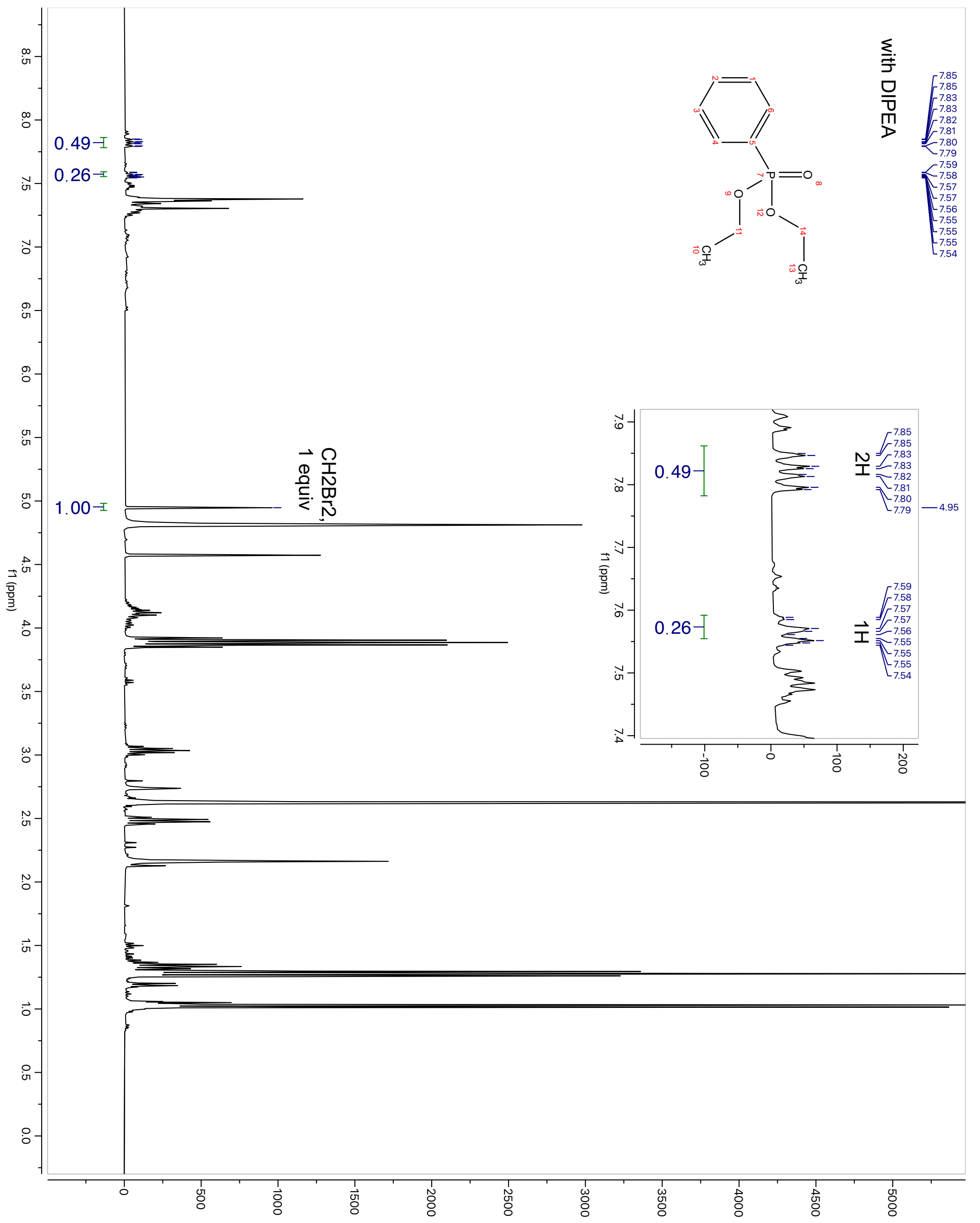




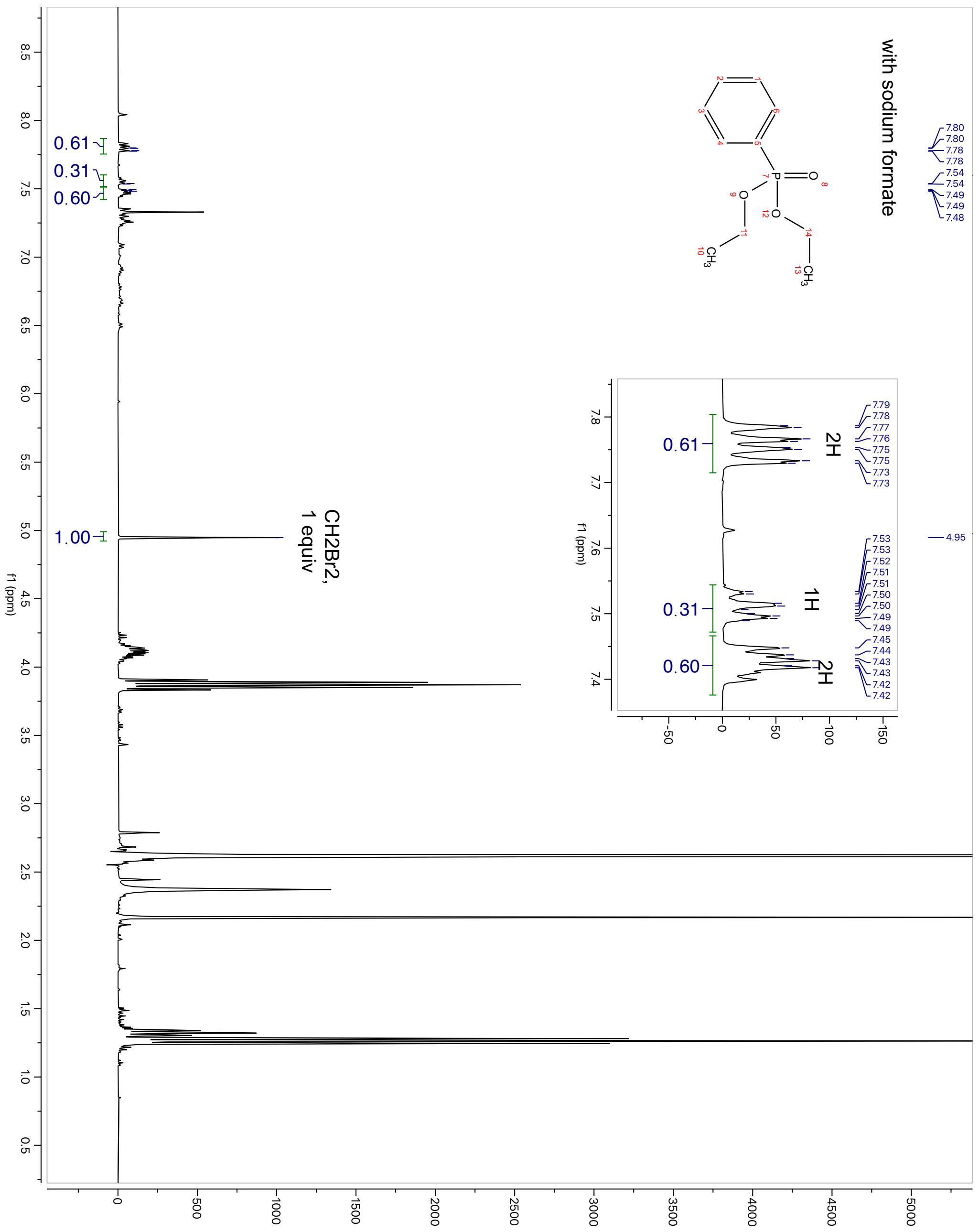




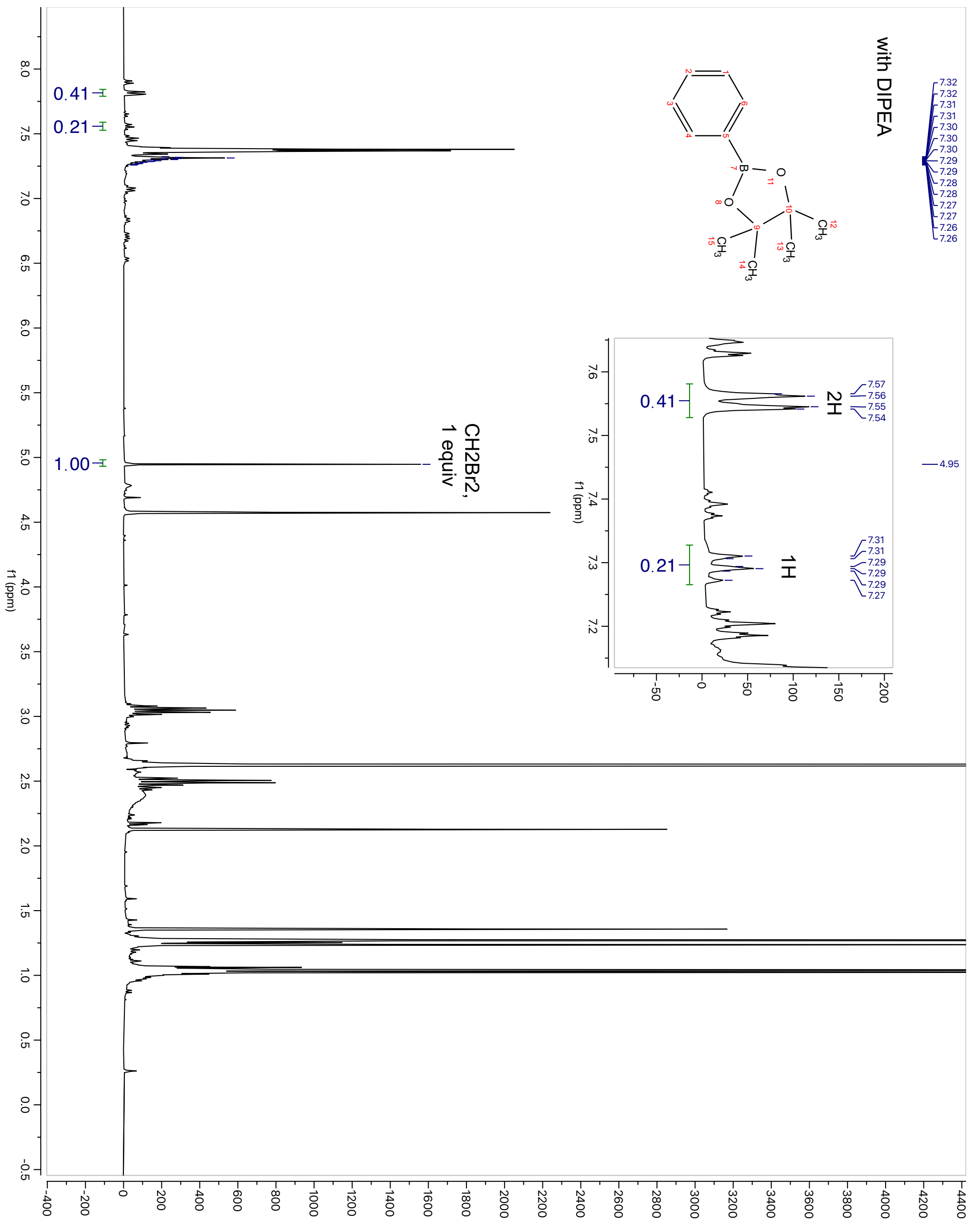




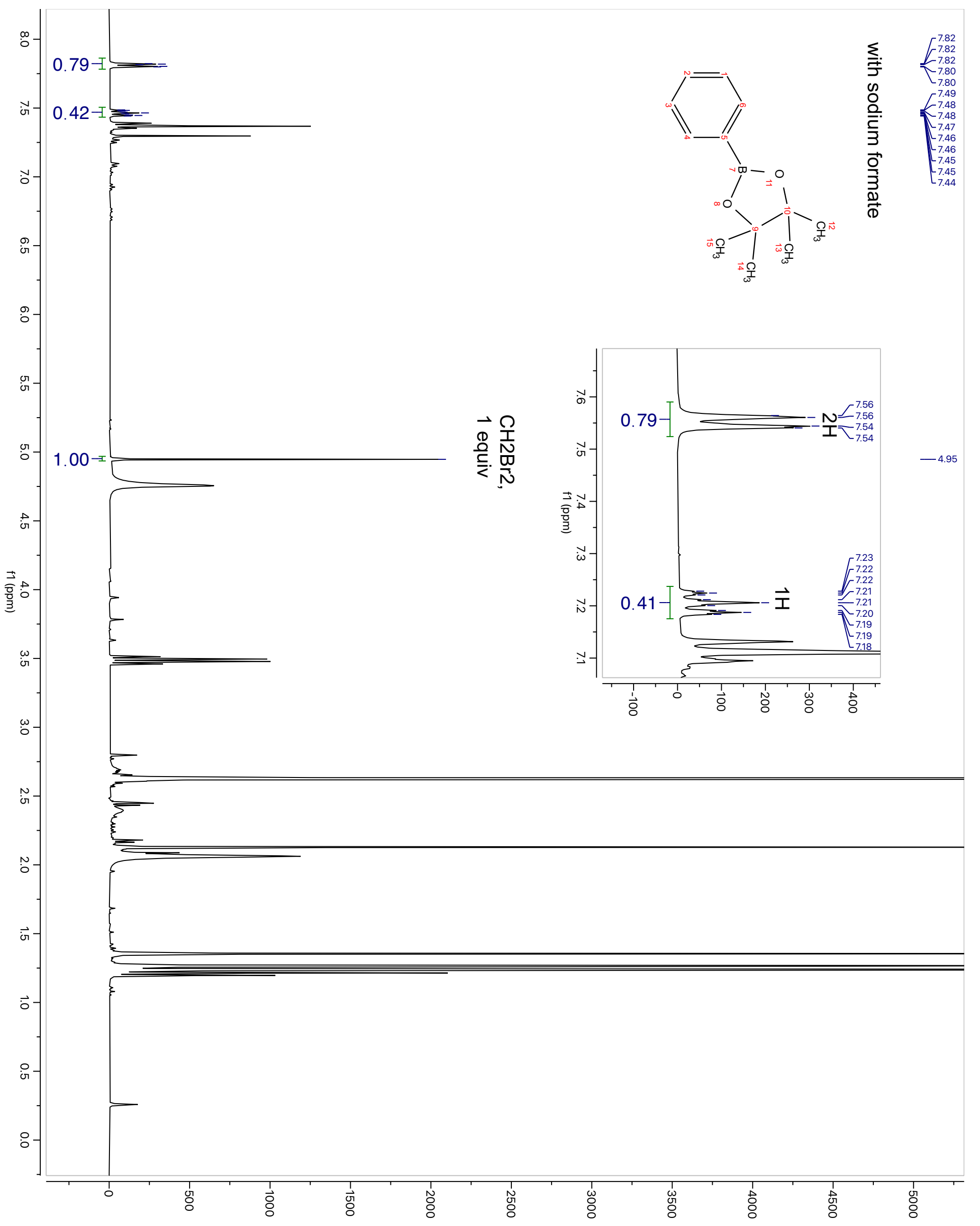




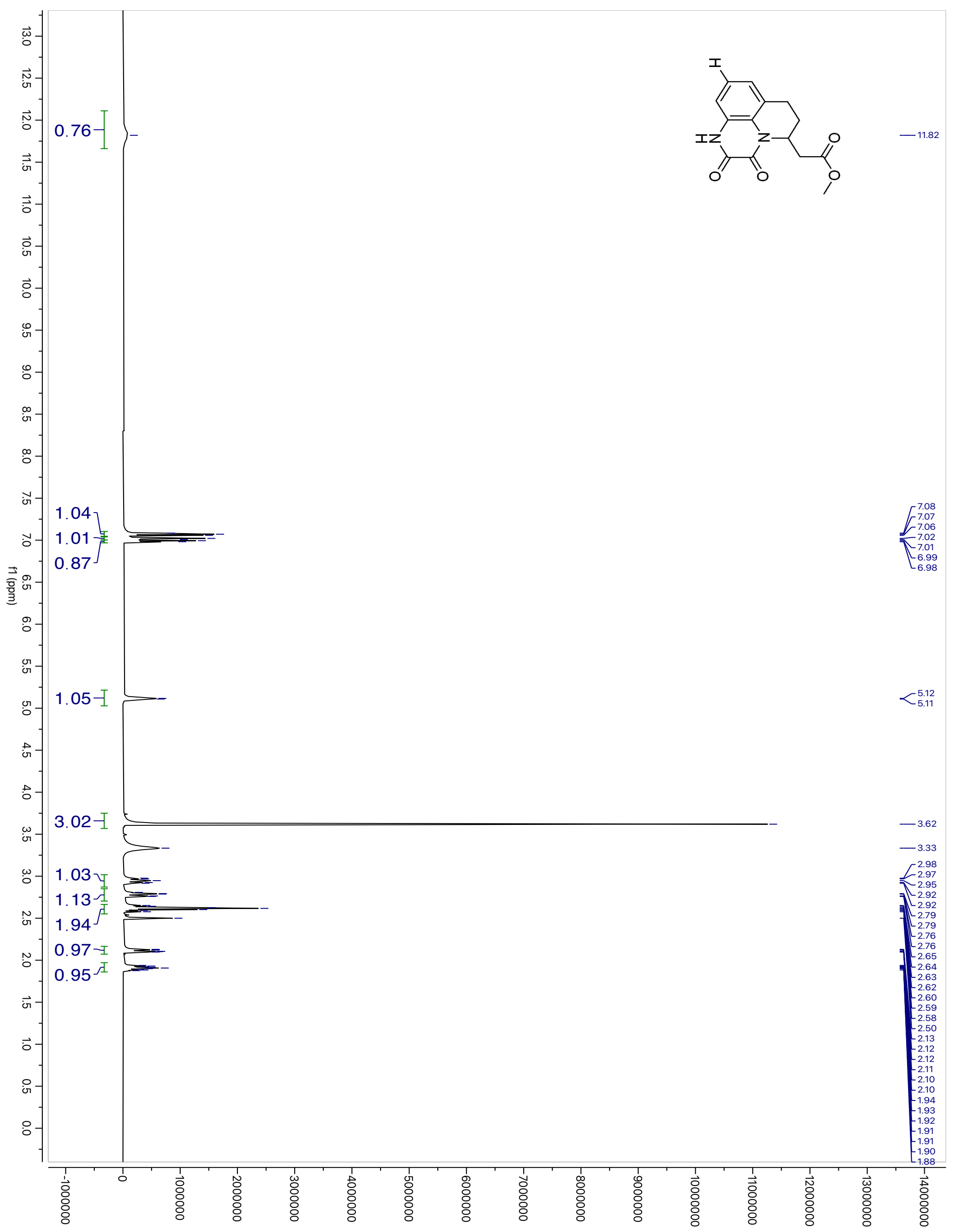




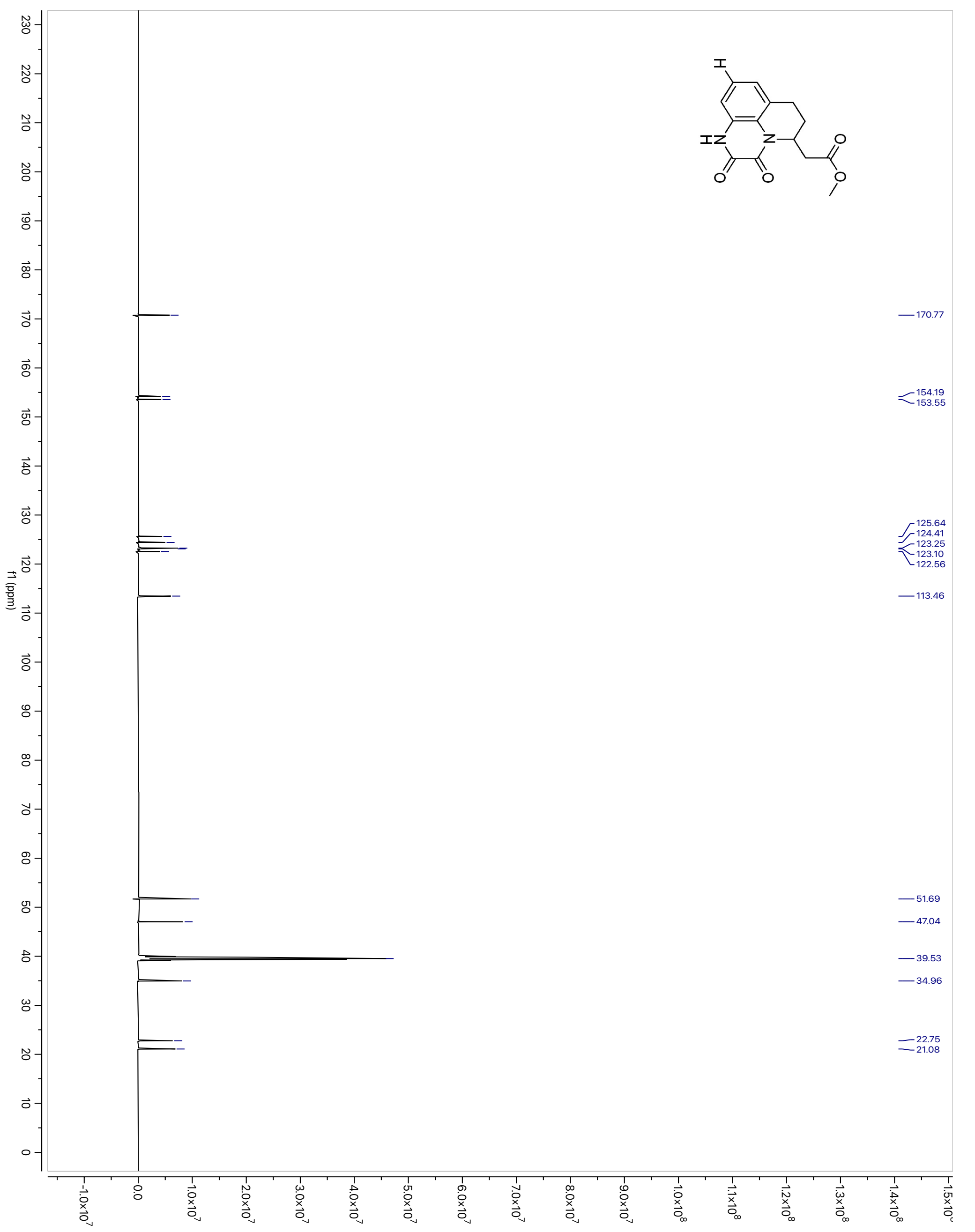




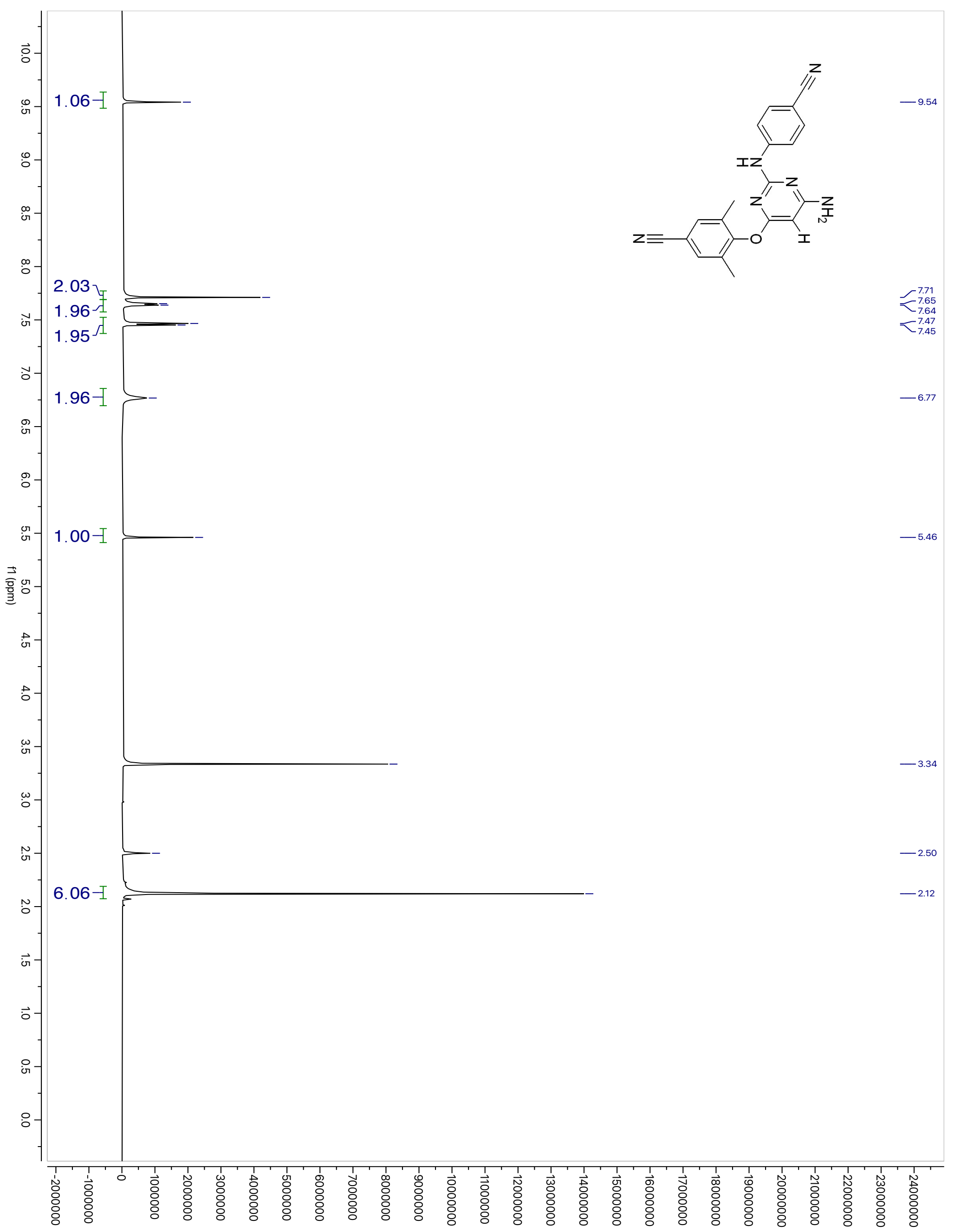




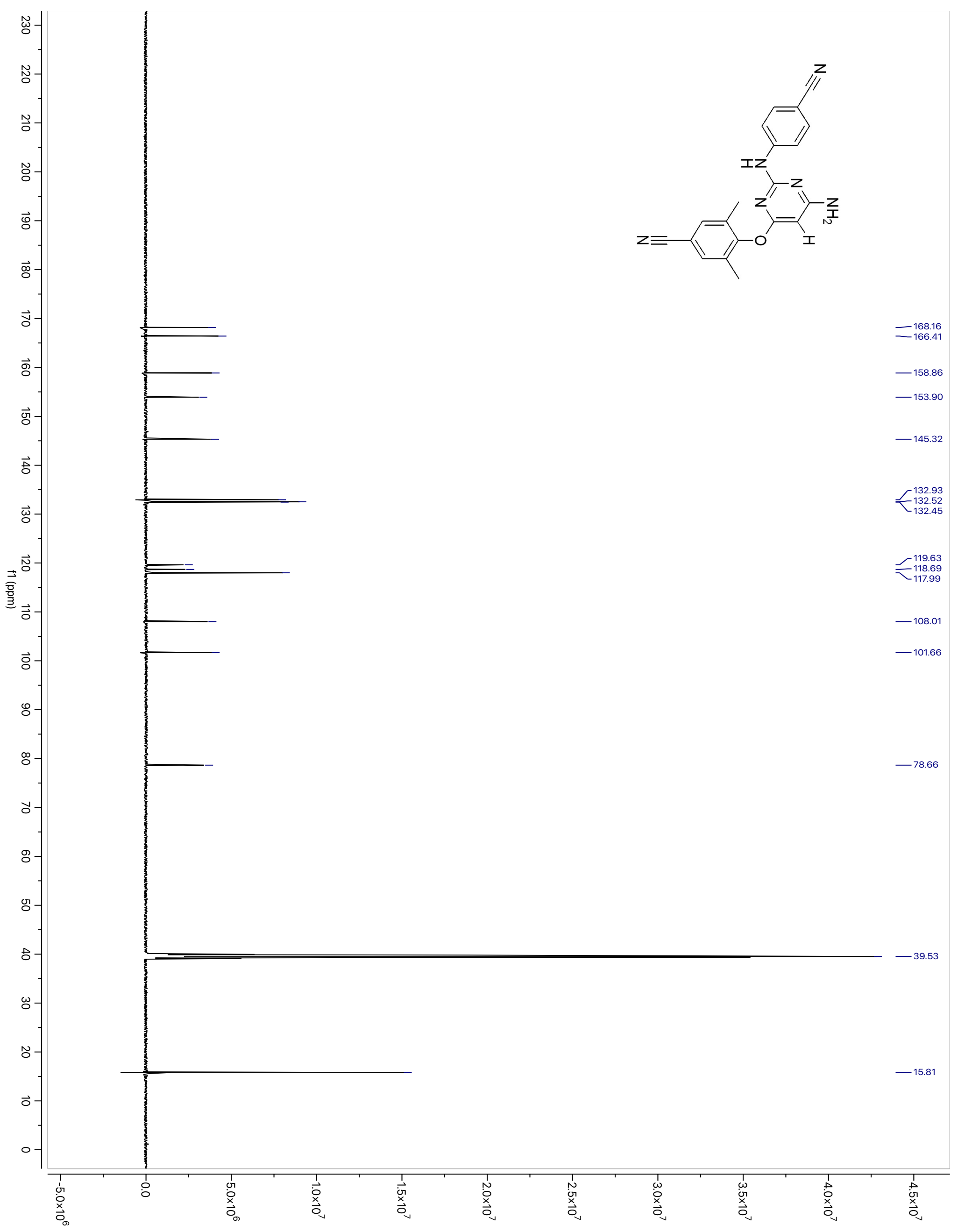




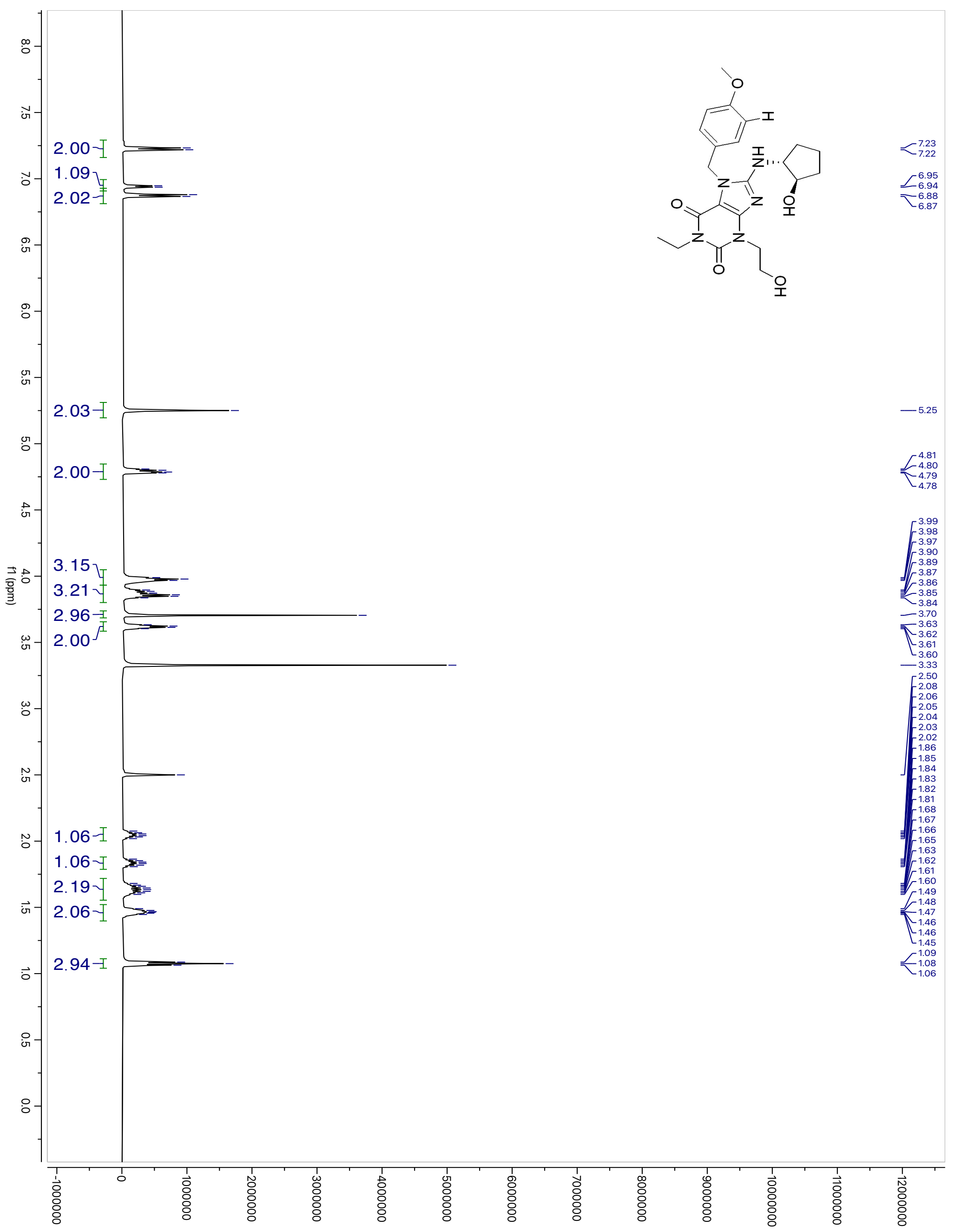




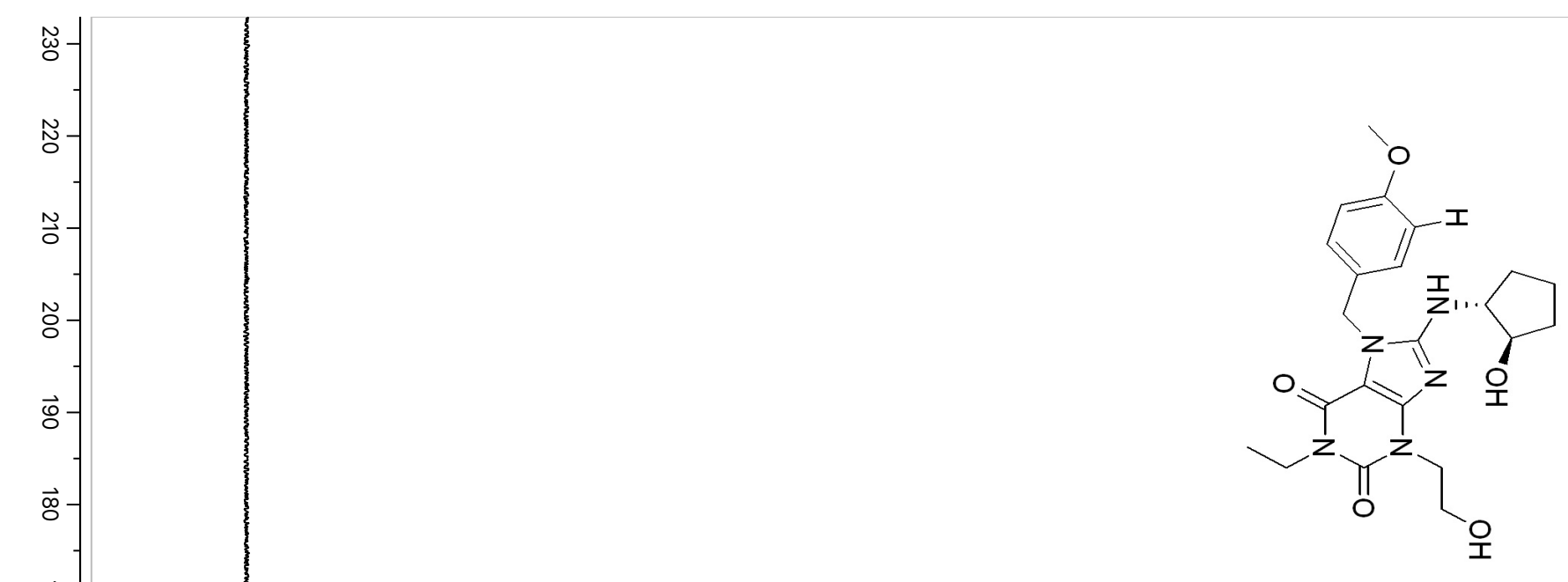

$-158.62$

$-153.45$

$-152.55$

150.42
$\sim_{148.67}$

ज़

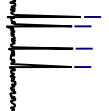

129.22

$<_{-128.82}^{129.22}$

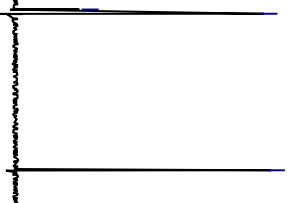

$-113.86$

$-101.19$

$-76.10$

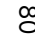

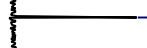

$\checkmark 61.49$

57.80
-55.05

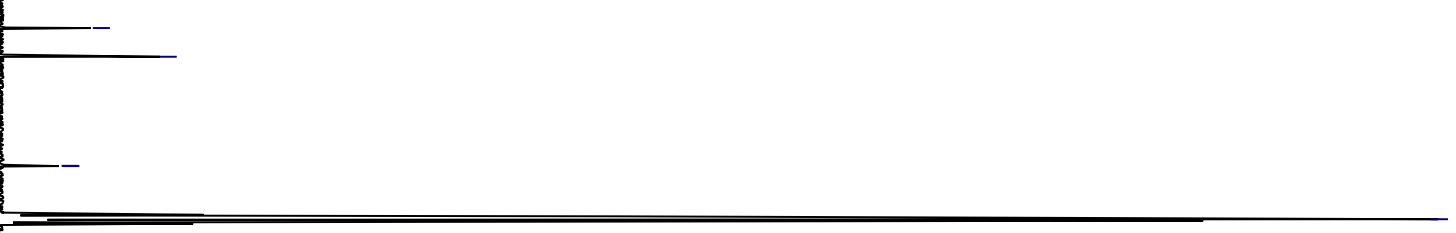

$<44.63$

$-39.53$

$-35.13$

$-32.43$

$-29.90$

$-20.53$

$-13.34$

7

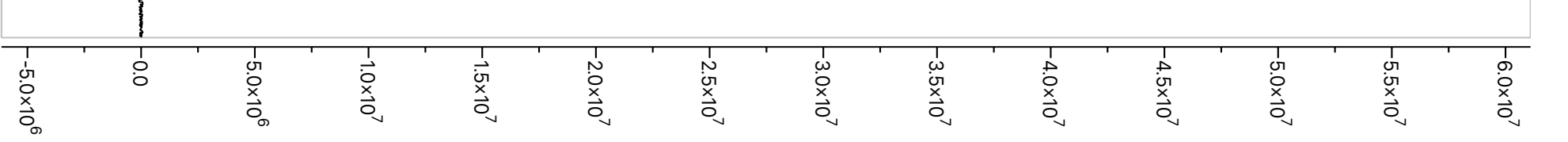




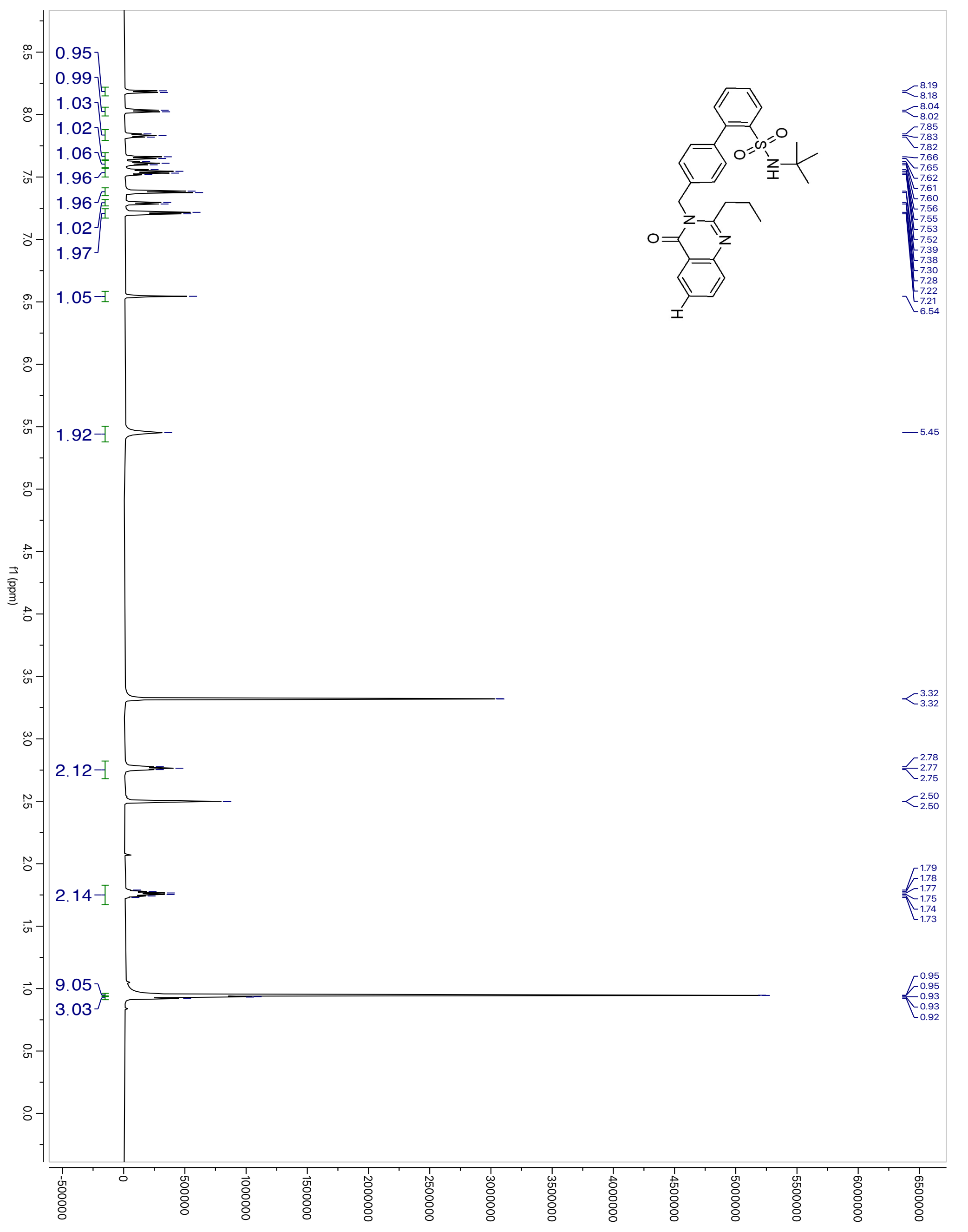



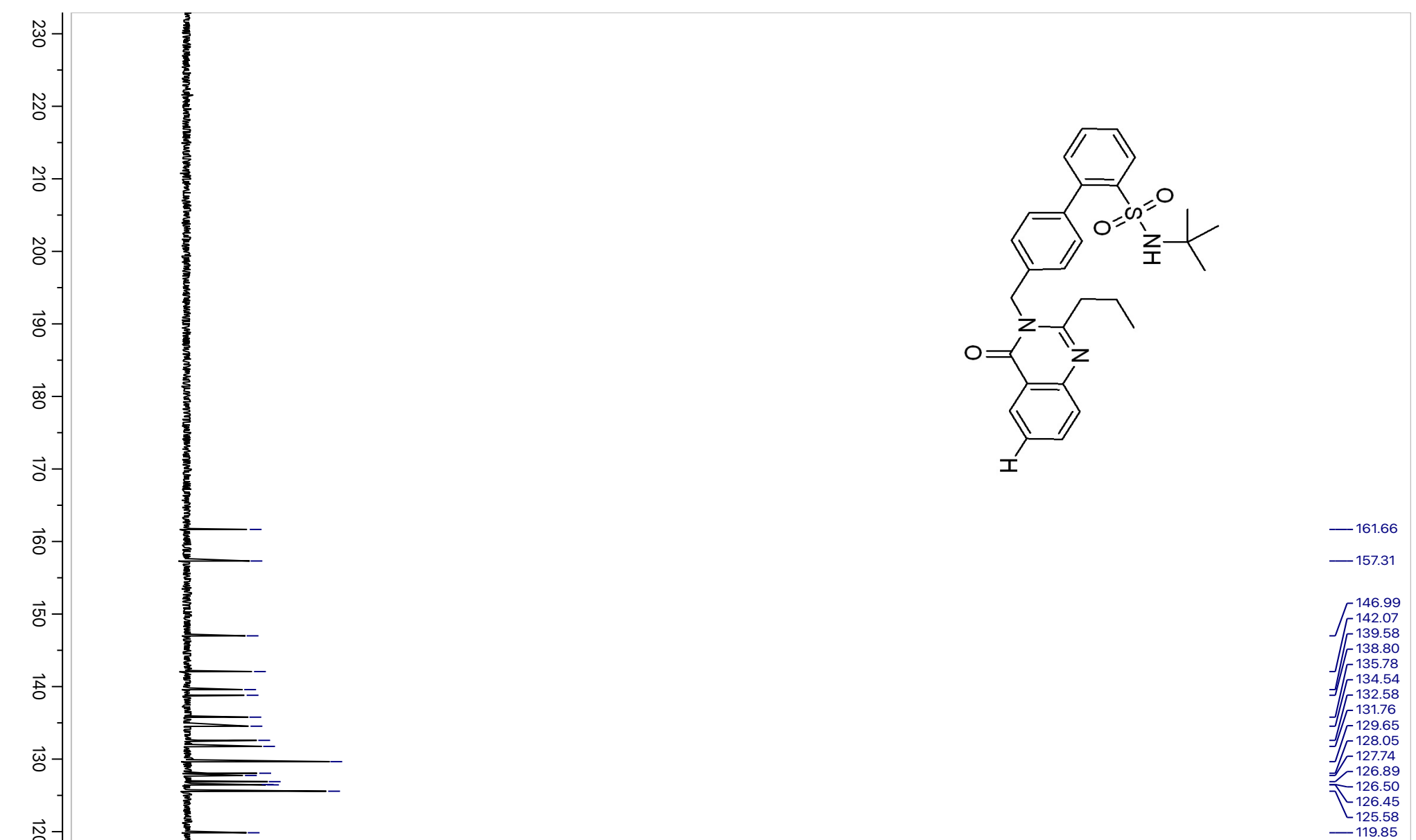


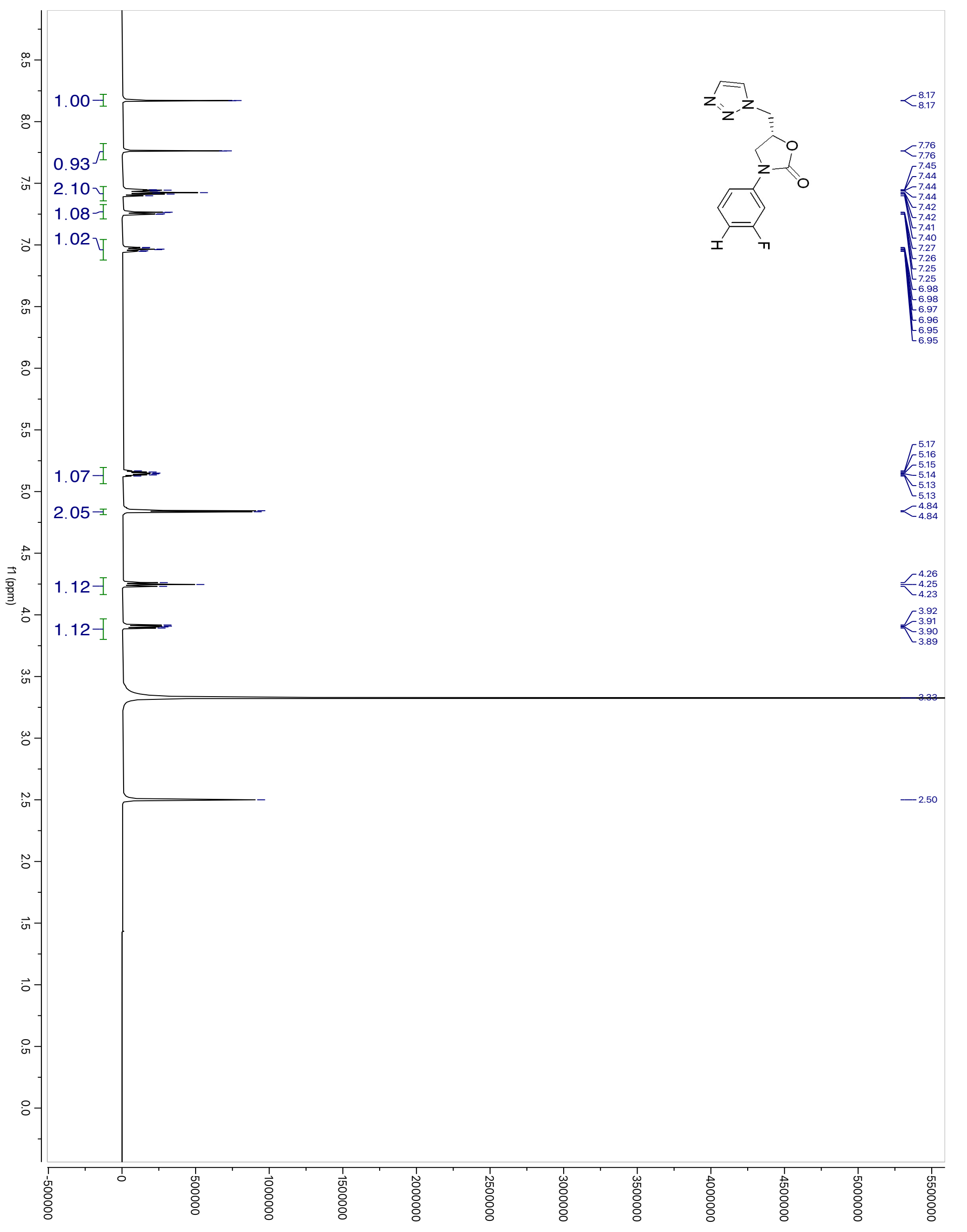




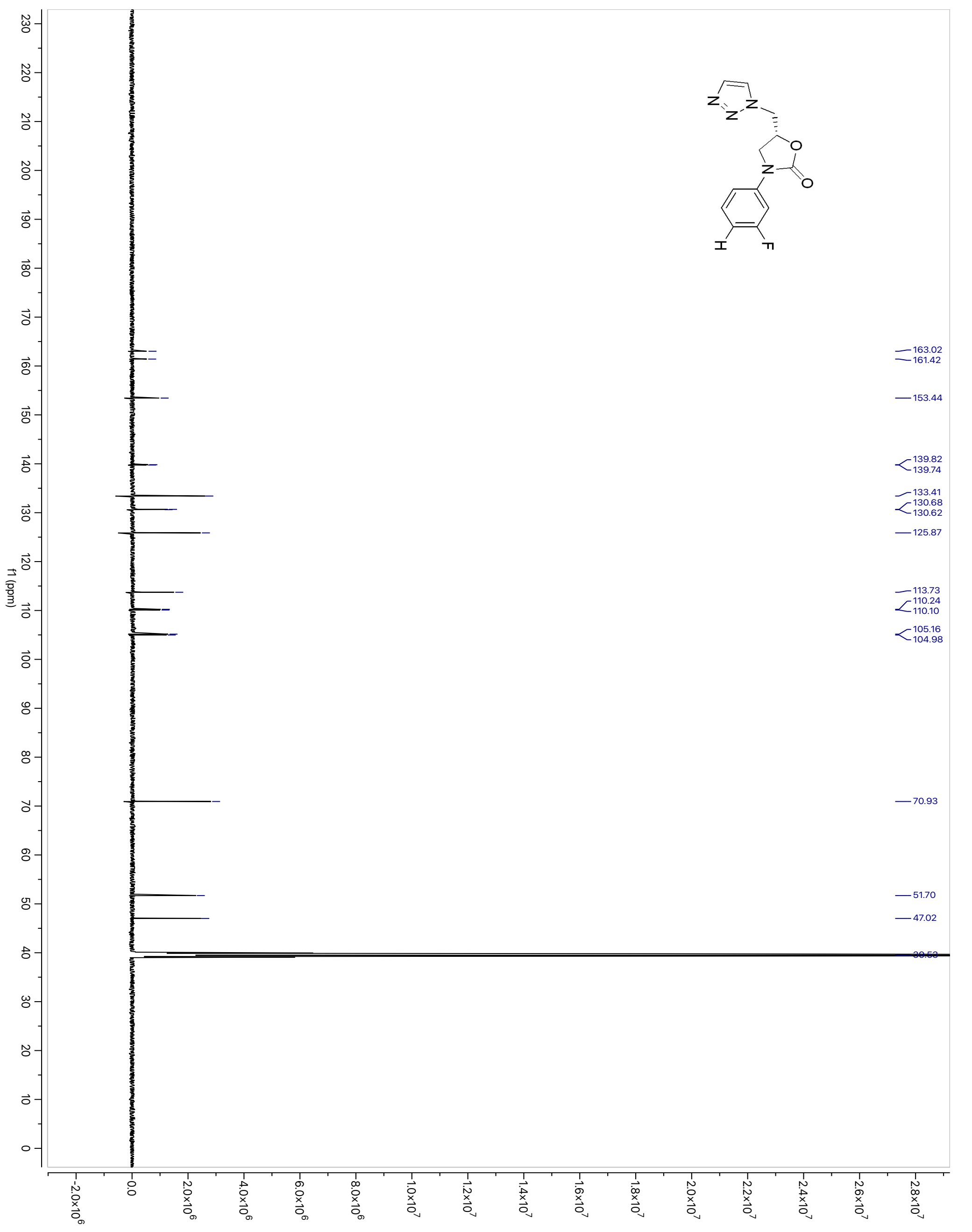




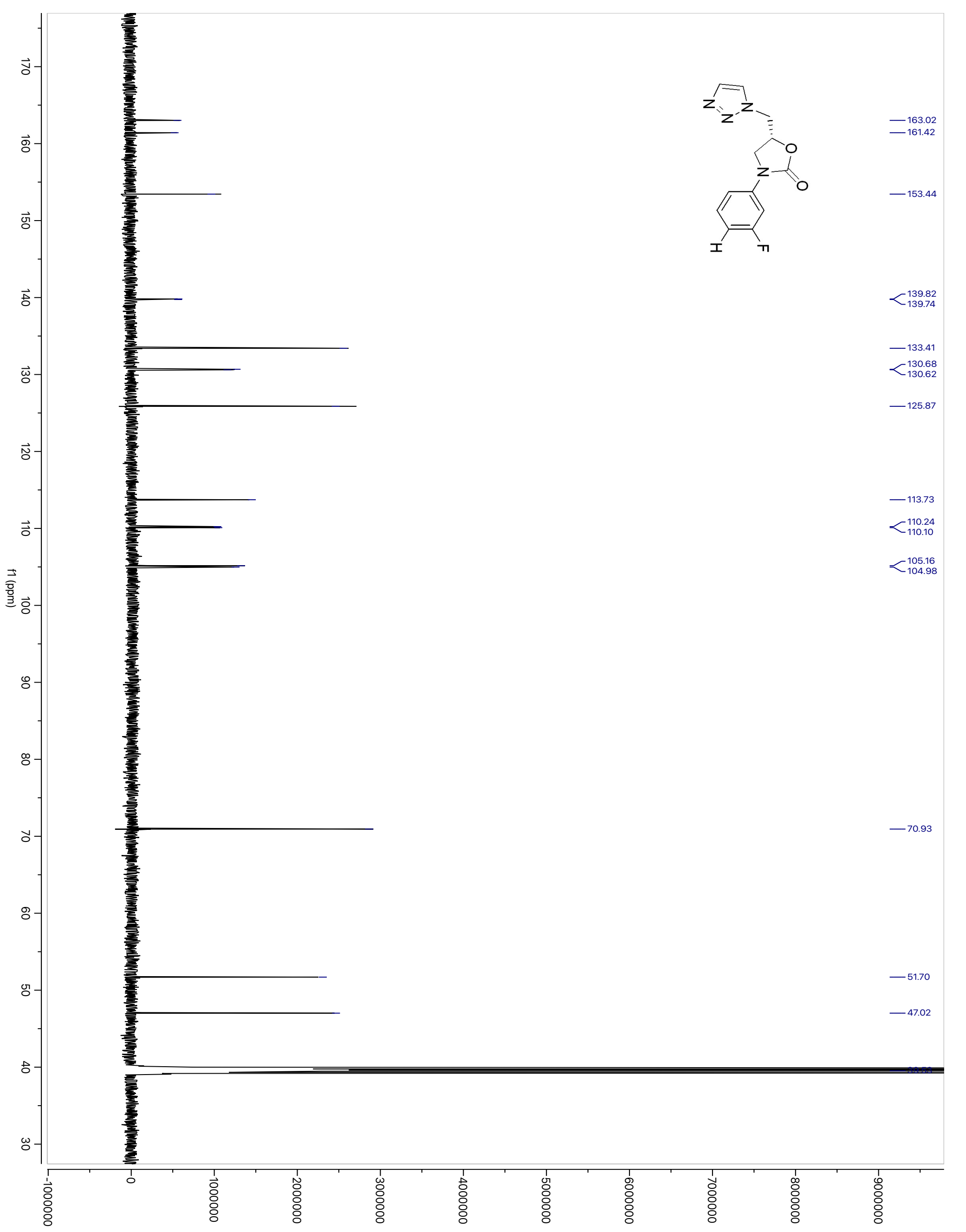




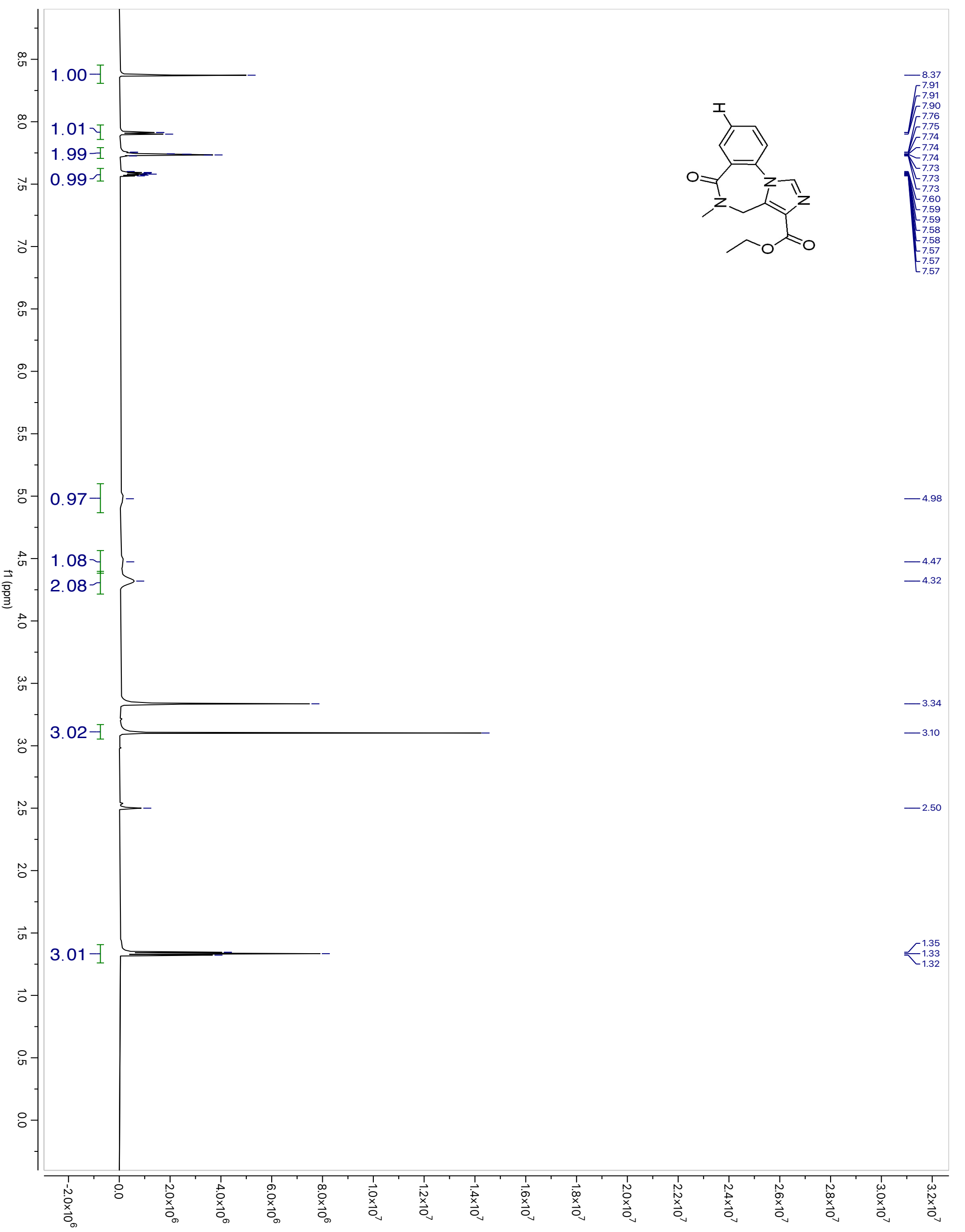




$$
E E^{*}
$$




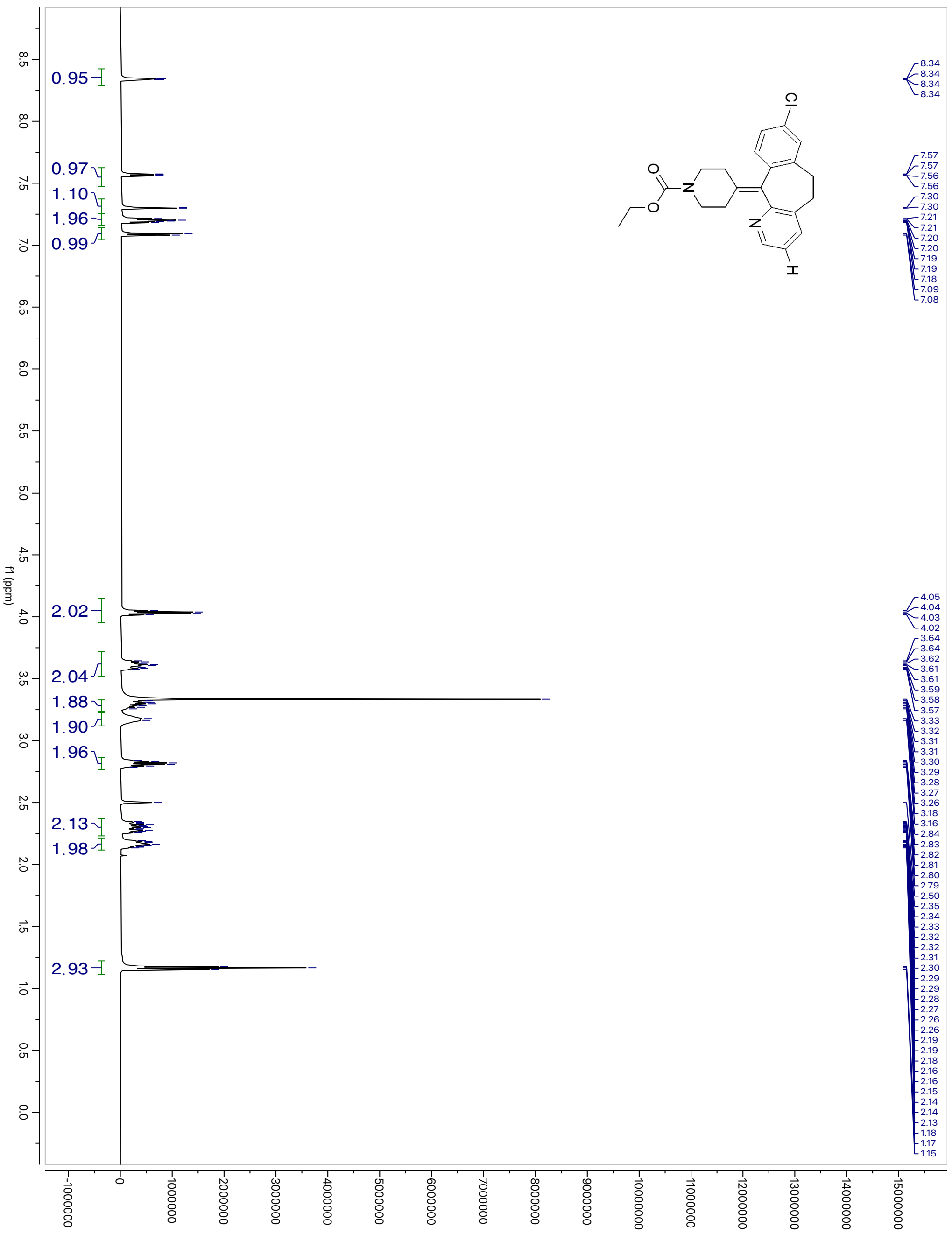




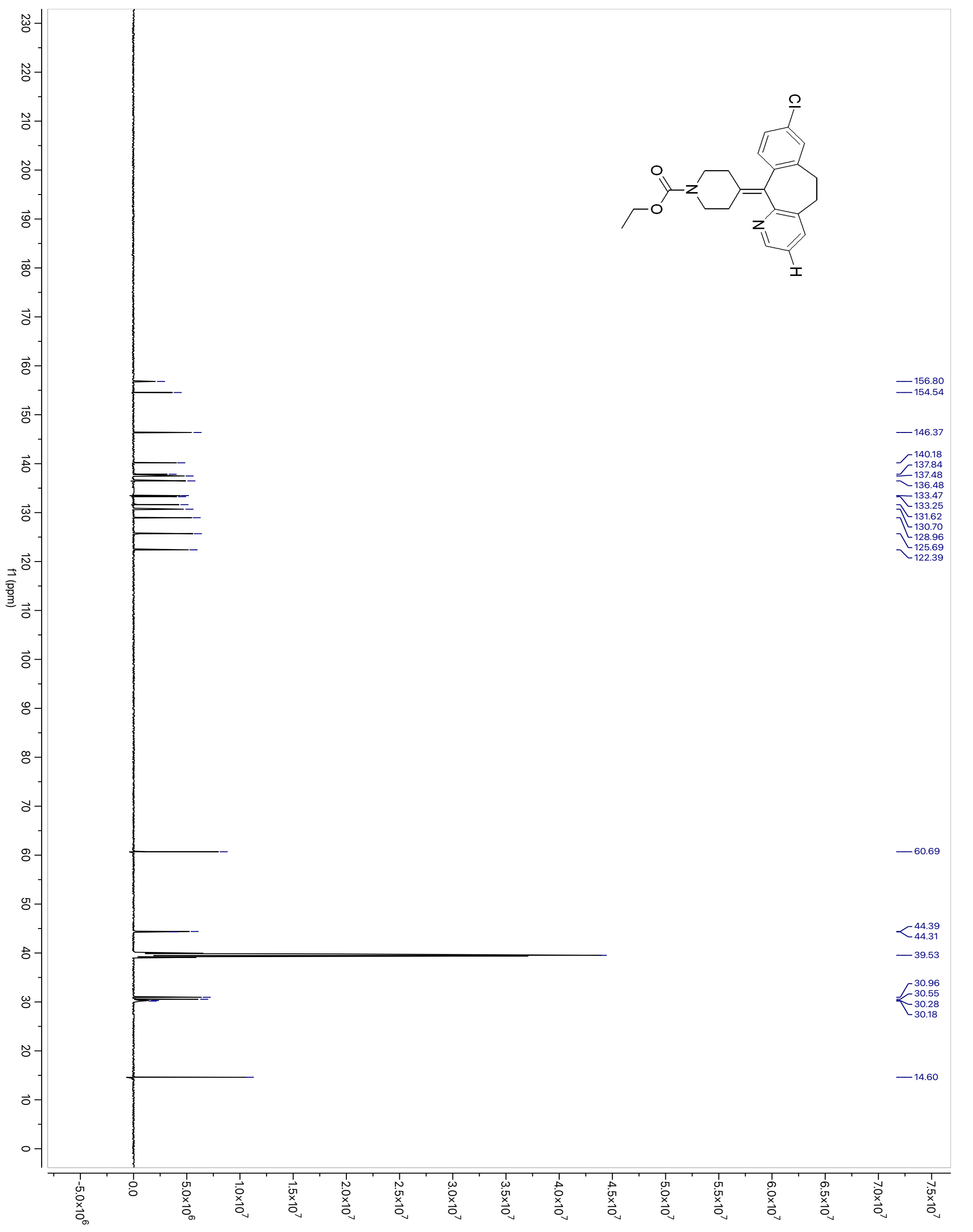




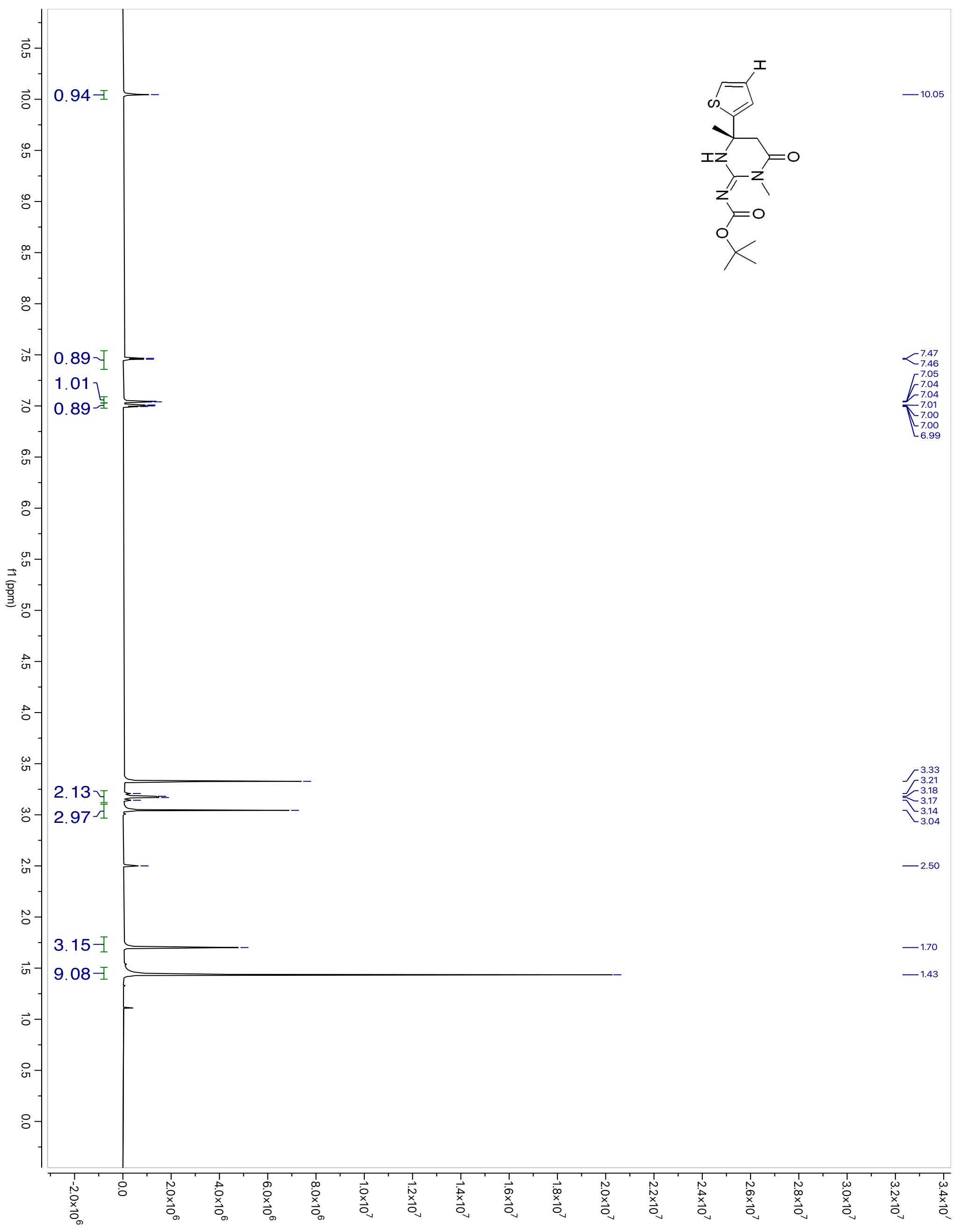




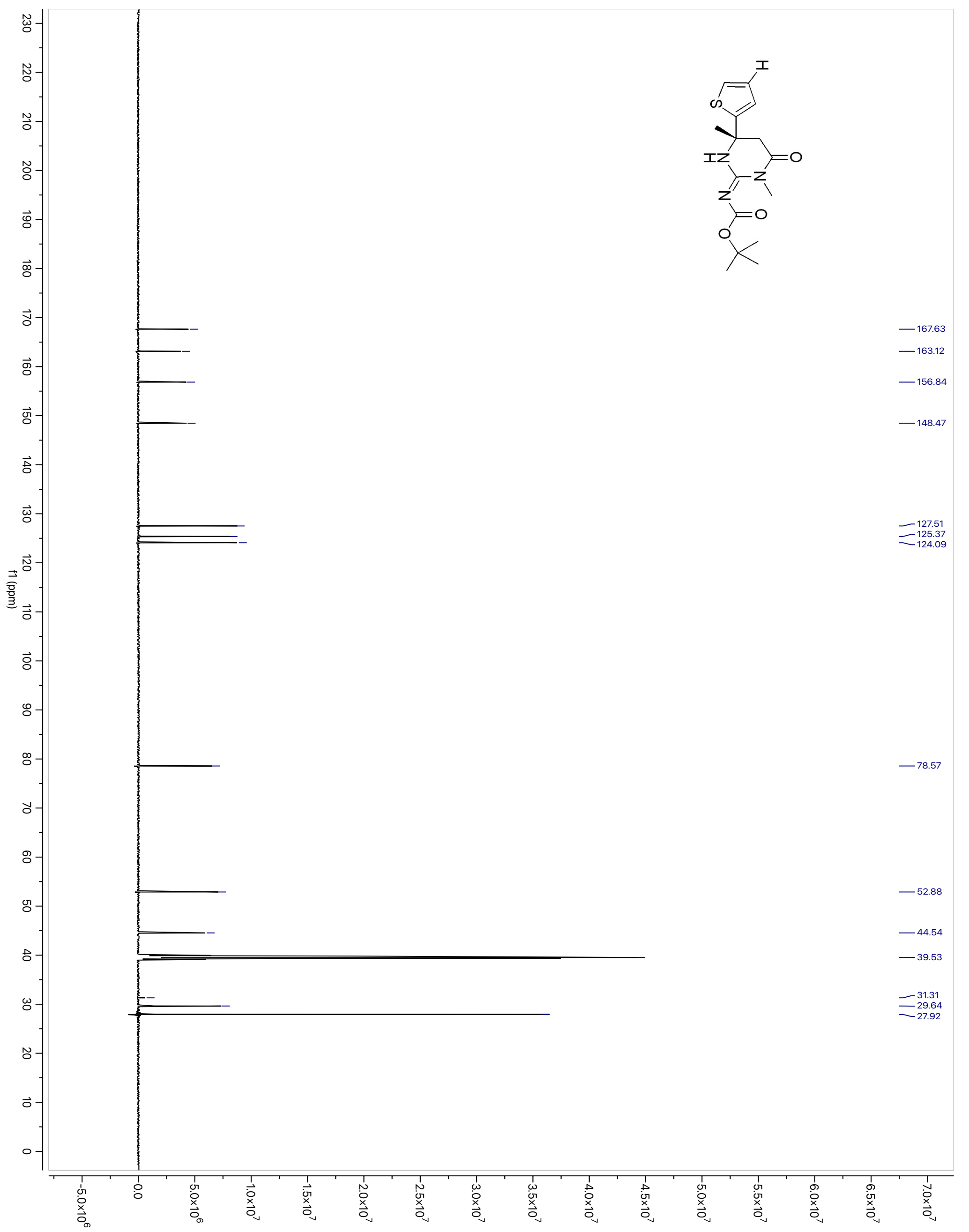




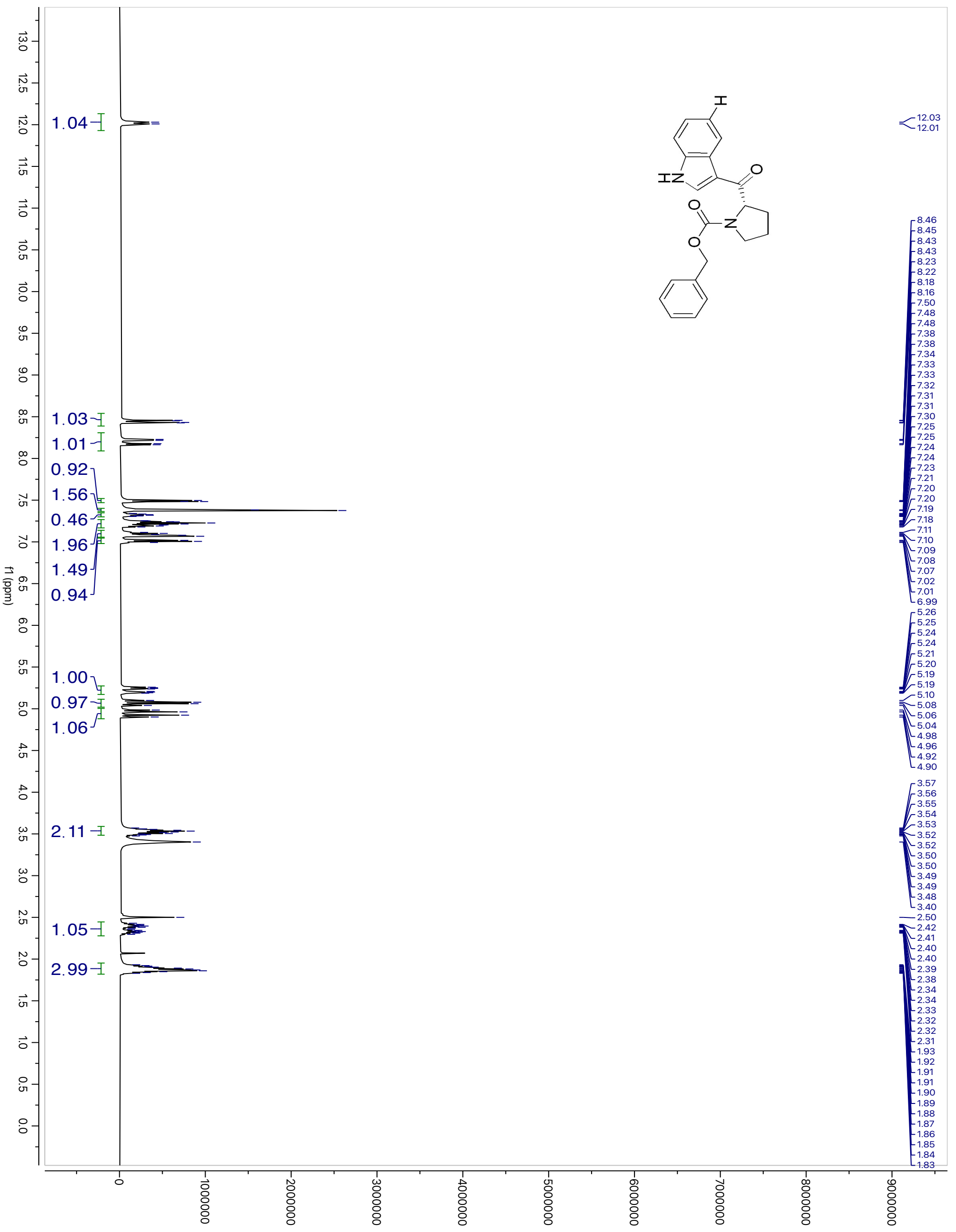




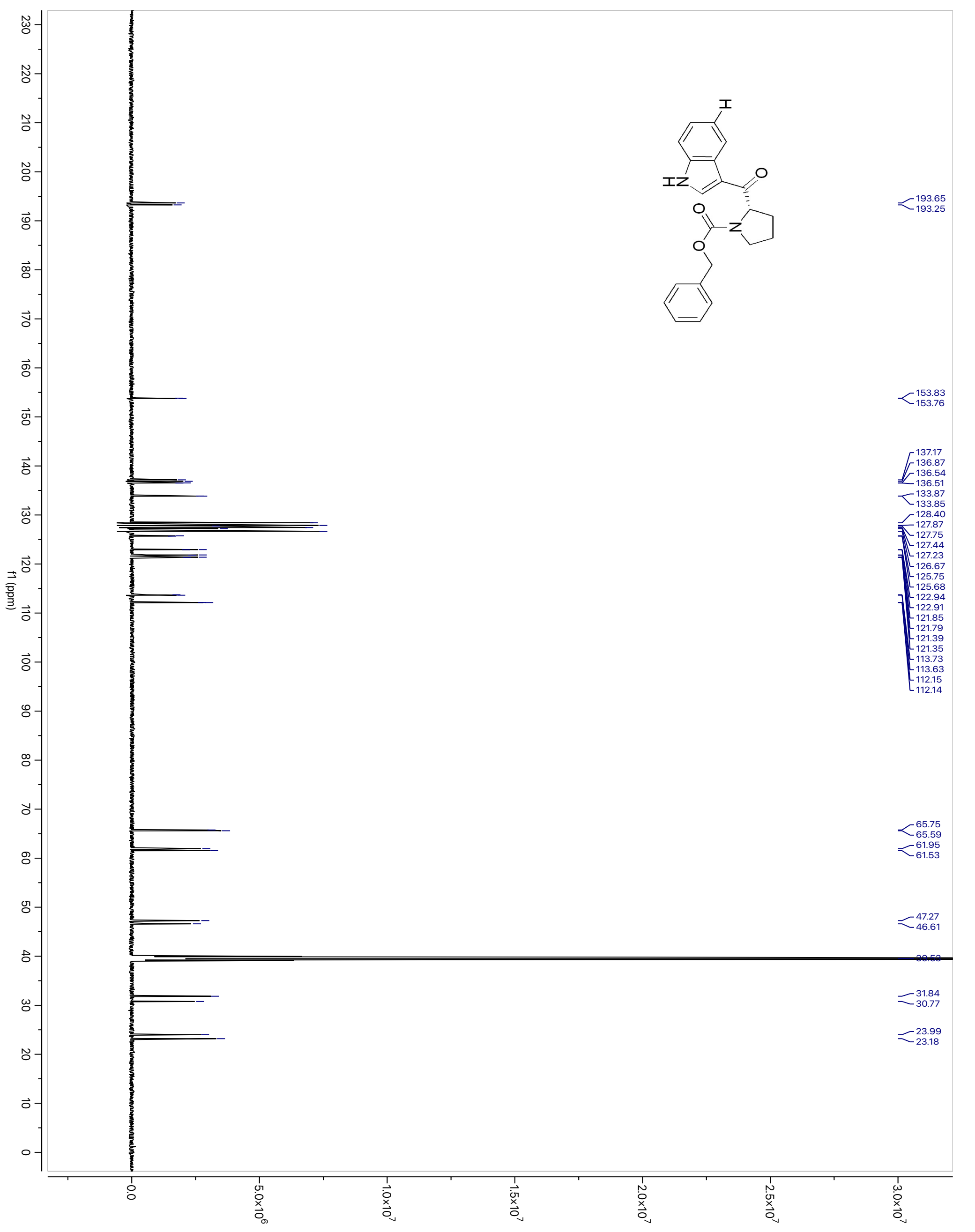




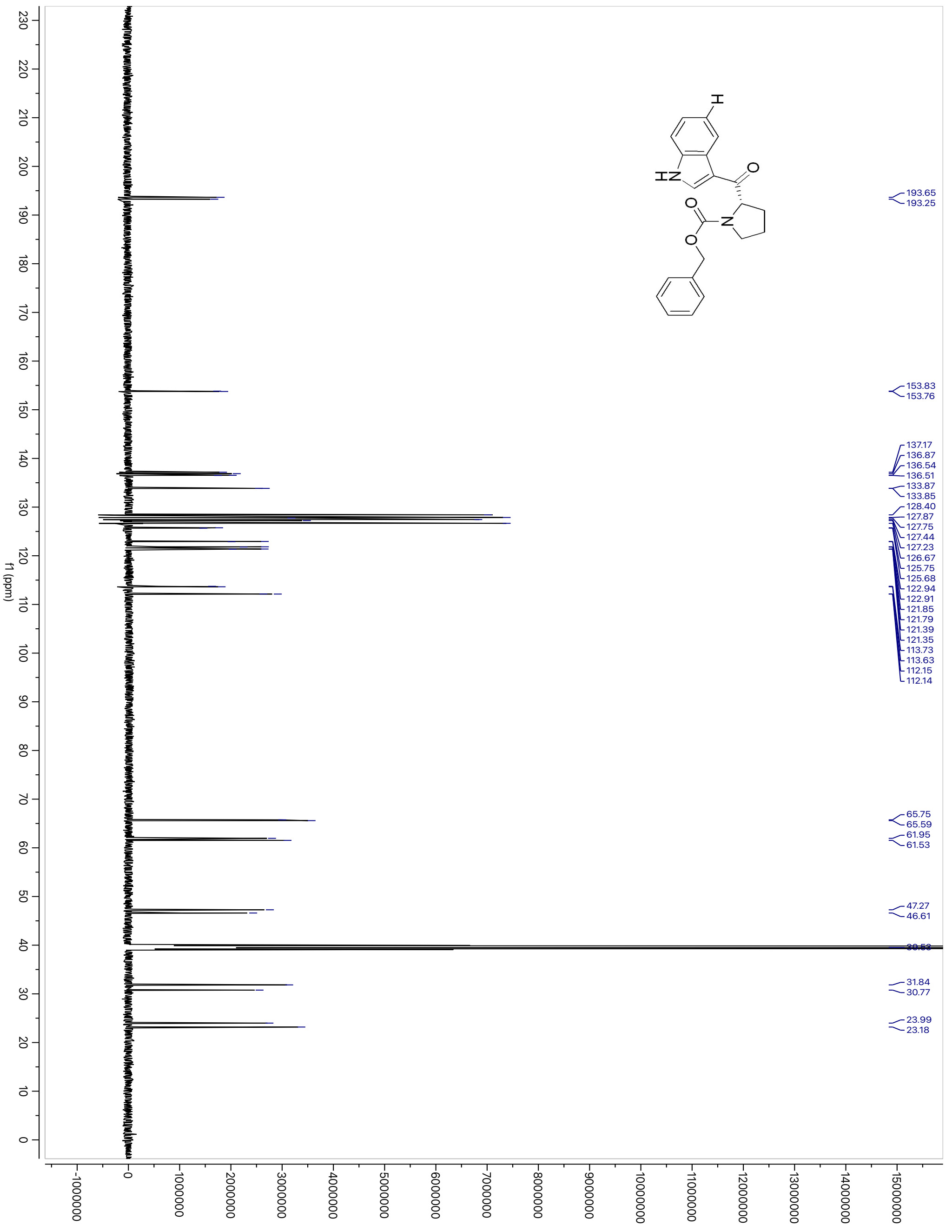




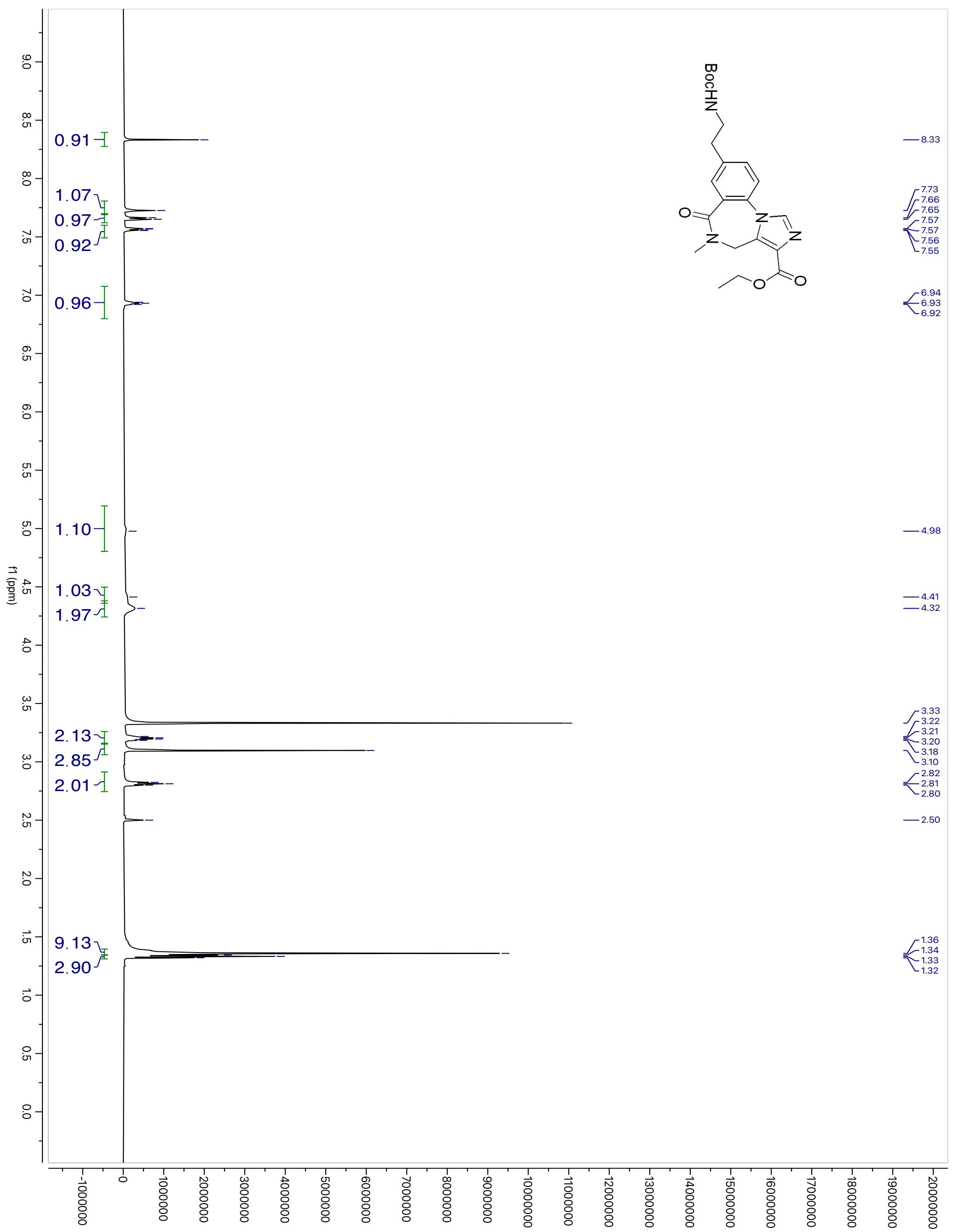




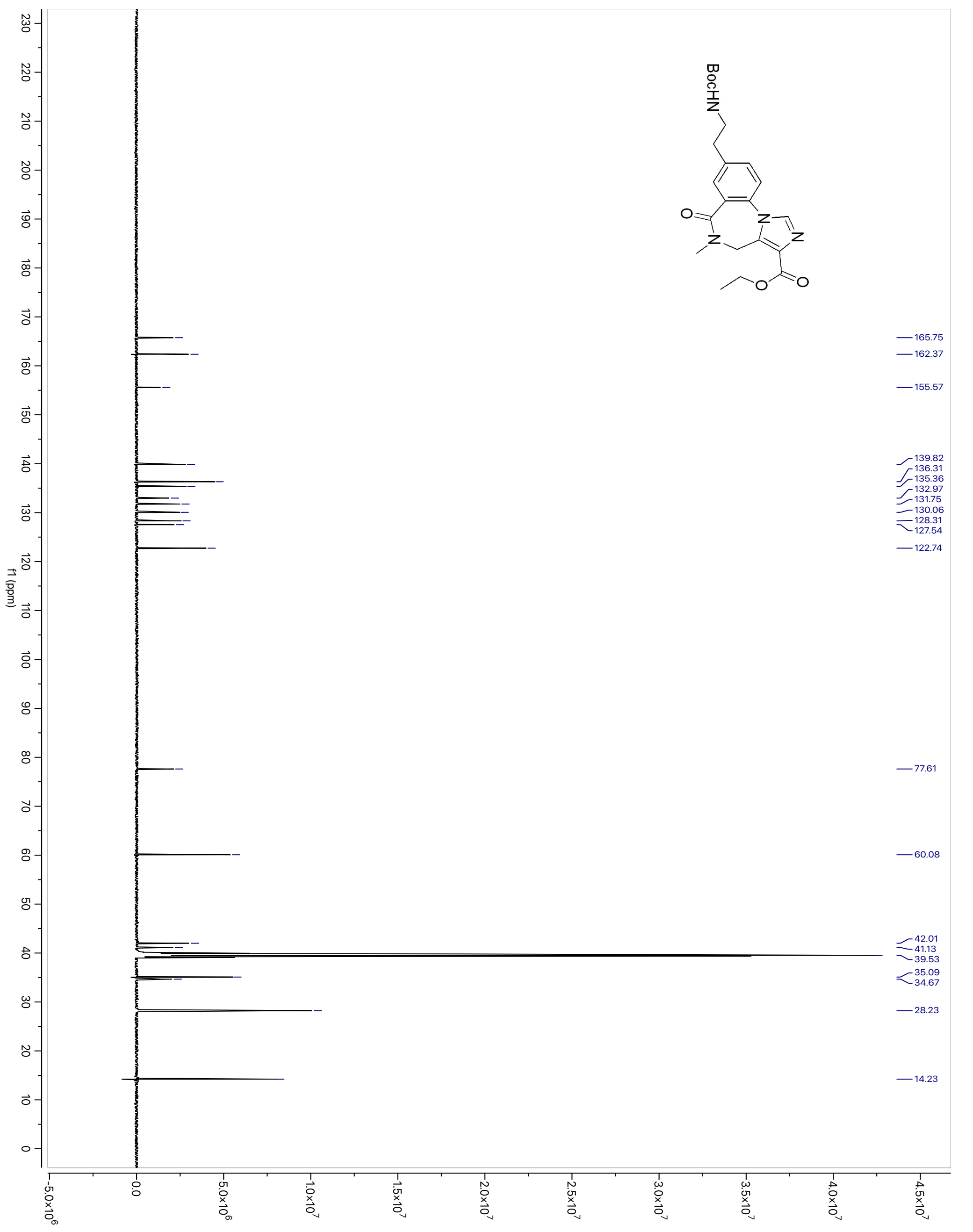

